\title{
Technical Issues Associated with the Use of Intermediate Ethanol Blends (>E10) in the U.S. Legacy Fleet: Assessment of Prior Studies
}

\section{August 2007}

Prepared by

R. Bechtold

J. F. Thomas

S. P. Huff

J. P. Szybist

T. J. Theiss

B. H. West

M. Goodman

T. A. Timbario

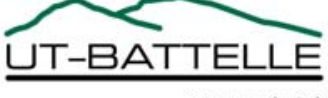




\section{DOCUMENT AVAILABILITY}

Reports produced after January 1, 1996, are generally available free via the U.S. Department of Energy (DOE) Information Bridge.

Web site http://www.osti.gov/bridge

Reports produced before January 1, 1996, may be purchased by members of the public from the following source.

National Technical Information Service

5285 Port Royal Road

Springfield, VA 22161

Telephone 703-605-6000 (1-800-553-6847)

TDD 703-487-4639

Fax 703-605-6900

E-mail info@ntis.gov

Web site http://www.ntis.gov/support/ordernowabout.htm

Reports are available to DOE employees, DOE contractors, Energy Technology Data Exchange (ETDE) representatives, and International Nuclear Information System (INIS) representatives from the following source.

Office of Scientific and Technical Information

P.O. Box 62

Oak Ridge, TN 37831

Telephone 865-576-8401

Fax 865-576-5728

E-mail reports@osti.gov

Web site http://www.osti.gov/contact.html

This report was prepared as an account of work sponsored by an agency of the United States Government. Neither the United States government nor any agency thereof, nor any of their employees, makes any warranty, express or implied, or assumes any legal liability or responsibility for the accuracy, completeness, or usefulness of any information, apparatus, product, or process disclosed, or represents that its use would not infringe privately owned rights. Reference herein to any specific commercial product, process, or service by trade name, trademark, manufacturer, or otherwise, does not necessarily constitute or imply its endorsement, recommendation, or favoring by the United States Government or any agency thereof. The views and opinions of authors expressed herein do not necessarily state or reflect those of the United States Government or any agency thereof. 
Engineering Science and Technology Division

\section{TECHNICAL ISSUES ASSOCIATED WITH THE USE OF INTERMEDIATE ETHANOL BLENDS (>E10) IN THE U.S. LEGACY FLEET: ASSESSMENT OF PRIOR STUDIES}

Rich Bechtold,* John F. Thomas, ${ }^{\dagger}$ Shean P. Huff, ${ }^{\dagger}$ Jim P. Szybist, ${ }^{\dagger}$ Tim J. Theiss, ${ }^{\dagger}$ Brian H. West, ${ }^{\dagger}$ Marc Goodman, and Tom A. Timbario*

\footnotetext{
*Alliance Technical Services, Inc.

${ }^{\dagger}$ Fuels, Engines, and Emissions Research Center, Oak Ridge National Laboratory
}

Prepared by

OAK RIDGE NATIONAL LABORATORY

Oak Ridge, Tennessee 37831-6283

managed by

UT-BATTELLE, LLC

for the

U.S. DEPARTMENT OF ENERGY

under contract DE-AC05-00OR22725 



\section{CONTENTS}

Page

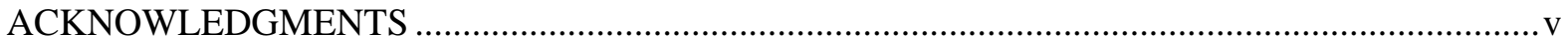

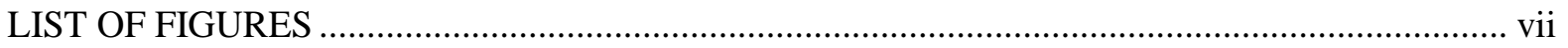

LIST OF TABLES

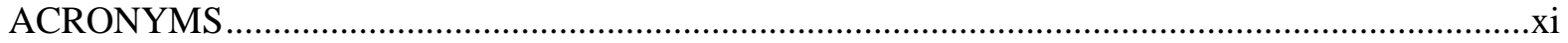

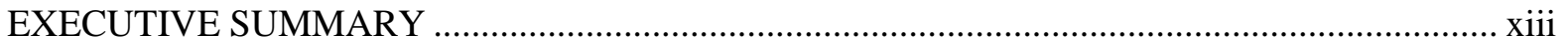

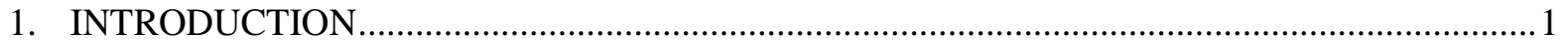

2. ETHANOL BLEND REGULATION AND BRAZILIAN EXPERIENCE .................................. 3

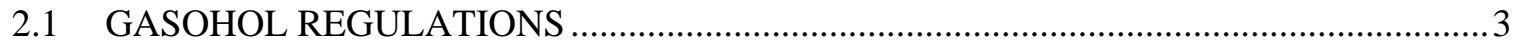

2.2 REGULATION OF ALCOHOL BLENDS OTHER THAN GASOHOL .............................

2.3 EPA DENIALS/REVOCATIONS OF WAIVERS AT HIGH ALCOHOL/OXYGEN

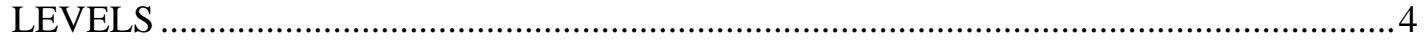

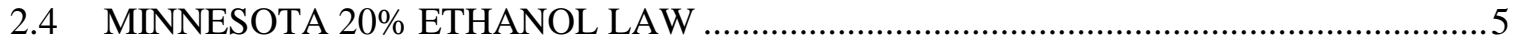

2.5 BRAZILIAN VEHICLE TECHNOLOGY DEVELOPMENT TO USE $20 \%$

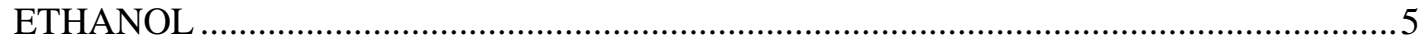

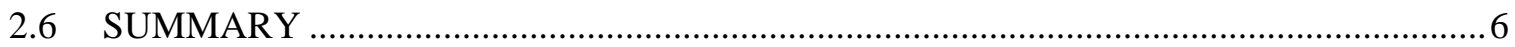

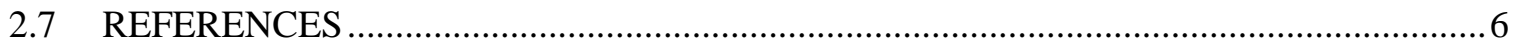

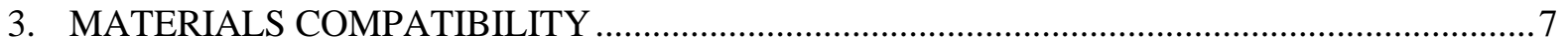

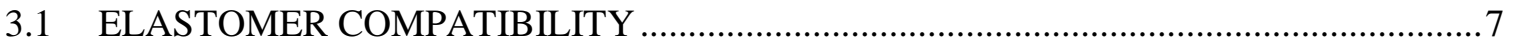

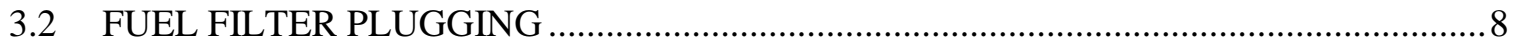

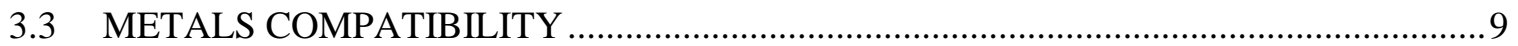

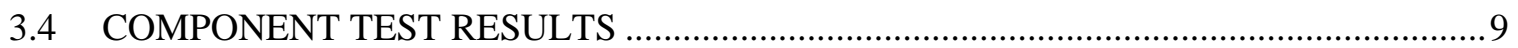

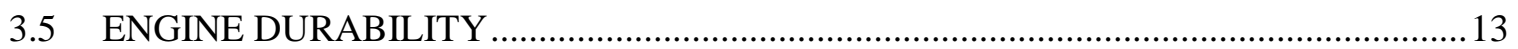

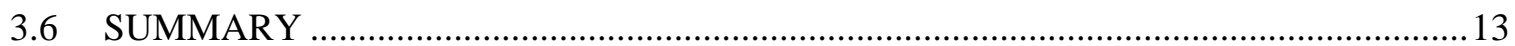

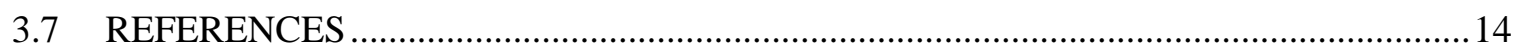

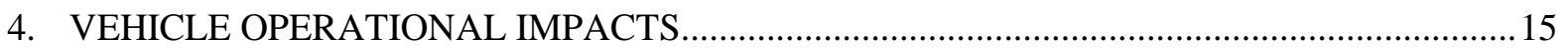

4.1 PROPERTIES OF GASOLINE, ETHANOL, AND ETHANOL BLENDS ........................15

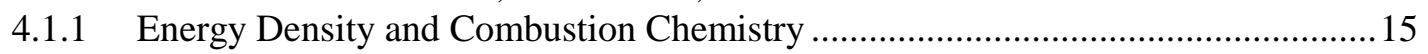

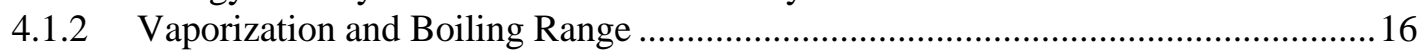

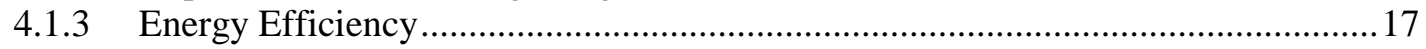

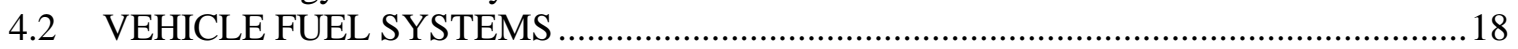

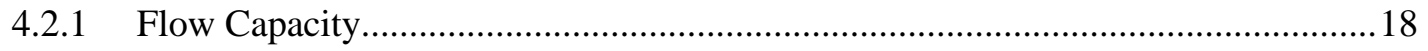

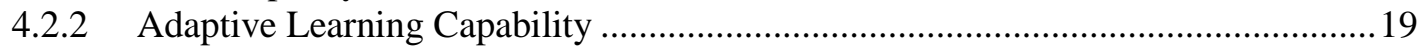

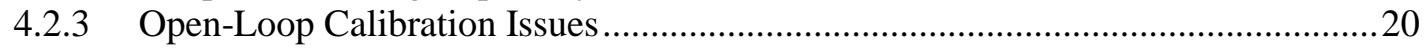

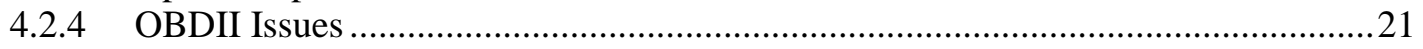

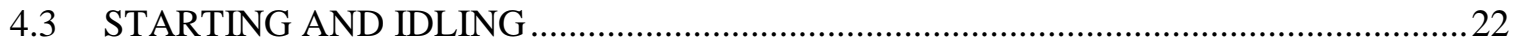

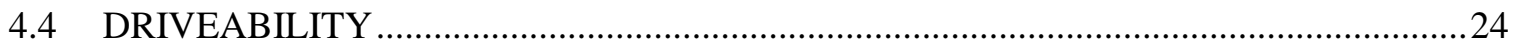

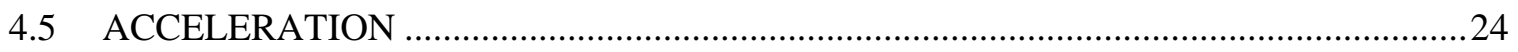

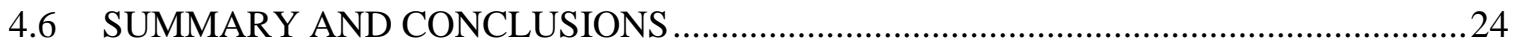

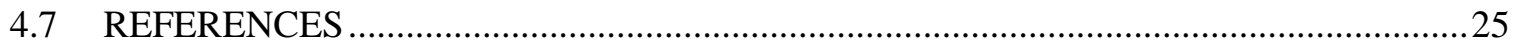

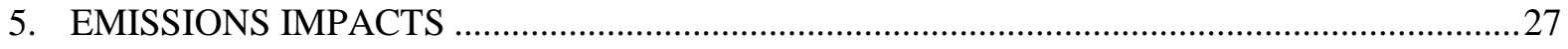

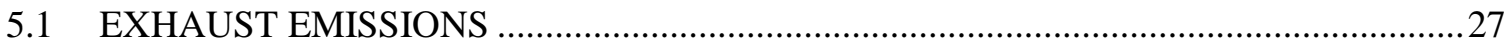

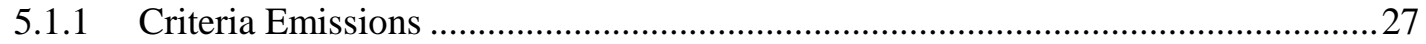

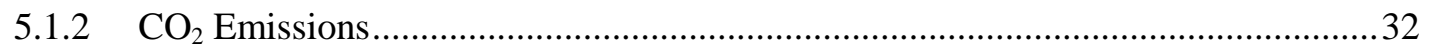

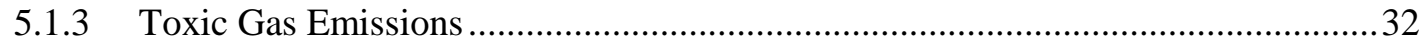




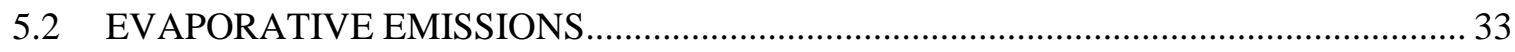

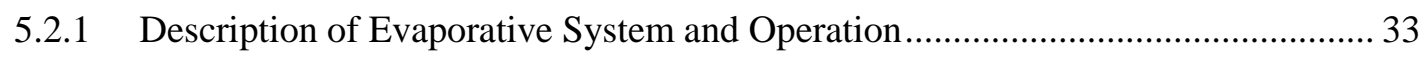

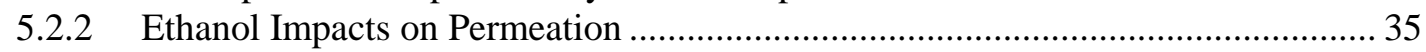

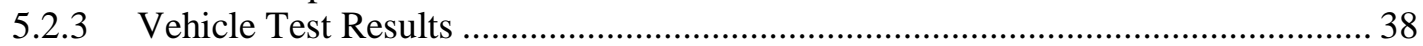

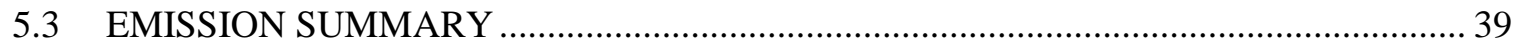

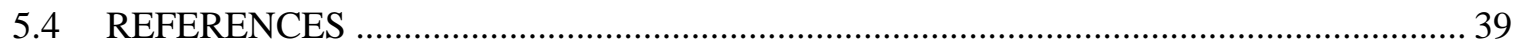

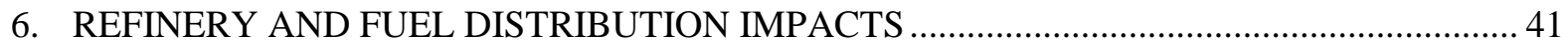

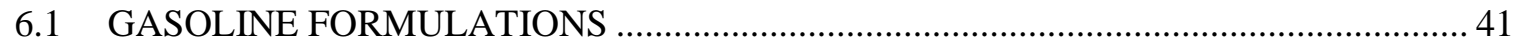

6.2 BLENDING AND TRANSPORTATION OF ETHANOL AND GASOLINE .................. 42

6.3 IMPACTS ON GASOLINE FORMULATION FOR MATCH BLENDING .................... 43

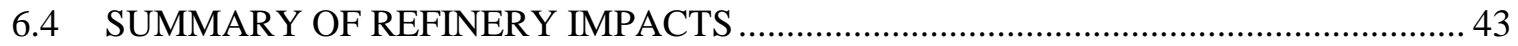

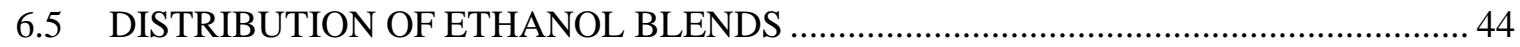

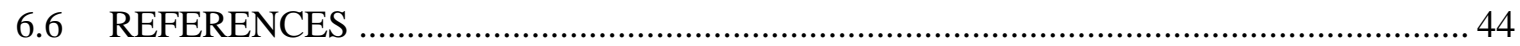

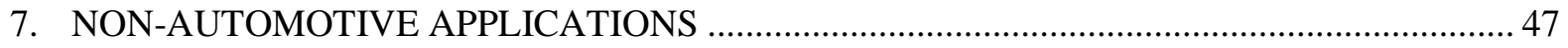

7.1 CATEGORIES OF NON-AUTOMOTIVE GASOLINE ENGINES …........................... 47

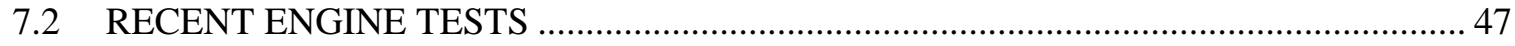

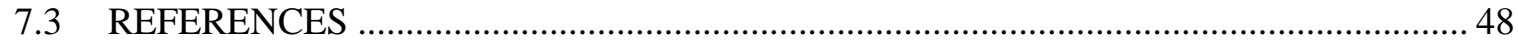

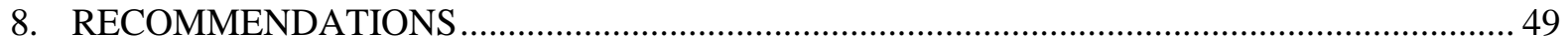




\section{ACKNOWLEDGMENTS}

This work was sponsored by the U.S. Department of Energy (DOE), Office of the Biomass Program (OBP). The authors gratefully acknowledge the support and guidance of Mr. Zia Haq, DOEOBP. This work has also benefited from substantial input and direction from Mr. Kevin Stork of the Office of FreedomCAR and Vehicle Technologies, which we appreciate. The authors also thank and acknowledge Ms. Wendy Clark, Mr. Keith Knoll, and Dr. Bob McCormick of the National Renewable Energy Laboratory for their contributions. Grateful acknowledgment is also due to Mr. Mark Downing for his review and Dr. Ron Graves for his review and overall sound judgment. A number of subject matter experts beyond the authors themselves were consulted in preparation of this assessment. In particular we would like to acknowledge Norman Brinkman and Jeffery Gutterman for their valuable input. 



\section{LIST OF FIGURES}

Figure

Page

3.1 Elastomer swell from exposure to gasoline, ethanol, and a $10 \mathrm{vol} \%$ ethanol blend ..........7

3.2 Polyester urethane compatibility with ethanol and methanol blends ............................. 8

3.3 Fluorocarbon compatibility with ethanol and methanol blends .....................................

3.4 Fuel filters plugged from introduction of ethanol blends ..............................................

3.5 Fuel pump commutator showing rust and tarnish after immersion in E20 ....................10

3.6 Fuel injector showing rust after immersion in E20 ................................................. 10

3.7 Fuel pressure regulator diaphragm showing rust and discoloration after immersion

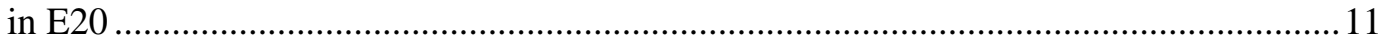

3.8 Pitted fuel pump shown on the right after immersion in E20 ...................................... 11

3.9 Pitted carburetor housing and corroded brass fittings shown on the right after

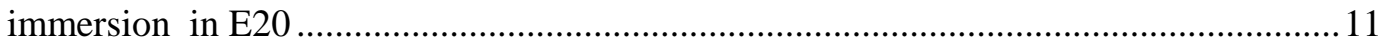

3.10 Fuel injection return hose shown on the right after immersion in E20 …..................... 12

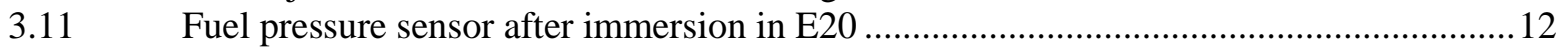

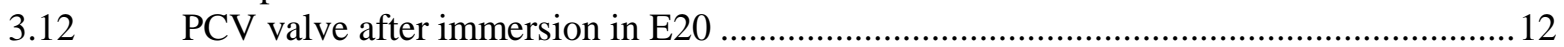

3.13 Piston deposit after 50,000 miles of operation on gasoline (left) and E20 (right) ............13

4.1 The effect of alcohol addition to gasoline RVP .......................................................... 17

4.2 Estimated volumetric fuel flow increase needed for ethanol blends relative to neat

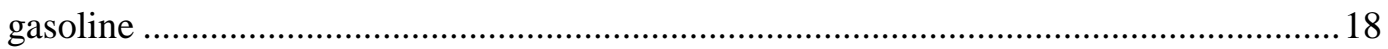

4.3 Hot-start test results for five 2001 model vehicles using $20 \mathrm{vol} \%$ ethanol .....................23

4.4 Cold-start test results for five 2001 model vehicles using $20 \mathrm{vol} \%$ ethanol ...................23

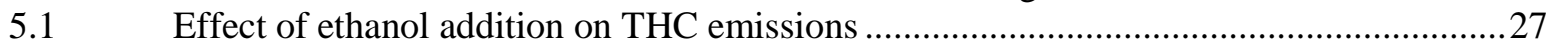

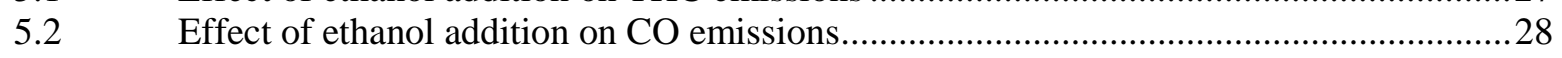

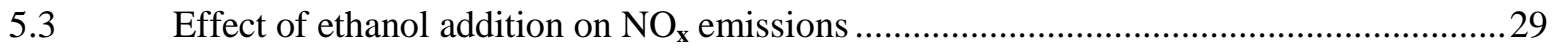

5.4 Change in THC emissions after 50,000 miles operation on E20 ….................................30

5.5 Change in $\mathrm{CO}$ emissions after 50,000 miles operation on E20 ...................................... 30

5.6 Change in $\mathrm{NO}_{\mathbf{x}}$ emissions after 50,000 miles operation on E20 ..................................31

5.7 Average change in emissions after 50,000 miles for operation on gasoline and E20 .......31

$5.8 \quad$ Effect of ethanol addition on acetaldehyde emissions ...................................................32

$5.9 \quad$ Effect of ethanol addition on acetaldehyde emissions …................................................3

$5.10 \quad$ Schematic diagram of a typical evaporative emission system ........................................34

5.11 Schematic diagram of typical fuel-injected fuel and evaporative emission control

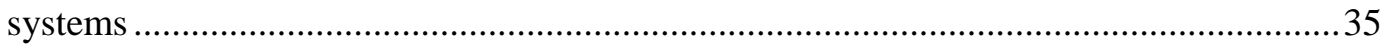

5.12 Effect of ethanol addition on permeation emissions of all vehicles except the FFV

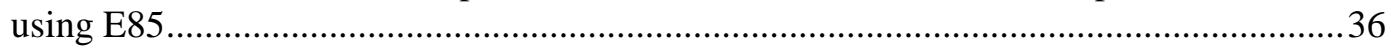

5.13 Effect of ethanol addition on permeation emissions of two $2.0 \mathrm{gm} /$ test vehicles with

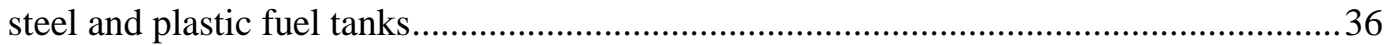

5.14 Effect of ethanol addition on permeation emissions of LEVII and PZEV vehicles..........37

5.15 Effect of ethanol addition on permeation emissions of a flexible fuel vehicle .................37

5.16 Evaporative emissions from five 2001 model vehicles using gasoline and a 20 vol \% ethanol blend 



\section{LIST OF TABLES}

Table

Page

3.1 Older model vehicle specifications for the materials compatibility testing .................... 10

3.2 Orbital engine company late-model test vehicles........................................................... 13

4.1 Selected properties of anhydrous ethanol and gasoline.................................................15

$5.1 \quad$ Changes in hydrocarbon toxics when using $20 \mathrm{vol} \%$ ethanol .......................................33

6.1 Example composition of refinery streams from various sources .....................................41

6.2 Effect of $10 \mathrm{vol} \%$ ethanol addition on gasolines of different RVP ................................42 



\section{ACRONYMS}

C5

CAAA

CARB

$\mathrm{CO}$

$\mathrm{CO}_{2}$

CRC

DOE

E10

E85

EPA

ETBE

EXX

FCC

FFV

FTP

$\mathrm{HC}$

LEVII

LHV

LTFT

MON

MTBE

MVMA

MY

$\mathrm{NO}_{\mathrm{x}}$

OBDII

OEM

ORNL

PCM

PCV

psi

PZEV

RBOB

RFG

RON

RVP

SAE

SI

STFT

THC

TWC

UL

WOT

paraffin containing 5 carbon atoms per molecule

Clean Air Act Amendment

California Air Resources Board

carbon monoxide

carbon dioxide

The Coordinating Research Council

(U.S.) Department of Energy

gasoline blend with $10 \mathrm{vol} \%$ ethanol, also known as gasohol.

gasoline blend up to 85 vol \% denatured ethanol, suitable for FFVs

(U.S.) Environmental Protection Agency

ethyl tertiary-butyl ether

gasoline blend with XX volume percent denatured ethanol

fluidized catalytic cracking

flexible fuel vehicle, capable of using E85, gasoline or any blend

Federal Test Procedure

hydrocarbon

Low emissions vehicle second phase

lower heating value

long-term fuel trim

motor octane number

methyl tertiary-butyl ether

Motor Vehicle Manufacturers' Association (now Alliance of Automotive Manufacturers [AAM])

model year

oxides of nitrogen $\left(\mathrm{NO}, \mathrm{NO}_{2}\right)$

on-board diagnostics II

original equipment manufacturer

Oak Ridge National Laboratory

powertrain control module

positive crankcase ventilation

pounds per square inch (pressure)

partial zero emission vehicle

reformulated blend stock for oxygenate blending

reformulated gasoline

research octane number

Reid vapor pressure

(formerly) Society of Automotive Engineers, SAE International

spark ignition

short term fuel trim

total hydrocarbon

three-way catalyst

unleaded gasoline

wide open throttle 



\section{EXECUTIVE SUMMARY}

The Oak Ridge National Laboratory (ORNL) supports the U.S. Department of Energy (DOE) in assessing the impact of using intermediate ethanol blends (E10 to E30) in the legacy fleet of vehicles in the U.S. fleet. The purpose of this report is to

- identify the issues associated with intermediate ethanol blends with an emphasis on the end-use or vehicle impacts of increased ethanol levels;

- assess the likely severity of the issues and whether they will become more severe with higher ethanol blend levels, or identify where the issue is most severe;

- identify where gaps in knowledge exist and what might be required to fill those knowledge gaps; and

- compile a current and complete bibliography of key references on intermediate ethanol blends.

This effort is chiefly a critical review and assessment of available studies. Subject matter experts (authors and selected expert contacts) were consulted to help with interpretation and assessment. The scope of this report is limited to technical issues. Additional issues associated with consumer, vehicle manufacturer, and regulatory acceptance of ethanol blends greater than E10 are not considered. The key findings from this study are given below.

\section{E.1 SUMMARY OF FINDINGS AND RECOMMENDATIONS}

- Limited data exist to address the use of ethanol blends higher than E10 in conventional gasoline vehicles in the United States.

- Most of the available data are for E20 testing. Almost no data exist for E15.

- Prior studies found materials compatibility issues with E20, and evidence of fuel filter obstruction even with E10.

- Credible studies reported in the literature found $\mathrm{NO}_{\mathrm{x}}$ increases up to $40 \%$ and accelerated longterm catalyst degradation with E20, relative to E0.

- Regarding driveability (stumble, hesitation, etc.), test programs with late-model vehicles indicated the average driver may not detect a difference between E20 and E10, at least in the short term.

- With older vehicles, E20 impacts on driveability would likely be noticed, raising concerns over owner tampering with emission control systems.

- A thorough test program will be necessary to quantify the effects of E15 or E20 on the U.S. fleet. The U.S. legacy fleet is too diverse to predict E15/20 impacts from the limited available data. This program should include examination of emissions, catalyst durability, materials compatibility, and driveability.

\section{E.2 ENVIRONMENTAL REGULATIONS}

- Fuels have been generally limited to $3.7 \mathrm{wt} \%$ or less oxygen and not more than 15 vol \% additive.

- $\quad$ EPA has denied several waiver requests for fuels with more than $3.7 \mathrm{wt} \%$ oxygen ( E10).

\section{E.3 MATERIALS COMPATIBILITY ISSUES}

- OEMs have been moving to non-metallic fuel lines between the tank and engine. Non-metallic fuel tanks have lower costs and have the capability of being moldable into complex shapes that 
maximize volume in tight vehicle confines. These changes can increase permeation emissions from ethanol blends compared with older vehicles.

- As elastomers age in service, they become less amenable to changes in fuels (i.e., durability and operability problems are more likely when older vehicles are exposed to high-level ethanol blends for the first time).

- Older vehicles that have not been exposed to ethanol blends may be affected by filter plugging, and the severity is likely to be a function of their mileage accumulation prior to ethanol introduction (even with E10).

- A 2003 study by Orbital Corporation Limited for the Australian government concluded that the materials used in older vehicles are not sufficiently compatible with E20 to be expected to work properly over the lives of the vehicles.

- Emissions and the technology level of the Australian cars tested suggest they are similar to U.S. Tier 1 on-board diagnostics second update (OBDII) vehicles.

- Data from a 2004 Orbital report show higher-level ethanol blends could accelerate engine wear and cause deposits, but the effects appear minor and are unlikely to significantly change engine durability.

\section{E.4 VEHICLE OPERATIONAL ISSUES (FUEL CONTROL AND PERFORMANCE)}

- Flow capacity limits should not be an issue for many vehicles operating on E10-E20. Generally, for the same power production, E15 requires 1.7 vol \% more fuel than E10 and 5.2 vol \% more than E0; E20 requires 3.5 vol \% more fuel than E10 and 7.1 vol \% more than E0.

- Modern vehicles with oxygen-sensor-based, closed-loop control, three-way catalyst (TWC) systems compensate for the oxygen in ethanol blends well—although many claim "enleanment" still occurs. At wide-open-throttle and other open-loop conditions, leaner (less rich) operation occurs in many vehicles.

- Some OEMs cite concern about high-load open-loop operation, even for new vehicles.

- Most OBDII vehicles (model year 1996 and later) are likely to operate on higher-level ethanol blends without any driveability issues noticeable to the driver.

- A significant percentage of older vehicles are likely to have noticeable driveability and cold-start problems.

- Each engine family is likely to differ in the capability to adjust to higher-level ethanol blends. Insufficient data are available to predict how many vehicles will have problems at higher ethanol blend levels.

\section{E.5 EMISSIONS}

- Carbon monoxide (CO) and hydrocarbons (HCs) decrease, whereas $\mathrm{NO}_{\mathrm{x}}$ and acetaldehyde typically increase with ethanol content. Depending on the vehicle, the increase may be of a magnitude that will be of significant concern.

- Vehicles with limited capability to compensate (for the lower energy density of ethanol blends) may show more rapid catalyst deterioration and, consequently, higher emissions of all constituents as they approach or exceed full useful life. E20 produced hotter exhaust at wide-open throttle for all five vehicles in the Australian study. More TWC degradation at 50,000 miles was seen for E20.

- If the ethanol blends are formulated for the same or lower Reid vapor pressure (RVP) and front end volatility, evaporative emissions should not increase relative to neat gasoline.

- Low-emissions vehicles, second phase (LEVII); partial-zero-emission vehicles (PZEV); and flexible-fuel vehicles (FFVs) do well at containing permeation emissions from ethanol blends. Proper materials result in good containment. 


\section{E.6 REFINERY IMPACTS}

- Refinery blend stocks will be required for ethanol match-blending.

- Additional products with unique specifications that must be met are difficult for refiners to manage.

- Ethanol incompatibility with pipelines complicates transportation logistics.

- Ethanol can be used to upgrade less expensive, lower-octane refinery streams.

- There is no Clean Air Act Amendment (CAAA) RVP waiver for ethanol blends >10 vol \%; without a similar waiver, producing higher-blend fuels with sufficiently low RVP may be problematic.

- Ultimately, refiners will choose the most economical way to comply with specifications.

\section{E.7 NON-AUTOMOTIVE APPLICATIONS}

- Orbital considered aircraft, marine craft, off-road vehicles, commercial consumer power equipment, and stationary power. Some issues are similar to the issues for vehicles.

- Orbital only tested two non-road engine models, both two-stroke designs. Materials compatibility problems were the chief concern for E20.

- Enleanment and higher exhaust temperatures are a concern because there is no (oxygen sensor) feedback control.

- Virtually no data exist on the impact of E15 use in non-automotive applications. 



\section{INTRODUCTION}

The Oak Ridge National Laboratory (ORNL) supports the U.S. Department of Energy (DOE) in assessing the impact of using intermediate ethanol blends (E10 to E20 for the purposes of this report) in the legacy fleet of vehicles in the United States. The purpose of this report is to

- identify the issues associated with increased ethanol blends, with an emphasis on the end-use or vehicle impacts of increased ethanol levels;

- assess the likely severity of the issues and whether they will become more severe with higherlevel ethanol blends, or identify where the issue is most severe;

- identify where gaps in knowledge exist and what might be required to fill those knowledge gaps; and

- compile a current and complete bibliography of key references on intermediate ethanol blends.

The primary motivation for this study stems from President Bush's "20 in 10" Initiative-a 2007 initiative by which the United States seeks to reduce current gasoline consumption by $20 \%$ in 10 years. However, interest in understanding the impact of increasing the amount of ethanol in gasoline has been keen for several years because of concerns about energy security, reduction of oil imports, environmental issues, and the like. Currently, roughly $99 \%$ of all ethanol used for transportation in the United States is in the form of low-level blends (E10); only 1\% of the ethanol is used in E85compatible FFVs. The U.S. passenger car fleet is approximately 240 million vehicles, of which roughly 6 million are currently FFVs. Congressional testimony given on July 31, 2007, by Alexander Karsner, Assistant Secretary for Energy Efficiency and Renewable Energy, before the Committee on Energy and Natural Resources of United States Senate highlights an alternative pathway.

"The Department believes that an E85 delivery system is an important goal of an alternative fuels infrastructure, but that intermediate blends (e.g., E15, E20) may offer an alternative approach to balance fuel production and use in parallel in order to enable continuous uninterrupted growth in production. In fact, intermediate blends may provide for more rapid absorption of renewable fuels into consumer markets in the near-term."

This report is focused on the end-use issues of intermediate ethanol blends (rather than ethanol production or distribution) and is the result of an extensive literature review and discussions with industrial experts. The authors themselves have a significant amount of expertise in alternative fuels use in vehicles, vehicle control technology in FFVs, and alcohol fuels in automotive applications. Our goal is to provide an objective assessment of the issues associated with intermediate ethanol blends and highlight the necessary future work so that appropriate follow-on activities can be conducted.

Any experimentation or significant new analysis is beyond the scope of this report. A thorough analysis of the impact of each issue on specific vehicles in the U.S. fleet is also beyond the scope of this report. Additional issues associated with consumer, vehicle manufacturer, and regulatory acceptance of ethanol blends greater than E10 are not considered here. These issues would include modification to the ASTM standard for gasoline (ASTM D4814) for including intermediate ethanol blends, economic incentives to promote blends greater than E10, the certification of full-useful-life emissions, and manufacturer warranty claims arising from a "new" fuel. These issues involve very different stakeholders to reach consensus decisions, are often lengthy to resolve, and may require legislative action to finalize. The omission of discussion on these topics is not to minimize their importance to the overall acceptance of intermediate ethanol blends, but to maintain the focus of this report on the technical data available at this time. 
Chapter 2 considers the regulatory history with ethanol and other oxygenates with the Environmental Protection Agency (EPA). This discussion provides perspective on past actions from the EPA and other efforts to increase the allowable ethanol level beyond E10. This chapter also includes some background on the Brazilian experience with ethanol blends and highlights some key distinctions between the U.S. experience with ethanol and that of Brazil.

Chapter 3 highlights the materials compatibility issues associated with increasing levels of ethanol for the fueling system and typical engine materials.

Chapter 4 covers the vehicle operational impacts of ethanol blends, including an assessment of the ability of the typical vehicle fuel system to accommodate higher levels of ethanol, cold-start, driveability, and acceleration considerations, as well as the potential impact on full useful life of the emissions control system. Specific attention is given to issues that the engine control system may encounter in adapting to the increased ethanol blends or switching between dissimilar fuels (e.g., E20 to gasoline).

Chapter 5 reports the known emissions impacts of increased ethanol blends, including both tailpipe emissions issues or changes and evaporative emissions.

Chapter 6 reviews the impact of intermediate ethanol blends on the refinery industry and issues that may arise in meeting required specifications for the finished fuel. Fuel distribution issues are also discussed. This chapter does not consider any economic issues of increased ethanol use from the viewpoint of the petroleum industry.

Chapter 7 examines issues with the use of ethanol blend fuels in non-road engines.

Chapter 8 provides our recommendations for follow-on activities. 


\section{ETHANOL BLEND REGULATION AND BRAZILIAN EXPERIENCE}

It has been known virtually from the invention of the internal combustion engine that ethanol is a suitable fuel. Henry Ford was a proponent of ethanol because he recognized its renewable benefits and the positive economic impact its use could have on agriculture. However, it would be several decades before ethanol was seriously considered for use as a fuel in the United States In 1971, the Nebraska Agricultural Products Industrial Utilization Committee was created by the Nebraska legislature in response to efforts by State Senator Loren Schmidt to promote ethanol blends in gasoline. ${ }^{1}$ About this time, blends of 10 vol \% ethanol in gasoline were named "gasohol." In 1972 the Nebraska legislature reduced the Nebraska state excise tax by 3 cents per gallon for gasohol. This action was followed by a similar measure by Iowa in 1973. The oil embargo of 1973 created intense interest in all potential alternative fuels to gasoline and diesel fuel, and gasohol has been in growing use ever since. The resulting research highlighted the impacts of fuel properties on vehicle emissions, which led to subsequent regulation of alcohol blends in gasoline. The Clean Air Act amendments of 1977 included the creation of Sect. 211(f), which prohibits the introduction into commerce of any fuel or fuel additive that is not substantially similar to fuels used in vehicle certification. The EPA may issue a waiver of the prohibition if a party demonstrates that the fuel/additive will not cause or contribute to the failure of any emissions control device or system.

\subsection{GASOHOL REGULATIONS}

The first waiver request received by EPA for an oxygenated compound was submitted by Gas Plus and the Illinois Department of Agriculture in June 1978 for "gasohol," a blend of $90 \%$ gasoline and $10 \%$ ethanol. The waiver application contained no actual data on ethanol/gasoline blends. Instead, it included data on methanol/cosolvent blends and on methyl tertiary-butyl ether (MTBE); these data were argued to show expected emissions impacts from ethanol as well. There was also a reference to some emissions tests conducted by the state of Nebraska on 26 vehicles, apparently with gasoline/ethanol blends. The blends were not identified and no data were given, but a statement said that the tests showed higher oxides of nitrogen $\left(\mathrm{NO}_{\mathrm{x}}\right)$ and somewhat lower carbon monoxide $(\mathrm{CO})$ and hydrocarbon (HC) emissions.

Because of the lack of data, EPA was unable to grant the waiver application. However, EPA also declined to deny the waiver application and, under the terms of Sect. 211(f)(4), applications are deemed granted after 180 days if they have not been denied by then. On April 6, 1979, EPA issued a Federal Register notice confirming that the application had been deemed granted by expiration of the 180-day period.

The gasohol waiver application included no specifications defining use of the waiver. Because EPA issued no notice granting the waiver, it also failed to impose any specifications. This situation led to a need to subsequently issue interpretation of the waiver in April 1982 clarifying that blends of less than $10 \%$ could also be used. Although such a decision is not specified anywhere, EPA has also interpreted these percentage limits to apply by volume rather than by weight or mole.

The $10 \mathrm{vol} \%$ limit on ethanol was generally believed to translate to approximately $3.5-3.7 \mathrm{wt} \%$ oxygen in the gasoline by weight, based on sample analysis.

\subsection{REGULATION OF ALCOHOL BLENDS OTHER THAN GASOHOL}

While EPA established the allowance for ethanol by default, the agency has evaluated and allowed the use of other oxygenates through more affirmative determinations, both by grants of waivers and by progressive promulgation of an "Interpretive Rule" defining what fuel parameters are deemed "substantially similar" to certification fuel (gasoline defined by EPA for emissions testing) and thus allowed for use. 
In 1979, EPA issued its next three waivers-for up to 7 vol \% tertiary butyl alcohol (TBA), for up to $7 \mathrm{vol} \% \mathrm{MTBE}$, and for up to $5.5 \mathrm{vol} \%$ of a combination of methanol with TBA in equal parts. These waivers allowed about $2 \mathrm{wt} \%$ oxygen.

In October 1980, EPA promulgated its first real Interpretive Rule defining which fuels and additives were considered substantially similar to certification fuels. (Prior to this rule, EPA considered only those identical to fuels and additives used in certification to be "substantially similar" or "sub-sim.") EPA treated aliphatic ethers and alcohols other than methanol as sub-sim in volumes contributing $2 \%$ or less oxygen by weight.

In July of 1981, EPA issued a revised Interpretive Rule further defining "sub-sim." It allowed for use of up to $2.75 \mathrm{vol} \%$ methanol with an equal volume of TBA (or higher alcohols), as previously provided by waiver, essentially confirming that allowances made in waivers are applicable to all marketers, not merely the applicant. EPA was asked in this rulemaking to increase the oxygen limit to $3.7 \mathrm{wt} \%$, equivalent to that of gasohol, but EPA declined to do so based on observed $\mathrm{NO}_{\mathrm{x}}$ increases, keeping the sub-sim oxygen limit at $2 \mathrm{wt} \%$.

In November 1981, EPA granted a waiver for use of ARCO's "Oxinol," allowing up to $4.75 \mathrm{vol} \%$ methanol with an equal amount of TBA, which provides approximately 3.5-3.7 wt \% oxygen. This oxygen level became the effective limit thereafter. EPA granted waivers to DuPont Corporation (1985) and Texas Methanol Corporation (1988) allowing methanol/cosolvent combinations of up to $3.7 \mathrm{wt} \%$ oxygen and including ethanol as a cosolvent alcohol.

EPA also granted a waiver for up to 15 vol \% MTBE in 1988, which provides approximately $2.7 \mathrm{wt} \%$ oxygen. This waiver was requested and granted at less than the oxygen limit allowed for alcohols because of the high volume of the oxygenate itself. Because oxygenates have various properties, distillation impacts, etc., that are significantly different from the properties of gasoline hydrocarbons, 15 vol \% was seen as the acceptable limit for oxygenates, independent of the oxygen contribution.

In 1991, on a petition from the Oxygenated Fuels Association, EPA revised the Interpretive Rule on sub-sim to allow for mixtures of MTBE (or ETBE) and aliphatic alcohols other than methanol providing up to the $2.7 \mathrm{wt} \%$ oxygen limit. (The $2.7 \mathrm{wt} \%$ oxygen limit would allow about $19 \mathrm{vol} \%$ ETBE, but it was not expected that this high-cost oxygenate would be used at such a high level.)

In workshops relating to implementation of the reformulated gasoline (RFG) program, EPA was informed that with the (lower-density) fuels anticipated as RFG, $10 \mathrm{vol} \%$ ethanol would provide approximately $4 \mathrm{wt} \%$ oxygen by weight, whereas EPA's model only extended up to $3.7 \mathrm{wt} \%$ oxygen. EPA confirmed that use of $10 \mathrm{vol} \%$ ethanol would be allowed in RFG even with the oxygen at somewhat above $3.7 \mathrm{wt} \%$ (no oxygen limit having been established for $10 \mathrm{vol} \%$ ethanol blends).

\subsection{EPA DENIALS/REVOCATIONS OF WAIVERS AT HIGH ALCOHOL/OXYGEN LEVELS}

In March 1980, EPA denied a waiver application to Beker Industries for up to $15 \mathrm{vol} \%$ methanol. The denial was based largely on the absence of adequate data. (In fact, no data had been submitted on methanol without cosolvent additives.) But EPA also noted that the data submitted for high alcohol levels suggested that there could be problems, including increases in emissions and deteriorated driveability from the higher oxygen levels.

In August 1980, EPA denied a waiver application to Conservation Consultants of New England for $5 \mathrm{vol} \%$ ethanol with $5 \mathrm{vol} \%$ methanol (oxygen content $4.4 \mathrm{wt} \%$ ). The application had also requested waivers for (1) $10 \%$ methanol with 5 vol \% ethanol and (2) 8 vol \% methanol with 2 vol \% ethanol, but these requests had been withdrawn by the applicant. The denial was based on absence of data, but EPA noted problems anticipated with exhaust emissions, evaporative emissions, driveability, and materials compatibility.

In October 1981, EPA granted a waiver to Anafuel Unlimited for a mixture of up to 12 vol \% methanol with 6 vol \% butanols and a proprietary inhibitor. The waiver was granted under extreme 
duress-pressure from the White House and senators favoring Anafuel's position. This waiver would have provided around $7 \mathrm{wt} \%$ oxygen in the fuel. Subsequent testing, however, showed that the test data submitted did not reflect the alcohol package in that volume; and the Motor Vehicle Manufacturers' Association (MVMA) filed both a court challenge and a petition for EPA reconsideration. EPA revoked the waiver by reconsideration (1984) but the Washington, D.C., circuit court ruled that waivers were not subject to such reconsideration beyond a 30-day period provided in Sect. 211(f)(4). The Washington, D.C., circuit subsequently ruled in favor of MVMA's suit, however, vacating the original granting of the waiver so that EPA's evaluation of it would resume without the tainted data. EPA denied and finally revoked the waiver in 1986. In the meantime, American Methyl Corp., successor to Anafuel, had applied for another waiver with a variation of the formula at a 5 wt \% oxygen level. EPA denied that request in November 1983.

In 1987, at essentially the same time that Texas Methanol Corporation's waiver application was pending, EPA was asked by AM Laboratories, Inc., to grant a waiver for use of up to 5 vol \% methanol with $5 \mathrm{vol} \%$ ethanol, for an oxygen contribution of $4.4 \mathrm{wt} \%$, similar to the waiver it had denied in 1981 to Conservation Consultants. The application attached a report of a major Canadian test program that included such 5\%/5\% blends, in which it was argued that the driveability demerits were not excessive. The automakers fiercely opposed the application, arguing that other existing data clearly showed driveability to be degraded unacceptably at levels above around $3.7 \mathrm{wt} \%$ oxygen. For the first time, opposition was not limited to U.S. automakers but included opposing submissions from Toyota, as well. In January 1988, EPA issued its Federal Register notice and decision document denying the waiver.

\subsection{MINNESOTA $20 \%$ ETHANOL LAW}

The auto industry adamantly opposed the May 2005 legislation in Minnesota to require 20 vol \% ethanol in gasoline sold there. The final legislation delays implementation until 2013 and makes it contingent on a Sect. 211(f)(4) waiver being granted by EPA. The automakers tempered, but did not cease, their opposition. Many interested parties think it unlikely that Minnesota and the ethanol industry will be able to show that the higher blend level will not cause or contribute to the failure of emissions systems so as to obtain a waiver.

\subsection{BRAZILIAN VEHICLE TECHNOLOGY DEVELOPMENT TO USE $20 \%$ ETHANOL}

The statement is often made to the effect that "the Brazilians use high level ethanol blends interchangeably with gasoline without problems." Analysis of available reports provides insight into the Brazilian experience with 20 vol \% ethanol blends.

In the late 1970s, Ford Motor Company conducted a comprehensive analysis of two of its Brazilian vehicles (one 1976 model and one 1978 model, both with 1.4-L engines) to determine how effectively they operated on gasoline and $20 \mathrm{vol} \%$ ethanol. $^{2}$ The report made the following statement in its conclusion: "Most Brazilian vehicles are calibrated to accept either gasoline or a $20 \%$ ethanol blend. This calibration must be a compromise between the two fuels and is not optimum for either; operation on gasoline is too rich for best economy and operation on the blend is close to driveability limits."

In a recent critique of a World Bank report, consultants working for the Brazilian ethanol industry describe how ethanol was originally introduced in Brazil at a $10 \mathrm{vol} \%$ level but increased to $15 \mathrm{vol} \%$ by 1979 and to $20 \mathrm{vol} \%$ by 1981(Ref. 3). Until the late 1970s, ethanol was used in unmodified vehicles. By 1980, vehicles were modified or designed to run on the $20 \mathrm{vol} \%$ ethanol, but many Brazilian vehicles remained unmodified. The report says 
"At this point it is important to clarify that gasoline vehicles manufactured for the Brazilian market until the very beginning of the Proalcool were not especially engineered or calibrated to operate with the high ethanol contents of gasoline that in 1979 were at $15 \%$ and in 1981 at 20\%. It was possible to use those levels because in-use vehicles were manufactured with large tolerances, with no emissions or fuel economy requirements and reliability was not at high standards even with ordinary gasoline (ethanol-free). However, Proalcool soon prompted the development and application of new technologies that lifted Brazilian automotive engineering to a high level of expertise. Therefore, since the late seventies gasoline fueled vehicles have been engineered and calibrated to operate with high ethanol content gasoline and later, in the late eighties, were upgraded to attain the regulated emission levels." (p. 35).

What the Brazilian report is saying in such oblique terms is that it was only possible to get away with using high ethanol levels (15-20 vol \%) because the vehicles at that time did not have emission controls and the tight calibrations needed to support them. There were emission increases and reliability problems from the 15-20 vol \% ethanol, but they were not immediately distinguished from the common problems of the day. This description is in agreement with the testing Ford completed in the late 1970 s. $^{2}$

Discussion with a current automotive company representative confirmed that "conventional gasoline" vehicles today in Brazil are calibrated for E20 and operate at richer conditions when using neat gasoline (Norm Brinkman, General Motors, personal communication to Rich Bechtold, Alliance Technical Services, April 24, 2007.) These vehicles also have fuel system components compatible with ethanol.

\subsection{SUMMARY}

Blends of 15 and 20 vol \% ethanol in gasoline would contain about 5.6 and 7.5 wt \% oxygen, respectively, which is far beyond what EPA has granted for any waiver application to date. As demonstrated in the preceding discussion, EPA considers whether a fuel causes increased exhaust and evaporative emissions, deteriorated driveability, and problems with materials compatibility, which can lead to long-term failures of fuel system and emission control devices. Subsequent sections of this report will address what is currently known about these issues for blend fuels with greater than 10 vol \% ethanol.

\subsection{REFERENCES}

1. R. L. Bechtold, Compendium of Significant Events in the Recent Development of Alcohol Fuels in the United States, ORNL/Sub/85-22007/1, Oak Ridge National Laboratory, 1987.

2. G. K. Chui, R. D. Anderson, and R. E. Baker, "Brazilian Vehicle Calibration for Ethanol Fuels," Ford Engineering and Research Staff, USA; F. B. P. Pinto, Ford of Brazil, presented at the Alcohol Fuels Technology Third International Symposium, Asilomar, California, May 28-31, 1979.

3. P. M. Nastari, I. de Carvalho Macedo, and A. Szwarc, "Observations on the Draft Document Entitled 'Potential for Biofuels for Transport in Developing Countries,' The World Bank Air Quality Thematic Group,” July 2005. 


\section{MATERIALS COMPATIBILITY}

Automotive fuel systems contain a wide range of elastomeric ${ }^{*}$ and metallic components. The elastomers are used primarily as seals and fuel lines where movement is required, such as at locations between the engine and the body. However, vehicle manufacturers have recently been moving to fuel lines that are nonmetallic for the entire span between the fuel tank and the engine fuel system, greatly increasing the amount of interface area between elastomers and the fuel. Many fuel tanks are now nonmetallic as well for reasons of cost and ability to be molded into complex shapes that maximize volume in tight vehicle confines.

\subsection{ELASTOMER COMPATIBILITY}

Elastomers must not crack, leak, or become permeable to fuel or else vehicle safety is impaired and/or emissions will increase. No elastomer is completely unaffected by exposure to fuel, with changes occurring in volume (swell), tensile strength, and elongation. The addition of ethanol to gasoline causes changes in elastomers that are difficult to predict. Figure 3.1 illustrates testing done on various generic elastomers used in fuel systems (measuring swell) using two gasolines, neat ethanol, and a blend of the base gasoline and $10 \%$ ethanol. As these data show, predicting elastomer compatibility is fraught with uncertainties.

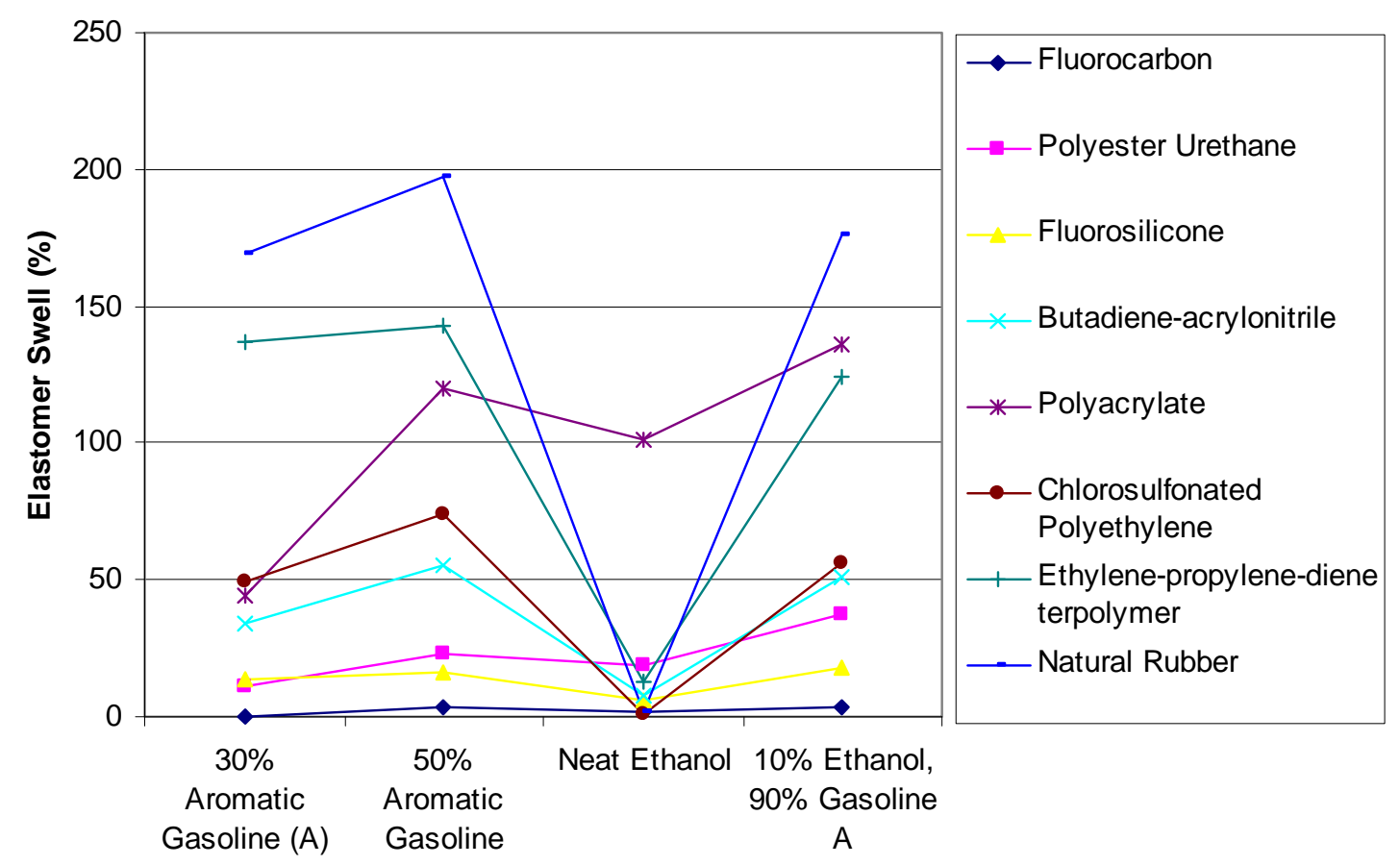

Fig. 3.1. Elastomer swell from exposure to gasoline, ethanol, and a 10 vol \% ethanol blend. Source: Ref. 1.

Figures 3.2 and 3.3 show additional test data for polyester urethane and fluorocarbon over the entire range of ethanol blends from 0 to $100 \%$ (Ref. 1). These data show that most of the change in elastomers occurs within the first 10 vol $\%$ of ethanol addition, with very little additional change

\footnotetext{
*Elastomer is a generic term that includes all soft parts in a fuel system, including rubbers, plastics, nylons, fluorosilicones, urethanes, etc.
} 

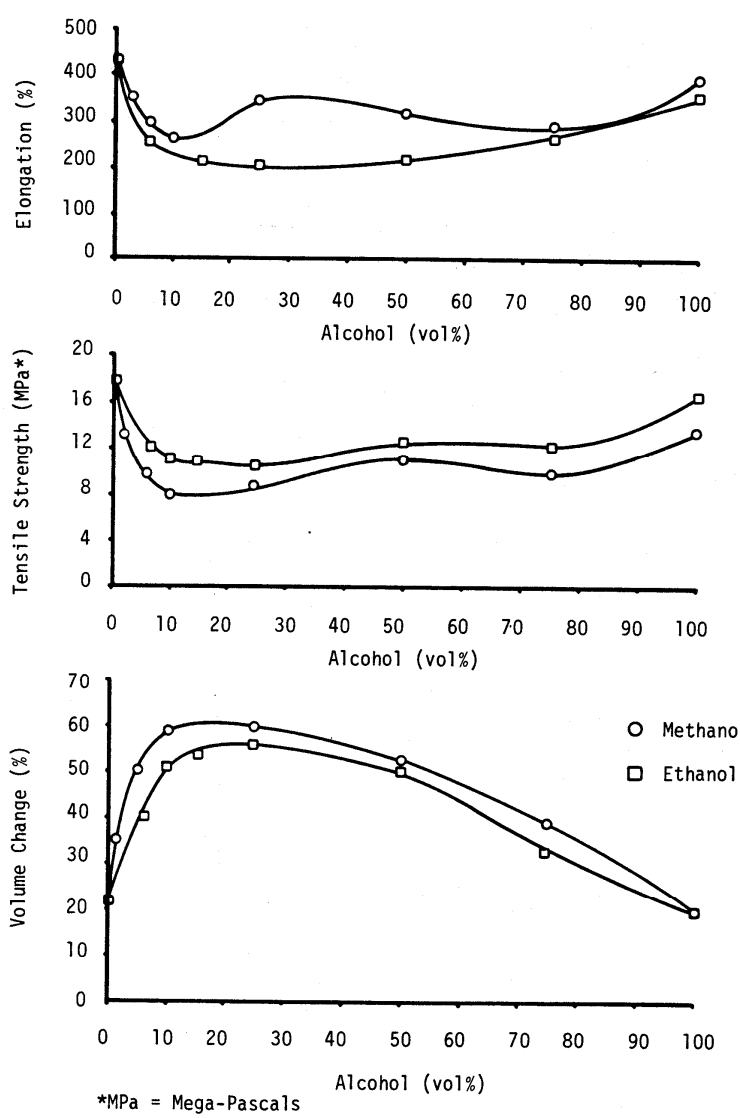

Fig. 3.2. Polyester urethane compatibility with ethanol and methanol blends. (Gasoline A from

Fig. 3.1, Source: Ref. 2)
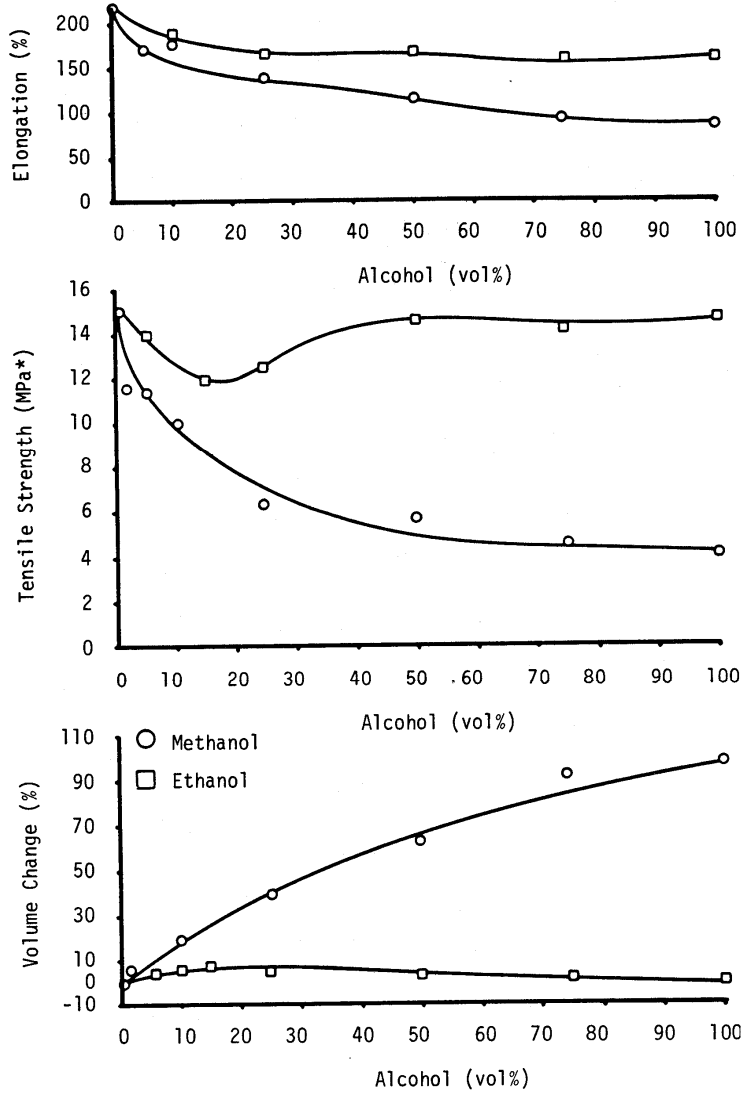

$\star \mathrm{MPa}=$ Mega-Pascals

Fig. 3.3. Fluorocarbon compatibility with ethanol and methanol blends. (Gasoline A from Fig. 3.1; Source: Ref. 2)

upon going to $20 \mathrm{vol} \%$. In many cases, most of any change that occurs is present with $20 \mathrm{vol} \%$ ethanol, with larger percentages causing the same or less severe changes.

These data suggest that while predicting elastomer compatibility is uncertain, $20 \mathrm{vol} \%$ ethanol does not appear to pose much of a change compared with $10 \mathrm{vol} \%$ ethanol. However, these tests were done using new elastomers and relatively pure fuels. As elastomers age in service, they are less amenable to change. There are several instances of field problems caused by changes in fuel properties. For example, the change to ultra-low-sulfur diesel fuel caused numerous fuel system leaks because the elastomers were adversely affected by a relatively small change in fuel properties. New versions of the same elastomers worked, illustrating the impact that aging can have on fuel system elastomers.

\subsection{FUEL FILTER PLUGGING}

Over time, vehicle fuel systems accumulate significant amounts of dirt, gum, hydrocarbon deposits, and corrosion. When systems are first exposed to ethanol blends, the highly solvent ethanol tends to remove these deposits rapidly, allowing them to be transported downstream where they are caught by the fuel filter. The typical result is fuel starvation with the engine stopping completely or the vehicle being able to operate only at very low loads. Figure 3.4 shows several fuel filters plugged by the introduction of $10 \mathrm{vol} \%$ ethanol. Results using $20 \mathrm{vol} \%$ ethanol will likely be similar. New vehicles 


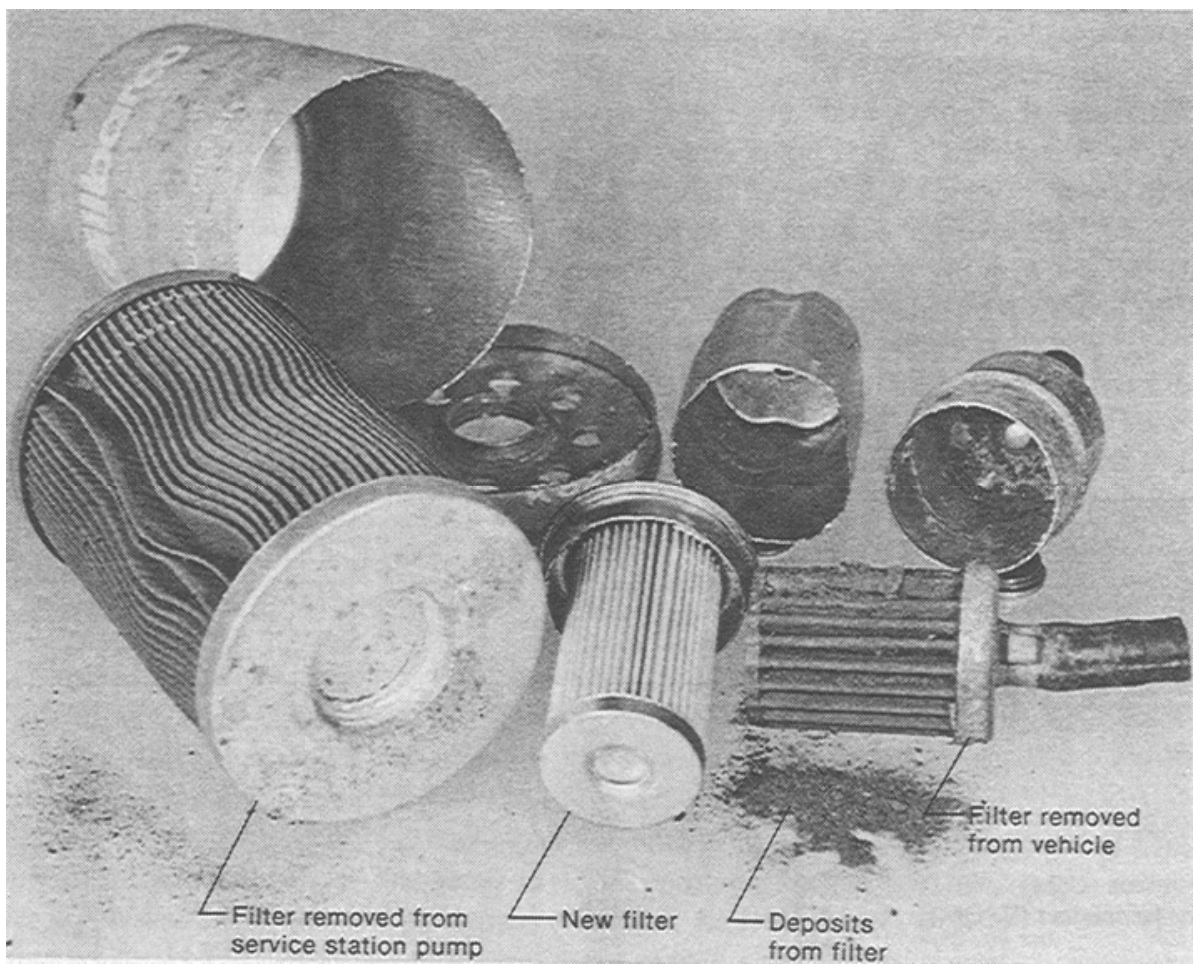

Fig. 3.4. Fuel filters plugged from introduction of ethanol blends. Source: Ref. 1.

exposed early to ethanol blends should not experience this problem. Older vehicles will be affected with a severity that is likely to be a function of their mileage accumulation.

\subsection{METALS COMPATIBILITY}

Some testing has shown that aluminum and brass are not appreciably affected by ethanol blends, although inconsistent or conflicting results are found. ${ }^{3-5}$ Steel tanks and fuel lines have demonstrated rusting over long-term use and severe pitting if exposed to mixtures of water and ethanol that have separated from a gasoline-ethanol blend. ${ }^{1,3}$ Use of appropriate corrosion inhibitors has been shown to prevent long-term rusting due to normal use. ${ }^{1}$ Magnesium is highly corroded by contact with ethanol in ethanol blends and should be avoided as a fuel system material. ${ }^{2}$ (No evidence of magnesium use in fuel systems was discovered in the course of this effort.)

\subsection{COMPONENT TEST RESULTS}

Much fundamental work on materials compatibility was conducted in the 1970s and 1980s, as well as some fleet tests. However, most field tests of ethanol blends were primarily anecdotal in nature, since gasohol was being used widely with few problems and little need was seen to conduct more rigorous testing. No reported field tests were found using blends with more than $10 \mathrm{vol} \%$ ethanol.

Recently, Environment Australia commissioned a very comprehensive test program to determine whether $20 \mathrm{vol} \%$ ethanol blends should be used there. ${ }^{2}$ In this test program, the Orbital Engine Company conducted compatibility testing of several fuel system parts taken from 1985 and 1990 model year vehicles.

Orbital performed materials compatibility testing using SAE standards to the closest degree possible. Those standards included SAE J1748 (polymeric material), SAE J1747 (metallic material), 
and SAE J1681 (test fluid). Materials and components selected for immersion were chosen on the basis of being in contact with E20 and having a propensity for failure. Vehicles used in the compatibility testing were selected based on being representative of the aging Australian vehicle population. Specifics for the vehicles chosen can be seen in Table 3.1.

Table 3.1. Older model vehicle specifications for the materials compatibility testing (Ref. 4)

\begin{tabular}{lcll}
\hline \multicolumn{1}{c}{ Make/model } & Model year & \multicolumn{1}{c}{ Fuel } & \multicolumn{1}{c}{ Fuel system } \\
\hline Holden Commodore & 1990 & Unleaded & Electronic fuel injection; 3-way catalyst \\
Ford Falcon & 1985 & Leaded & Electronic fuel injection \\
Holden Commodore & 1985 & Leaded & Carburetor \\
\hline
\end{tabular}

Testing was conducted with both unleaded and leaded gasoline as well as those two fuels mixed with $20 \mathrm{vol} \%$ ethanol and 1 vol \% corrosive water. ${ }^{*}$ Test temperatures were maintained at $55 \pm 2{ }^{\circ} \mathrm{C}$ $\left(131^{\circ} \mathrm{F}\right)$ for metals, elastomers, and plastics. The components were immersed for up to 2000 hours.

Testing determined that several metallic fuel system components were significantly degraded from contact with E20. Rust was found on metal surfaces in/on electric fuel pumps, fuel injectors, and fuel regulator diaphragms (see Figs. 3.5-3.7). The potential exists for the rust to become dislodged and clog fuel filters or settle in areas where mechanical components move, increasing wear rates.
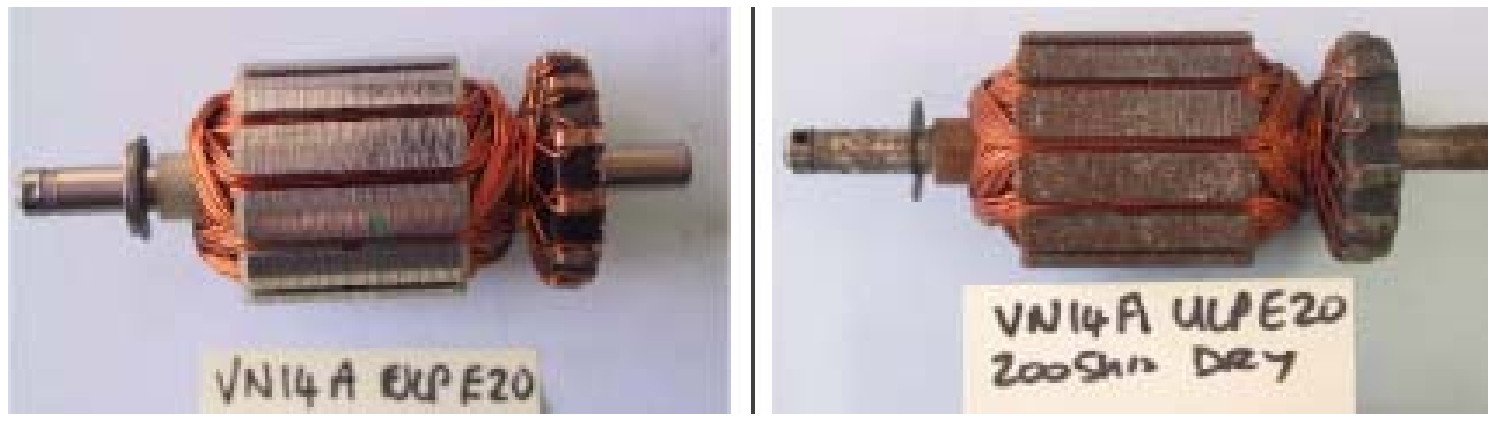

Fig. 3.5. Fuel pump commutator showing rust and tarnish after immersion in E20. Source: Ref. 5.

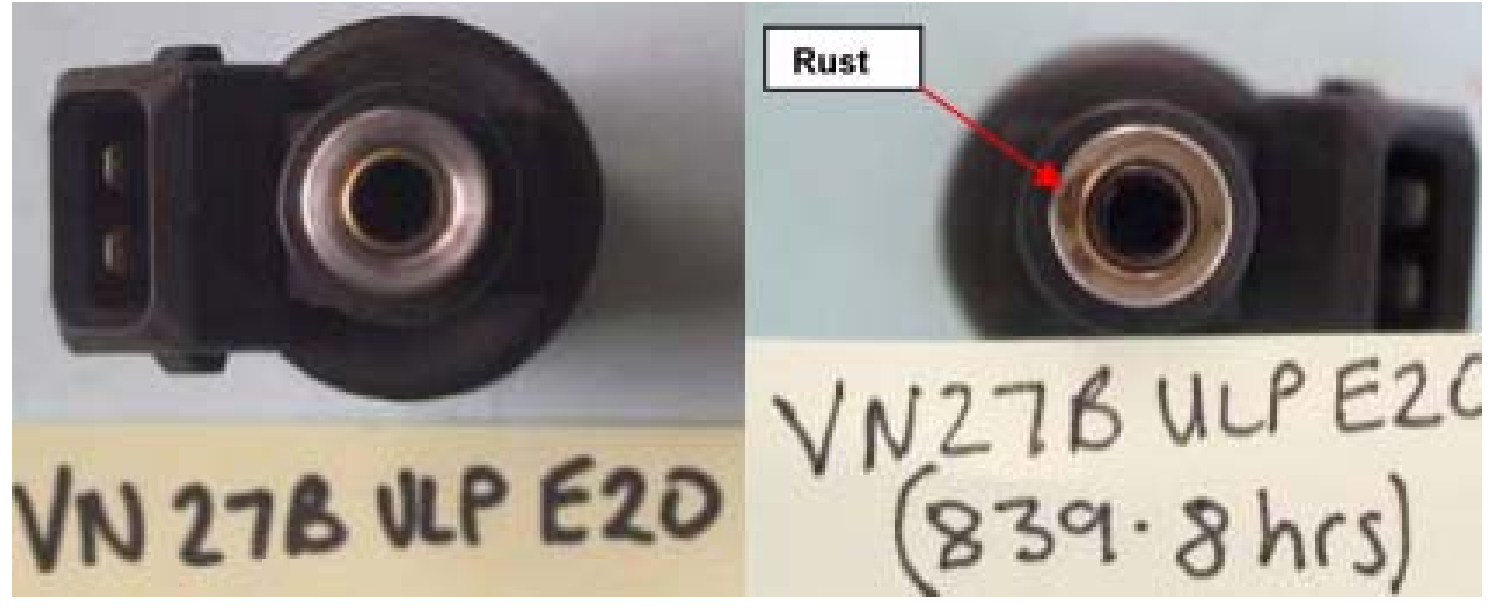

Fig. 3.6. Fuel injector showing rust after immersion in E20. Source: Ref. 4.

\footnotetext{
*"Corrosive" water is defined as part of SAE standard J1681.
} 

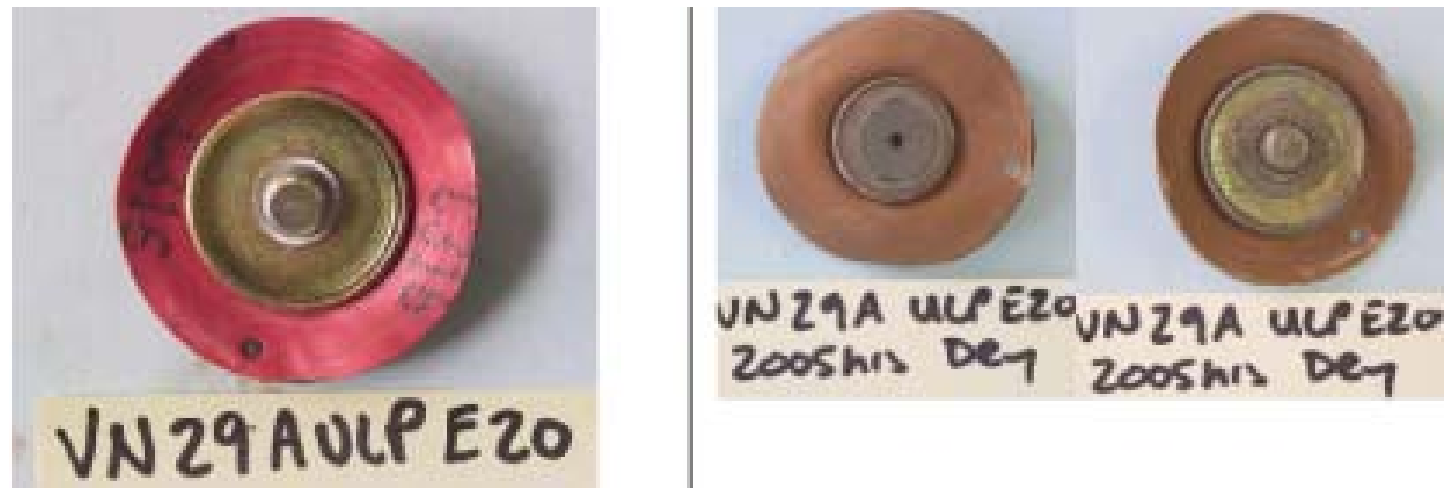

Fig. 3.7. Fuel pressure regulator diaphragm showing rust and discoloration after immersion in E20. Source: Ref. 5.

Accelerating the wear rate of bearings may lead to premature failure of components in these items. The fuel pump's aluminum casing was found to be vulnerable to pitting from immersion in E20 (see Fig. 3.8). Pitting was also found on aluminum surfaces of carburetors (see Fig. 3.9). Corrosion products from this pitting could block fuel metering devices, which in turn could lead to engine stalling and/or deteriorated driveability.

Tarnishing of brass and copper components increased when they were immersed in E20. In parts such as the fuel pump commutator, armature, and brushes, the corrosion products could increase wear rates, leading to premature component failure. These copper and brass pieces also carry current. If excessive corrosion were to collect on these parts, resistance could increase, causing decreases in fuel pump speed and pressure output, which in turn will limit engine output and vehicle performance.
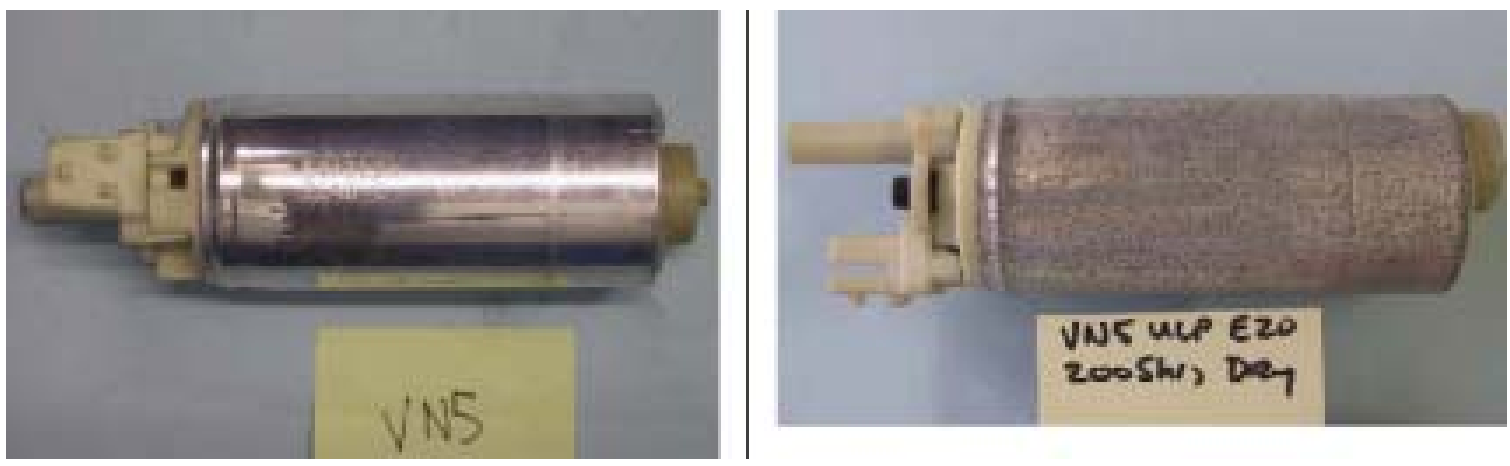

Fig. 3.8. Pitted fuel pump shown on the right after immersion in E20. Source: Ref. 5.

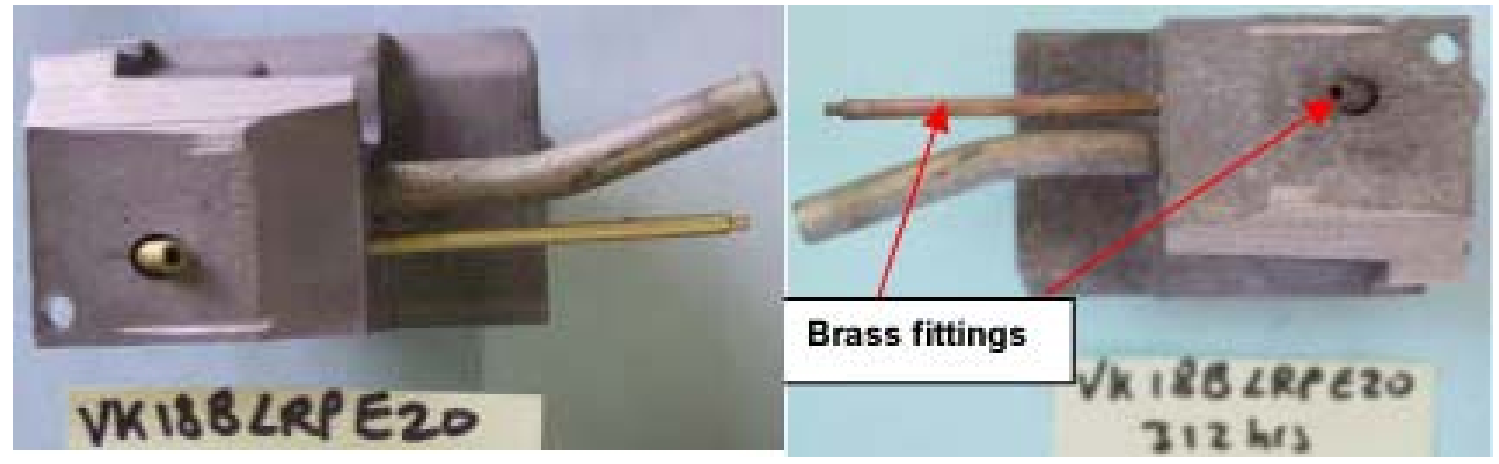

Fig. 3.9. Pitted carburetor housing and corroded brass fittings shown on the right after immersion in E20. Source: Ref. 4. 
When immersed in E20, rubber components increased in weight and decreased in hardness. Testing showed fuel pressure regulator diaphragms swell and distort, which could lead to premature failure. A failure of this part would cause the engine to stop. A fuel injection system return hose showed significant swelling after exposure to E20 (see Fig. 3.10). A fuel pressure sender was also found to be adversely affected and would likely fail before achieving its expected lifetime (see Fig. 3.11).

The plastics tested were found to have little to no change in properties (weight or hardness). Exceptions to this were carburetor floats and positive crankcase ventilation (PCV) valves (see Fig. 3.12). Plastic components of these parts softened and swelled. This condition could lead to deteriorated vehicle driveability and/or emissions increases. Orbital concluded, based on its testing, that the materials used in vehicles are not sufficiently compatible with E20 to be expected to work properly over the lives of the vehicles.

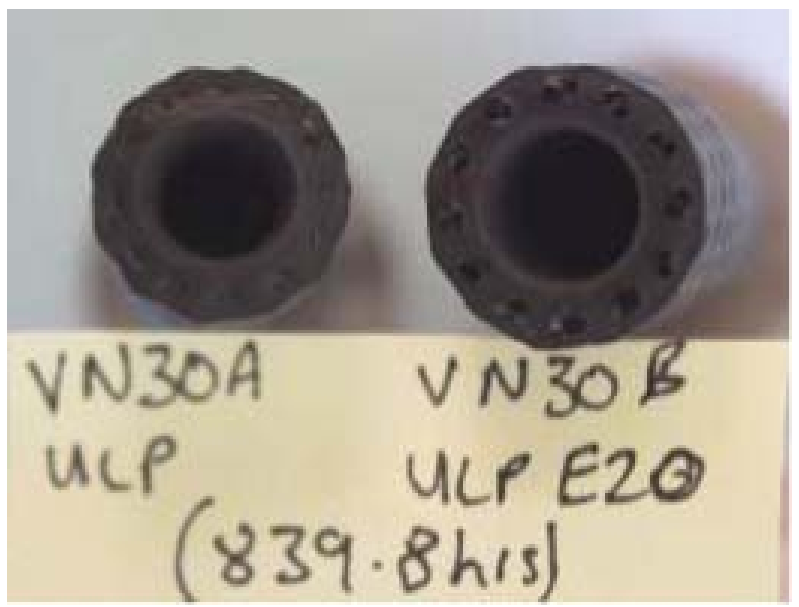

Fig. 3.10. Fuel injection return hose shown on the right after immersion in E20. Source: Ref. 4.

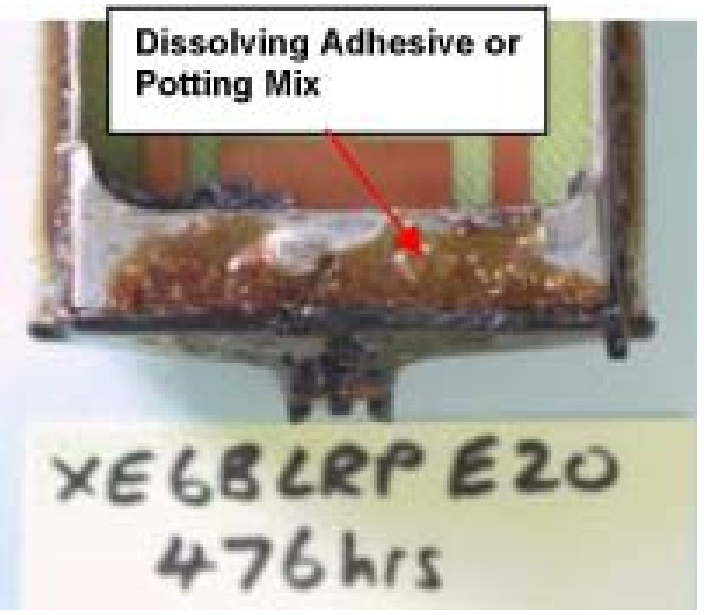

Fig. 3.11. Fuel pressure sensor after immersion in E20. Source: Ref. 4.

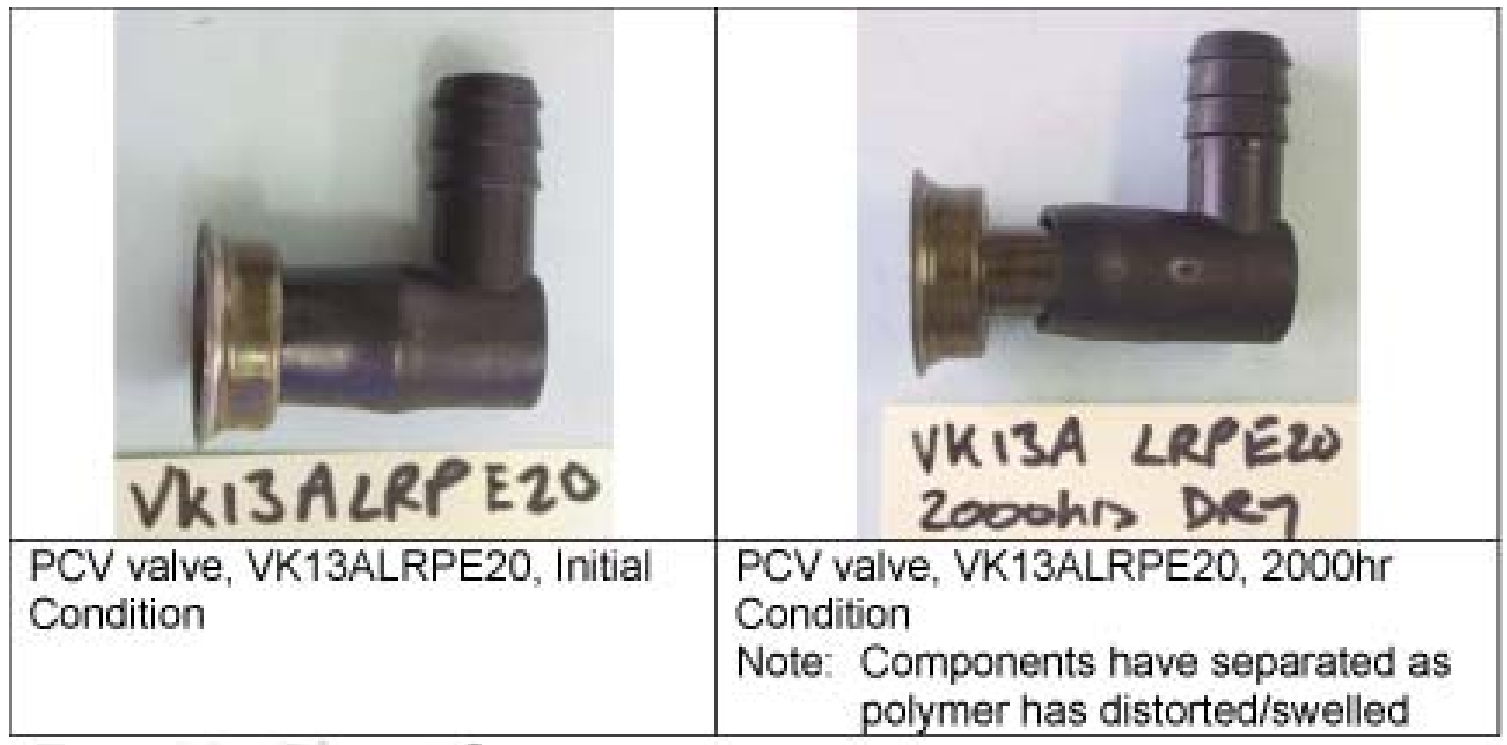

Fig. 3.12. PCV valve after immersion in E20. Source: Ref. 5. 


\subsection{ENGINE DURABILITY}

Orbital performed 50,000-mile durability testing of the five 2001-2002 vehicle models shown in Table 3.2, using a mileage accumulation dynamometer. ${ }^{6}$ Matched pairs of vehicles were operated, with one using neat gasoline and the other using E20. ${ }^{6}$ Orbital found similar materials compatibility issues in these vehicles as were found in the fuel system component immersion testing done separately. In general, it found slightly less pressure drop in the fuel filters, suggesting lower accumulation of deposits and increased fuel pump current draw consistent with higher fuel pump corrosion. No other trends in changes to fuel system components were noted.

Table 3.2. Orbital engine company late-model test vehicles

\begin{tabular}{lclcc}
\hline \multicolumn{1}{c}{ Make/model } & Model year & Class & Fuel & Delivery \\
\hline Holden Commodore & 2002 & Large & Unleaded & Electronic fuel injection \\
Ford Falcon & 2002 & Large & Unleaded & Electronic fuel injection \\
Toyota Camry & 2002 & Medium & Unleaded & Electronic fuel injection \\
Hyundai Accent & 2001 & Small & Unleaded & Electronic fuel injection \\
Subaru Impreza WRX & 2002 & Sports & Unleaded & Electronic fuel injection \\
\hline
\end{tabular}

All the engines were disassembled and assessed for both deposits and wear. They found small increases in piston skirt wear, cylinder bore wear, valve seat recession, and piston ring end gap. However, the increase in rate of wear was not judged to be high enough to cause a significant change in engine life. The most significant increase in engine deposits was found on the piston skirt (see Fig. 3.13). Deposits such as these could lead to sticking rings and/or increased bore wear. However, no indication was given as the type and amount of detergents in the gasoline that could control such deposits to acceptable levels.

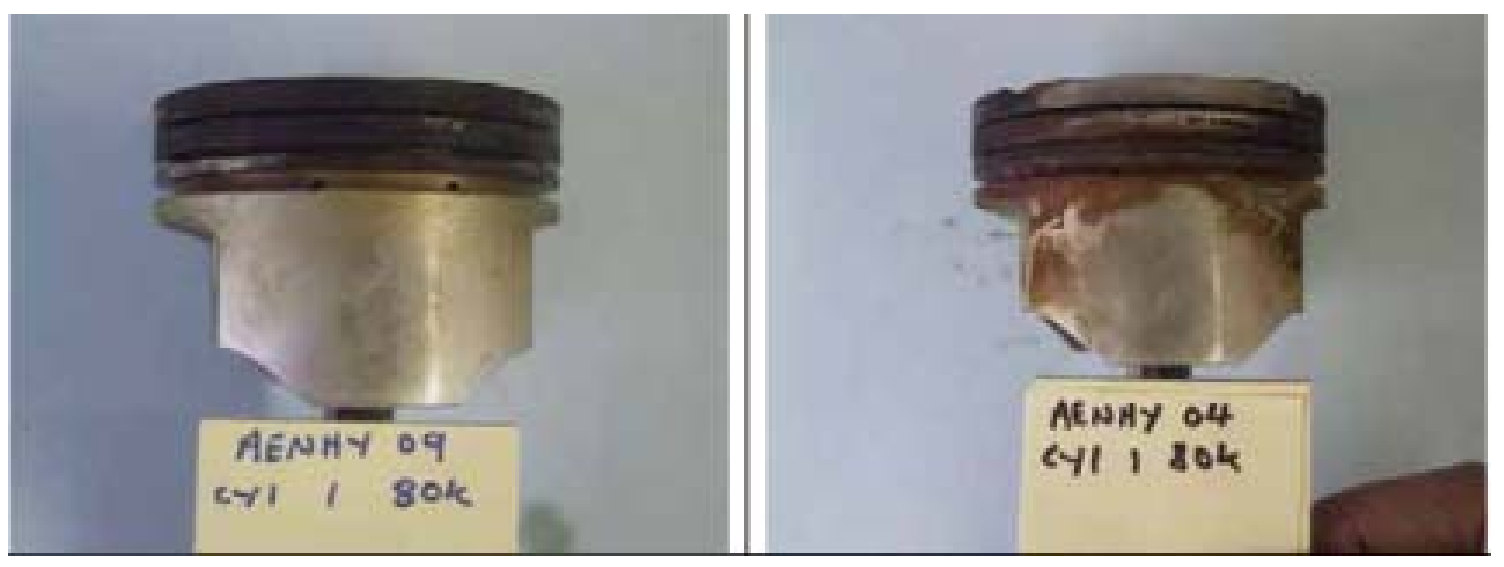

Fig. 3.13. Piston deposit after 50,000 miles of operation on gasoline (left) and E20 (right). Source: Ref. 6.

\subsection{SUMMARY}

Automotive original equipment manufacturers (OEMs) have been steadily moving to nonmetallic fuel lines for some time between the fuel tank and the engine. Today, nonmetallic fuel tanks have advantages in cost, weight, and capability of being molded into complex shapes that maximize volume in tight vehicle confines. These changes can increase permeation emissions from ethanol blends over those of older vehicles. As elastomers age in service, they become less amenable to change in fuels (i.e., durability and operability problems are more likely when older vehicles are 
exposed to high level ethanol blends for the first time). Older vehicles that have not been exposed to ethanol blends will be affected by filter plugging, with the severity likely a function of their mileage accumulation (even with use of E10). The full impact of this change on older vehicles is not known. In the 2003 study for the Australian government, Orbital concluded that the materials used in vehicles are not sufficiently compatible with E20 to be expected to work properly over the lives of the vehicles. Emissions and technology level of Australian cars tested suggest they are similar to U.S. Tier 1 OBDII vehicles.

\subsection{REFERENCES}

1. "Alcohols and Ethers-a Technical Assessment of Their Application as Fuels and Fuel Components," API Publication 4261, 2nd ed., American Petroleum Institute, 1220 L Street, Northwest, Washington, D.C., 20005, July 1988.

2. Status of Alcohol Fuels Utilization Technology for Highway Transportation: A 1981 Perspective, Vol. I-Spark-Ignition Engines, DOE/CE/56061-7, U.S. Department of Energy, May 1982.

3. Frank Cox, "The Physical Properties of Gasoline/Alcohol Automotive Fuels," in Proceedings of the Alcohol Fuels Technology Third International Symposium, May 28-31, 1979, Vol. II, U.S. Department of Energy, 1979.

4. Orbital Engine Company, Market Barriers to the Uptake of Biofuels Study-A Testing Based Assessment to Determine Impacts of a 20\% Ethanol Gasoline Fuel Blend on the Australian Passenger Vehicle Fleet, report to Environment Australia, March 2003.

5. Orbital Engine Company, A Testing Based Assessment to Determine Impacts of a $20 \%$ Ethanol Gasoline Fuel Blend on the Australian Passenger Vehicle Fleet-2000 hrs Material Compatibility Testing, report to the Department of the Environment and Heritage, Australia, May 2003.

6. Orbital Engine Company, Market Barriers to the Uptake of Biofuels Study, Testing Gasoline Containing 20\% Ethanol (E20), Phase 2B Final Report to the Department of the Environment and Heritage, Australia, May 2004. 


\section{VEHICLE OPERATIONAL IMPACTS}

\subsection{PROPERTIES OF GASOLINE, ETHANOL, AND ETHANOL BLENDS}

The properties of ethanol differ significantly from those of gasoline, causing the properties of ethanol blends to deviate from those of neat gasoline. Table 4.1 is a summary table comparing properties of ethanol and gasoline. Unlike ethanol, gasoline is a complex and variable mixture with properties that vary over some range. Ethanol (anhydrous) is a pure substance, yet the reported values vary somewhat. Some of the differing properties that are important to vehicle power system operation are noted briefly in this section. The discussion uses neat gasoline and neat ethanol comparisons to illustrate the differences.

Table 4.1. Selected properties of anhydrous ethanol and gasoline $e^{1-3}$

\begin{tabular}{lll}
\hline Fuel property & Ethanol & Gasoline \\
Formula & $\mathrm{C}_{2} \mathrm{H}_{5} \mathrm{OH}$ & $\mathrm{H}: \mathrm{C}=1.85-1.95: 1$ \\
& & Hydrocarbons $\mathrm{C}_{4}-\mathrm{C}_{12}$ \\
Specific gravity & 0.79 & $0.715-0.765$ \\
Electrical conductivity $(\mathrm{S} / \mathrm{m})$ & $1.35 \times 10^{-7}$ & $1 \times 10^{-12}$ \\
Latent heat of vaporization $(\mathrm{kJ} / \mathrm{kg})$ & 923 & $349,380-500$ \\
Lower heating value $(\mathrm{MJ} / \mathrm{L})$ & 21.1 & $30-33$ \\
Lower heating value $(\mathrm{MJ} / \mathrm{kg})$ & 26.8 & 42.7 \\
Stoichiometric air-fuel ratio (mass) & 9.0 & 14.7 \\
Research octane number & 108.6 & $88-100$ \\
Motor octane number & 89.6 & $80-90$ \\
Antiknock index $(\mathrm{R}+\mathrm{M}) / 2$ & 99.1 & $84-95$ \\
Vapor pressure $\left(\mathrm{kPa} @ 38^{\circ} \mathrm{C}\right)$ & 15.9 & $48-103$ \\
Boiling point or range $\left({ }^{\circ} \mathrm{C}\right)$ & 78 & $25-215$ \\
\hline
\end{tabular}

\subsubsection{Energy Density and Combustion Chemistry}

Energy density. The volumetric (combustion, lower heating value [LHV]) energy density of ethanol is about $67 \%$ of the value for gasoline. Approximately $50 \%$ more liquid volume is required for ethanol compared with gasoline to obtain the same amount of combustion energy. On a mass basis, it takes about $60 \%$ more ethanol than gasoline to obtain the same amount of energy. Ethanol blends will generally have properties that are proportionate to the blend composition (although some minor nonlinear density effects likely occur for the mixtures). Incrementally greater fuel delivery (volume and mass) will be required for ethanol blends to achieve comparable engine power.

Combustion air requirements. The combustion chemistry of ethanol and gasoline differs and so the combustion air requirements differ. Ethanol requires slightly less air than gasoline on an equal combustion energy (or power) basis. This difference is about $2 \%$ less air demand for stoichiometric combustion using the Table 4.1 mass-based values for LHV and the elemental composition of gasoline modeled as $\mathrm{C}_{1.0} \mathrm{H}_{1.85}$.

Exhaust effects. The combustion chemistry differences for ethanol and gasoline are reflected in the exhaust. Stoichiometric ethanol combustion produces approximately 4-5\% more exhaust on a molar basis and $2 \%$ more on a mass basis than gasoline (for equal combustion energy). It should be noted that ethanol produces somewhat lower-temperature exhaust compared with gasoline for the same engine conditions. ${ }^{3}$ Exhaust from pure ethanol will contain $45-50 \%$ more water than gasoline exhaust (the range accounts for variations in gasoline composition). On a molar basis, stoichiometric gasoline combustion exhaust contains about $12.5 \%$ water, and pure ethanol combustion exhaust contains about $18.4 \%$ water (gasoline elemental composition is assumed to be $\mathrm{C}_{1.0} \mathrm{H}_{1.85}$ ). 


\subsubsection{Vaporization and Boiling Range}

Latent heat of vaporization and boiling point. Because of a much higher latent heat of vaporization, significantly more energy is required to vaporize liquid ethanol compared with gasoline. This difference will result in more charge cooling - when complete ethanol vaporization is achieved. The boiling point of ethanol is obviously fixed at $78^{\circ} \mathrm{C}$, whereas gasoline has a boiling range often starting at $25^{\circ} \mathrm{C}$. The low boiling point constituents in gasoline are the most readily vaporized and are seasonally adjusted for good cold-starting. The difficulty with vaporizing ethanol in cold conditions is well known.

Cold-start. Cold-start with ethanol blends can be a concern. In cold conditions, starting depends on the most volatile components in gasoline to create a mixture that can be ignited by the spark. Higher-boiling-point components of gasoline and nearly all of the ethanol stay in liquid form. The higher latent heat of vaporization of ethanol means that what little ethanol does change phase also increases the charge cooling effect. Ethanol (and other alcohols) and gasoline blends form lowboiling azeotropes and can cause vapor pressure increases. This effect is likely to translate into a very slight aid for cold-start, but this effect will be masked at low temperatures by ethanol's high latent heat of vaporization and boiling point considerations. Commercial ethanol fuel blends with greater than $10 \mathrm{vol} \%$ ethanol will likely be tailored for seasonal temperatures, as gasoline and E10 are currently. The fuel vapor pressure and cold-start considerations would be part of the fuel's design. Cold-start testing of vehicles is covered in Sect. 4.3.

Wall wash. In cold engine conditions (especially below $30^{\circ} \mathrm{F}$ ), and particularly cold-start, excess fuel must be supplied to allow stable combustion conditions. For ethanol blends, the higher-boiling components of gasoline and the ethanol do not vaporize and some of this fuel can "wash" the piston walls. A quantity of these fuel components is transferred to the oil. These components vaporize back out of the oil when the oil reaches sufficient temperature. This ethanol "wash" effect is known to be a consideration for E85 FFVs; it is likely to be a much more minor consideration for much lower ethanol blends.

Ethanol boil-off. As described, during cold-start with ethanol fuel and cold engine operation $\left(<30^{\circ} \mathrm{F}\right)$, liquid ethanol will collect in the crankcase oil. Later there will be a "boil-off" when the oil temperature reaches the boiling point of ethanol. The resulting ethanol vapor will be ingested through the PCV system and therefore enrich (significantly) the air/fuel mixture. Experience with E85 and M85 (gasoline blend with up to $85 \%$ methanol) reveals that repeated short vehicle trips in very cold conditions can result in fuel accumulation in the crankcase, which can be problematic. Later, when ethanol boil-off occurs, the crankcase ventilation into the intake causes a temporary enrichment condition and problematic engine behavior unless the engine control system can compensate very quickly. In FFVs, this phenomenon may temporarily corrupt the adaptively learned fuel scaling factors. If the FFV is shut off with the corrupted scaling factor, this problem may lead to startability and/or driveability issues when the vehicle is started up next time. The same considerations will apply to non-FFVs using fuel blends above $10 \mathrm{vol} \%$ ethanol. Certainly, ethanol wall wash and boil-off issues will be diminished for lower-level ethanol blends, but they should still be considered.

Vapor pressure. While the Reid" vapor pressure (RVP) of ethanol is only 2.3 psi compared with gasoline that is typically in the range of 7-9 psi, adding ethanol to gasoline causes an increase in vapor pressure. This increase is due to ethanol combining with certain low molecular weight hydrocarbons to form what are called azeotropes. These azeotropes have lower boiling points than the hydrocarbons from which they are made, resulting in an increase in vapor generation at lower temperatures. Figure 4.1 illustrates this phenomenon, which has been documented widely by several researchers. $^{4-6}$

Figure 4.1 shows that the effect of ethanol on gasoline vapor pressure peaks around 5-6\% and decreases with larger additions, decreasing in an almost linear fashion to 2.3 psi at $100 \%$ ethanol. For

\footnotetext{
* Reid vapor pressure refers to a specific ASTM test (D323) conducted at $100^{\circ} \mathrm{F}$.
} 


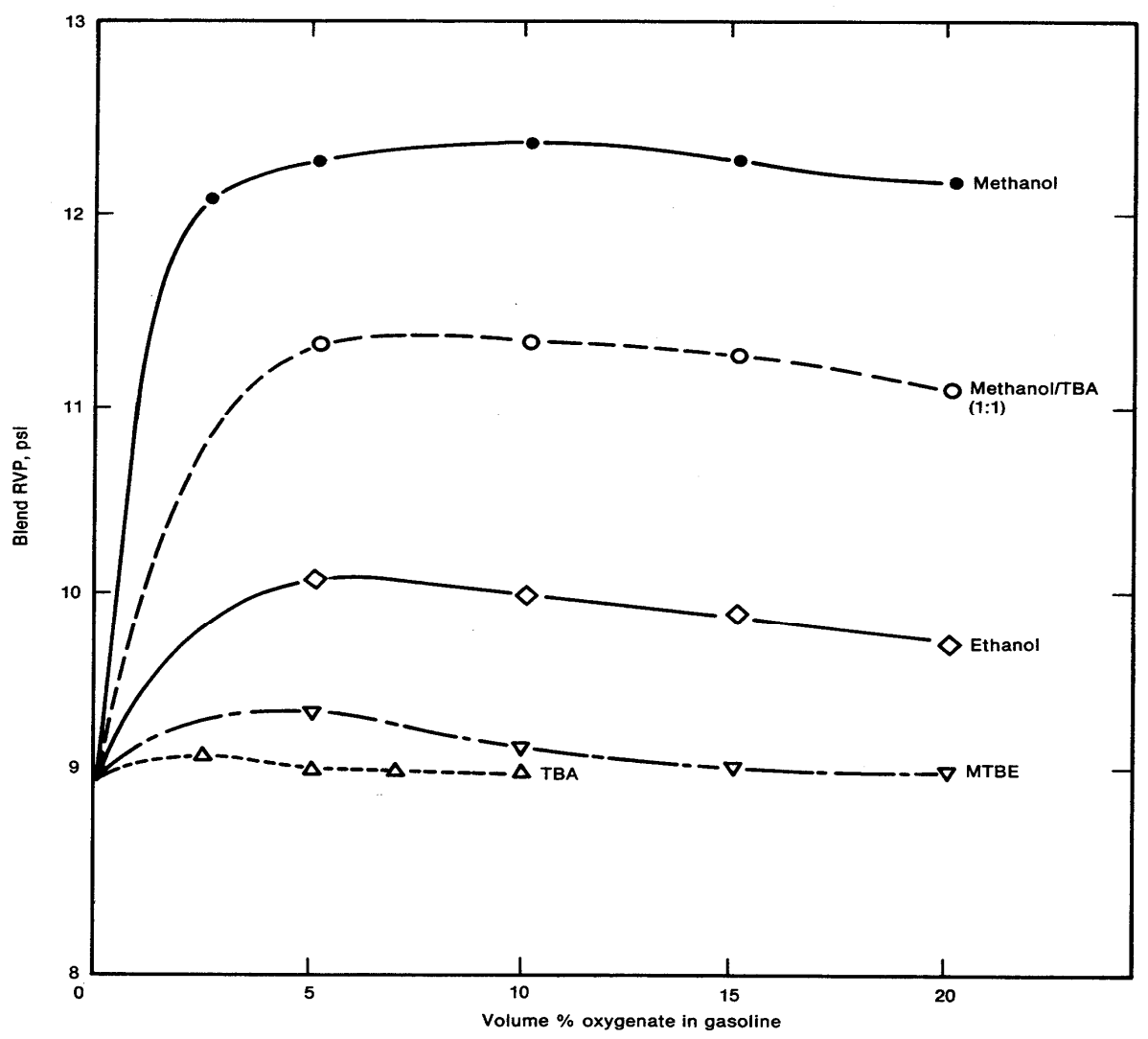

Fig. 4.1. The effect of alcohol addition to gasoline RVP. Source: Ref. 5.

the same base gasoline, the addition of 20 vol \% ethanol will cause a smaller increase in RVP than 10 vol \% addition. However, gasoline suppliers are likely to adjust the base gasoline used to make 20 vol \% ethanol blends so that the RVP comes out the same, by removing low-boiling-point hydrocarbons to counteract azeotrope boiling point depression. The ethanol content at which the peak vapor pressure value occurs has been variously reported by researchers to be anywhere from $5-12$ vol \%, ${ }^{5,6}$ but trends are quite similar and differences would be expected because of variations in the gasoline used.

While blend fuel vapor generation is a function of both the amount of alcohol and the hydrocarbons in the gasoline, it is unlikely that $20 \mathrm{vol} \%$ ethanol blends would have significantly different vapor generation characteristics from those of $10 \mathrm{vol} \%$ ethanol blends.

\subsubsection{Energy Efficiency}

Antiknock index. Ethanol is a well-known octane/anti-knock improver. Engine knock is one of the fundamental limiting factors for efficiency and power, so ethanol affords numerous strategies for improvement. In regard to the legacy fleet, there are some engines with a knock sensor system and controls that search for higher-efficiency operation, usually by optimizing spark timing. Octane improvement would improve power and efficiency incrementally for these vehicles.

When ethanol blends are splash blended, the octane number is increased. In current practice, the neat gasoline has adequate octane, and the resultant blend is then relatively high octane. The same benefits may not be realized for match blended fuels, because the resultant octane ratings are targeted in this process. A discussion of splash blending and match bending is in Sect. 6. 
Engine energy efficiency. There are several variables that feed into the energy efficiency effects from increasing ethanol in blend fuel. These include the higher octane rating, charge cooling effect, and molar advantage in combustion gas produced. The limited experience with operating existing fleet vehicles with ethanol blends shows that the energy efficiency is about the same, with modest gains or losses seen in some vehicles. ${ }^{6-10}$ The general findings for ethanol blends are that the fuel economy in miles per gallon is proportional to the volumetric energy density of the fuel.

\subsection{VEHICLE FUEL SYSTEMS}

The ability of engines to adjust with some precision to variations in fuel properties and changes in ambient conditions (temperature, altitude), has evolved over time. Some major improvements began with feedback-controlled carburetors $(\sim 1978)$ and the introduction of the three-way catalyst (TWC) emission system around 1981. ${ }^{11}$ This system featured a closed-loop feedback system using an oxygen sensor, with the objective being to control the engine to operate in the near-stoichiometric range under most conditions. Over time, the controls became more sophisticated and precise. By 1996, most if not all new U.S. vehicles were equipped under the OBDII mandate, which included monitoring of the fuel system, engine operation, and emissions control systems.

\subsubsection{Flow Capacity}

Because the volumetric energy density of ethanol is approximately $67 \%$ that of gasoline, about $50 \%$ more liquid volume is required for ethanol compared with gasoline to obtain the same amount of combustion energy. It follows that ethanol blends contain less energy per unit volume than gasoline, and so at a given engine power output, ethanol blends require more volumetric fuel flow. Assuming linear effects and no engine energy efficiency change, Fig. 4.2 illustrates the additional fueling needs for ethanol blends. As an example, the flow change needed for E30 vs gasoline would be about an $11 \%$ fuel delivery increase and there is about a $7 \%$ increase for E30 vs E10. So an important question is, how much flow capacity margin do vehicles have, and could a limitation restrict ethanol blend fueling?

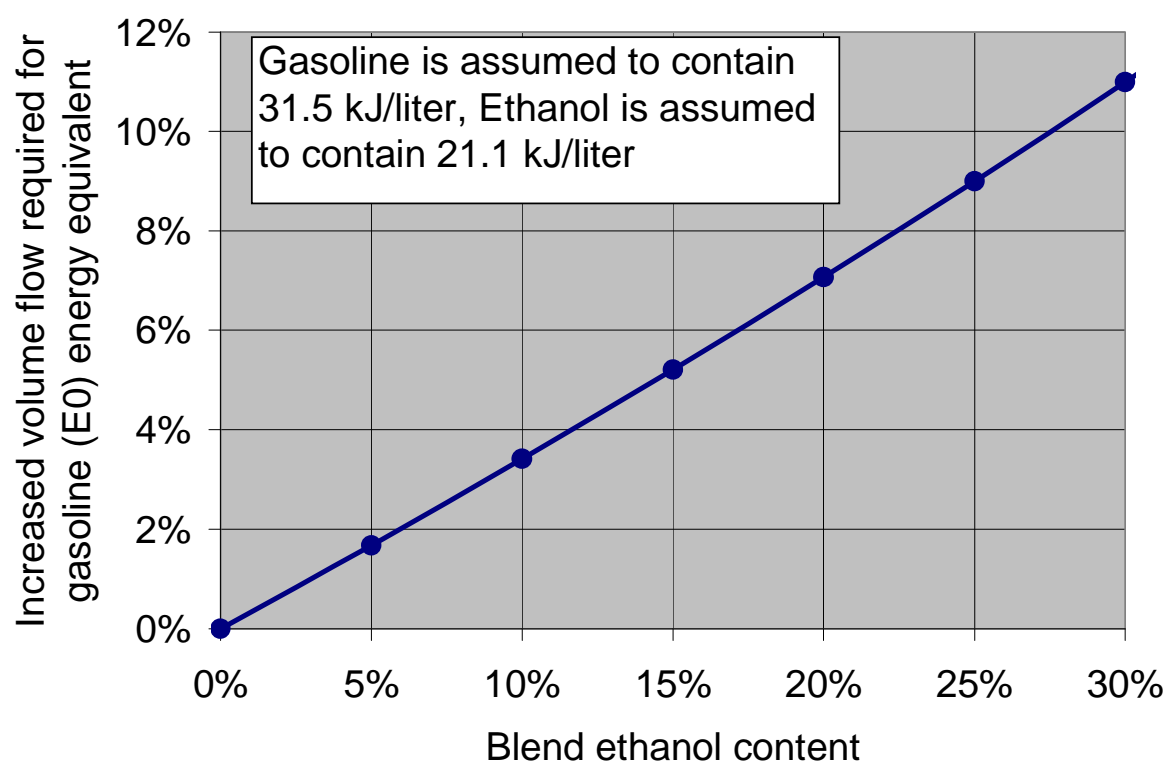

Fig. 4.2. Estimated volumetric fuel flow increase needed for ethanol blends relative to neat gasoline. 
With the exception of vintage/antique vehicles, all spark ignition (SI) engine vehicles on the road today are designed to accept E10 in normal service. It is likely that most vehicles were designed with enough fuel delivery margin for the fueling system to handle E10-E40 when new. Furthermore, the engine would run satisfactorily under many (but probably not all) circumstances even on E30-E40.

There are several studies that indicate this assertion is correct. ${ }^{7-9}$ However, there are uncertainties and risks related to this fueling capacity issue and the adaptive learning for achieving correct fuel flow. Generally, these uncertainties and risks increase with the level of ethanol in blends higher than E10. These issues are discussed in the sections that follow.

Vehicle aging could impair the fuel system's ability to provide some maximum fuel delivery rate. Aging can be accompanied by injector deposits and scale that lower fuel injection rates, and injector response may degrade with aging. The fuel pump may lose the ability to provide the full fuel rail pressure with age, which can also lower fuel flow rates through the injectors. The engine control system software likely has a set of fixed maximum fuel commands and will not violate this limit (sometimes called range of authority). Aging may lower the fueling rate when engines operate at or near these maximum fuel delivery points. The fuel control system is normally designed with enough authority to handle the aging process with gasoline and E10 fueling. Using a fuel that requires significantly more fuel flow carries the risk that some parts of the engine operating envelope demanding high fuel flow will not be "reached." This shortcoming could result in less than desired power, undesired lean combustion conditions, and higher exhaust and catalyst temperatures (this issue is discussed further in the next subsection).

\subsubsection{Adaptive Learning Capability}

Much of the SI vehicle fleet has some adaptive learning incorporated into the electronically controlled fueling system. All but vintage/antique vehicles use closed-loop control with a TWC system that can adjust to some changes in fuel properties and conditions. When operating in closedloop mode, the system will adjust the fueling commands until (near) stoichiometric operation is detected by one or more exhaust oxygen sensors. More precisely, the oxygen sensor gives feedback on how the system is dithering between slightly rich and slightly lean conditions. This feedback signal is used to make small changes in fueling. The control system strives to obtain some ideal oxygen sensor signal trace indicating excellent TWC system operation.

Closed-loop fuel control by adaptive learning. Modern (non-FFV) SI engine control systems adaptively learn (or adjust) fuel scaling factors during closed-loop operation. This learning allows near-optimum engine control despite variations in fuel properties and ambient conditions (altitude, temperature, humidity). The indicated engine speed, levels of air flow (air throttle position, indicated flow, and other variables), and fuel flow (fuel injector commands) are "known" to the control system when near-stoichiometric conditions are achieved, and the fuel scaling is "remembered" for future use. This learning and memory capability means that the vehicle has limited flex-fuel capability and is designed to handle normal variations in properties of gasoline, including E0 to E10 fuel, without difficulty. (Compensation for vehicle component aging is also accomplished by this same adaptive learning.) Vehicles from model year (MY) 1981 and beyond have some adaptive learning capabilities because they all use TWC. This capability has increased as vehicle control systems have become more sophisticated. Flex-fuel vehicles are designed to have an adequate range of authority to adjust fueling for E0 to E85.

Short-term and long-term adaptively learned factors (short-term fuel trim [STFT] and long-term fuel trim [LTFT]) may be estimated by the control system in some separate manner; some discussion of this subject is found in the 2002 literature review by Orbital. ${ }^{6}$ STFT adjusts to serve the immediate demands of the engine and vehicle operation and is in response to the last report from the oxygen sensor. STFT adjustment is what causes the oxygen sensor to cross to either the slightly rich or slightly lean side of stoichiometric. (The oxygen sensor and STFT react to each other.) The LTFT adjusts for fuel composition, ambient conditions (such as elevation), and aging. (LTFT is designed to 
keep the oxygen sensor at stoichiometric over the long-term average.) The control system will have separate sets of control maps for various segments (speed and load range or speed and manifold boost range) of the engine operating envelope. Each may have a separate scaling factor or multiplier that is based in part on the particular fuel. After a fuel change, the multipliers may need to be learned or reestimated for most or all of the different segments of the engine operating envelope as the engine "visits" those segments. That is, a newly learned fuel multiplier may or may not be shared with the separate control system segments.

Previous ethanol studies related to adaptive learning. A looming unknown is the extent and speed of learning capabilities for the various segments of the vehicle fleet, and how this issue would play out with ethanol blends higher than E10. A study ${ }^{7}$ performed with E10 and E30 indicated that 15 vehicles from model years 1985-1998 would operate on E30 in what seemed to be a satisfactory manner. Surprisingly, there were no noticeable driveability problems for any of the 15 vehicles roaddriven and dynamometer-tested. However, rigorous tests looking at driveability and wide open throttle (WOT) -type conditions were not reported. Emissions were reported to meet the federal standards. It was noted that the fuel change "learning" could be very slow for some vehicles, ${ }^{7}$ and engine operation and emissions certainly could be different during this learning period.

A second study by EPA ${ }^{8}$ tested six passenger cars with numerous fuels varying in composition from E0 to E40. Five vehicles were MY 1990 and one was MY 1992. It is stated that the engine operation became increasingly lean as ethanol concentrations increased, but no specific vehicles or enleanment quantities are offered (such as exhaust oxygen content measurements). It is also stated that this enleanment was observed before the vehicles reached their maximum fueling capability and that it was a characteristic of the TWC control system behavior with ethanol blends. It appears the enleanment was relatively mild but increased with greater ethanol content. When the points were reached where the control system no longer had "authority" to increase fueling to the level demanded, the enleanment effect became more severe. A re-analysis of $\mathrm{NO}_{\mathrm{x}}$ emissions data from the Guerrieri et al. ${ }^{8}$ study by Orbital $(2002)^{6}$ indicates at least some vehicles ran out of fueling authority for the E35 and $\mathrm{E} 40$ fuels tested. This conjecture is based on the $\mathrm{NO}_{\mathrm{x}}$ emissions upward trend with ethanol, suddenly increasing beyond E30. The general emission trends agreed with other studies- $\mathrm{HC}$ and $\mathrm{CO}$ decrease with ethanol content while $\mathrm{NO}_{\mathrm{x}}$ increases.

\subsubsection{Open-Loop Calibration Issues}

Most, but not all, engine operation utilizes the closed-loop feedback previously discussed. The special cases that are open-loop include, but are not limited to, (1) engine starting, (2) cold enrichment (warm-up phase), (3) full-load engine operation (called power enrichment or WOT), (4) throttle and manifold absolute pressure (MAP) enrichment, and (5) trailing throttle (decelerations with low or zero fuel demand). For trailing throttle, lean conditions or no fueling is commanded because combustion is not needed and emissions will not be an issue. Cold engine starting and power enrichment will be discussed further.

The issue of open-loop calibration for fueling vehicles with E20 was examined as part of a large and detailed Australian ethanol fuel study by Orbital Engine Co. ${ }^{10}$ The study included use of E20 in five representative Australian passenger vehicles, MY 2001 and 2002. All five vehicles adjusted quickly and accurately between E0 and E20 during closed-loop operation. Two were found to apply the E20 calibrations (or scaling factors) to high-load (WOT), open-loop conditions. The remaining three vehicles apparently did not change calibration for WOT and displayed the expected leaner operation (actually less rich) for high-load open-loop conditions with E20. Delivered fuel volumetric quantities at WOT were similar to those expected for E0 fueling, and the exhaust temperatures were higher with E20. Although these are not U.S. market vehicles, the fact that some vehicles will not apply learned scaling factors to WOT and perhaps other open-loop conditions is important to note. Certification in Australia uses the same test procedures as in the United States and for the era of vehicles tested, emissions regulations were higher compared with current U.S. standards. 
Wide open throttle. The high-load open-loop condition for engines, sometimes known as WOT, is a special case in which rather rich conditions are needed to protect the downstream TWC system from high temperatures. This condition is typified by the accelerator pedal being pushed near or to its limit for hard acceleration. Enrichment can reach a point where only about $70 \%(\lambda=0.7)$ of the oxygen needed for complete combustion is present. Exhaust can be hot, but the rich conditions keep temperatures below the point of rapidly degrading the emissions system or harming other components. The enrichment also allows hard acceleration to be strong and smooth and increases the peak power, which is maximized at slightly rich conditions. Obviously, WOT is an aggressive condition only occasionally needed in normal driving.

WOT lean operation. As discussed previously in the Australian (Orbital) study, ethanol blends will run relatively lean (less rich) at WOT conditions unless a new fueling calibration is applied. The fueling system controls will utilize protective rich operation at WOT (and similar very hot exhaust conditions) to avoid excessive TWC temperatures and to protect other components. If the system runs less rich, exhaust temperatures will be higher and rapid catalyst aging could be a concern. The cited study showed exhaust temperature to be about $25^{\circ} \mathrm{C}$ higher for E20 compared with E0 in the two of the vehicles that did not adjust fueling at WOT. A third vehicle showed about a $50^{\circ} \mathrm{C}$ temperature rise. Of the two vehicles that appeared to recalibrate for E20 at WOT, one showed a small exhaust temperature increase and the other still gave about a $30^{\circ} \mathrm{C}$ increase for the E20 case. Although these results are not particularly compelling, the concern regarding excessive exhaust temperature was a conclusion of the Orbital study and is a potential concern for the U.S. fleet.

WOT rich misfire. A danger to be avoided during WOT operation is rich misfire. At $\lambda=0.7$, good ignition is generally ensured. If too much enrichment occurs, misfires will send raw fuel and oxygen to the already hot TWC. Expansion energy is not removed with misfire, and burning will take place in the TWC. Very hot catalyst conditions may result, leading to degradation and failure. The potential for increased risk of rich misfire conditions may be a reason why the adaptively learned E20 calibrations cited earlier were not transferred to WOT conditions for three of the five vehicles. If somehow an erroneous value were applied to WOT resulting in overly rich conditions, the consequences could be severe.

If the catalyst temperature were monitored and were part of the fueling control system, the added information could make it "safer" to apply learned fueling calibration to WOT conditions. It is not known if any portion of the fleet uses such a measurement as part of the fuel control system. Another possibility is to use a wide-range oxygen sensor to monitor open-loop conditions and avoid overfueling and under-fueling conditions. Again, it is unknown if any vehicles are equipped with such a system.

Cold start. Cold starting and warm-up enrichment are important open-loop engine operating conditions. Both circumstances have a dependence on the lightest fuel components vaporizing to make a spark-ignitable combustible mixture. For an ethanol blend above 10 vol $\%$ to supply the same cold vapor-mix as gasoline, either more fuel must be delivered or the blend fuel must be purposefully made to have proportionally more cold-vaporizing components. If the control system cannot or has not applied a learned multiplier to the cold-start fuel command, or the fuel is not made with proportionally more cold-start volatile components, there may be increased cold-starting difficulties.

\subsubsection{OBDII Issues}

The OBDII systems are designed to detect various failures, particularly those that will impact the vehicle emissions. The term "failure" used here would most often mean operation excessively far from defined specifications, and this obviously includes situations in which something ceases to function (such as an open circuit). Because of the wide variety of vehicles, manufacturers, and engine families in the vehicle fleet, it is reasonable to assume that there is significant variation in how the OBDII systems would respond to fuels with greater than $10 \mathrm{vol} \%$ ethanol. The diagnostics of OBDII systems that could be affected by the ethanol content of the fuel include fuel trim specifications, 
misfire, canister purge, TWC efficiency, oxygen sensors (stoichiometry), and fuel system leak check. Other diagnostics may also be affected.

An obvious example of an OBDII monitored parameter that will change for fuel blends with greater than $10 \mathrm{vol} \%$ ethanol is fuel trim value. Because fuel trim values will shift to give increased volumetric fueling commands, the OBDII safety margins for detecting a fuel system failure will be shifted. The shift of safety margins will make the OBDII more apt to indicate a fuel system lean failure, but less likely to indicate a fuel system rich failure. A number of other failure threshold values (or combinations of values) monitored by the OBDII system may depend on the fuel trim values, and these will also be shifted. In any case, as ethanol content increases beyond 10 vol \% for blend fuels, the OBDII system would be incrementally more likely to falsely indicate some types of failure and also incrementally more likely not to indicate when other failure thresholds were reached. The significance of this issue for a fuel such as E15 may be very small, but it has not been verified in any way.

\subsection{STARTING AND IDLING}

Orbital Engine Company evaluated the impact of a 20 vol \% ethanol blend on the cold-start, hotstart, driveability, and WOT performance of five MY 2001/2002 vehicles listed in Table 3.2. All of these vehicles have electronic fuel injection and TWC emission control systems. ${ }^{9,10}$ While these vehicles were chosen to be representative of the fleet in Australia, they have similar fuel and emission control systems as their U.S. counterparts, perhaps with different calibrations. Orbital evaluated changes through the use of scored ratings (based on defined rating scales) by trained operators, similar to the way auto companies evaluate the driveability of their vehicles. Distillation data and RVP for the E20 fuel indicate it was purposefully match blended to mitigate the increase in fuel volatility due to adding ethanol.

Rating scales were developed from 1 to 10,1 being a "very bad" rating and 10 being an "excellent" rating. "Very bad" describes uncontrollable or unpredictable operation. No defects and excellent driveability earn the excellent rating. A rating of 7 (satisfactory) is considered to be the typical production target. The description for satisfactory is one or more slight defects that would be barely noticeable to the average driver. For the starting and idling portion of the testing, a rating scale of 1 to 7 was used, with 1 scoring "no start" for starting or "engine stall" for idling; a 7 score represented "normal" for both starting and idling. The ratings were capped at 7 since there was no means for distinguishing between a "satisfactory" start and an "excellent" start.

Orbital evaluated the starting and idling performance of the five vehicles under ambient $\left(25^{\circ} \mathrm{C}\right)$, hot $\left(40^{\circ} \mathrm{C}\right)$, and cold $\left(-10^{\circ} \mathrm{C}\right)$ temperatures. At the ambient temperature, operators noted a few small changes but judged them to be within the range of typical operation and not discernable to the typical driver.

To test hot temperature starting and idling, Orbital evaluated time to start after an initial start, after 20 minutes of idling, and after a 30-minute hot-soak. Figure 4.3 shows the results. Only one vehicle showed a significant increase in starting time. Orbital judged three vehicles to have idle quality that was slightly reduced and of a magnitude such that the typical driver would notice a difference but would not be concerned that something was wrong.

To evaluate cold starting, Orbital soaked the vehicles for 8 hours at $-10^{\circ} \mathrm{C}$ before testing them. They found significant problems with the Ford and Subaru vehicles (Fig. 4.4). The other vehicles were all judged to have acceptable starting using the 20 vol \% ethanol fuel. 


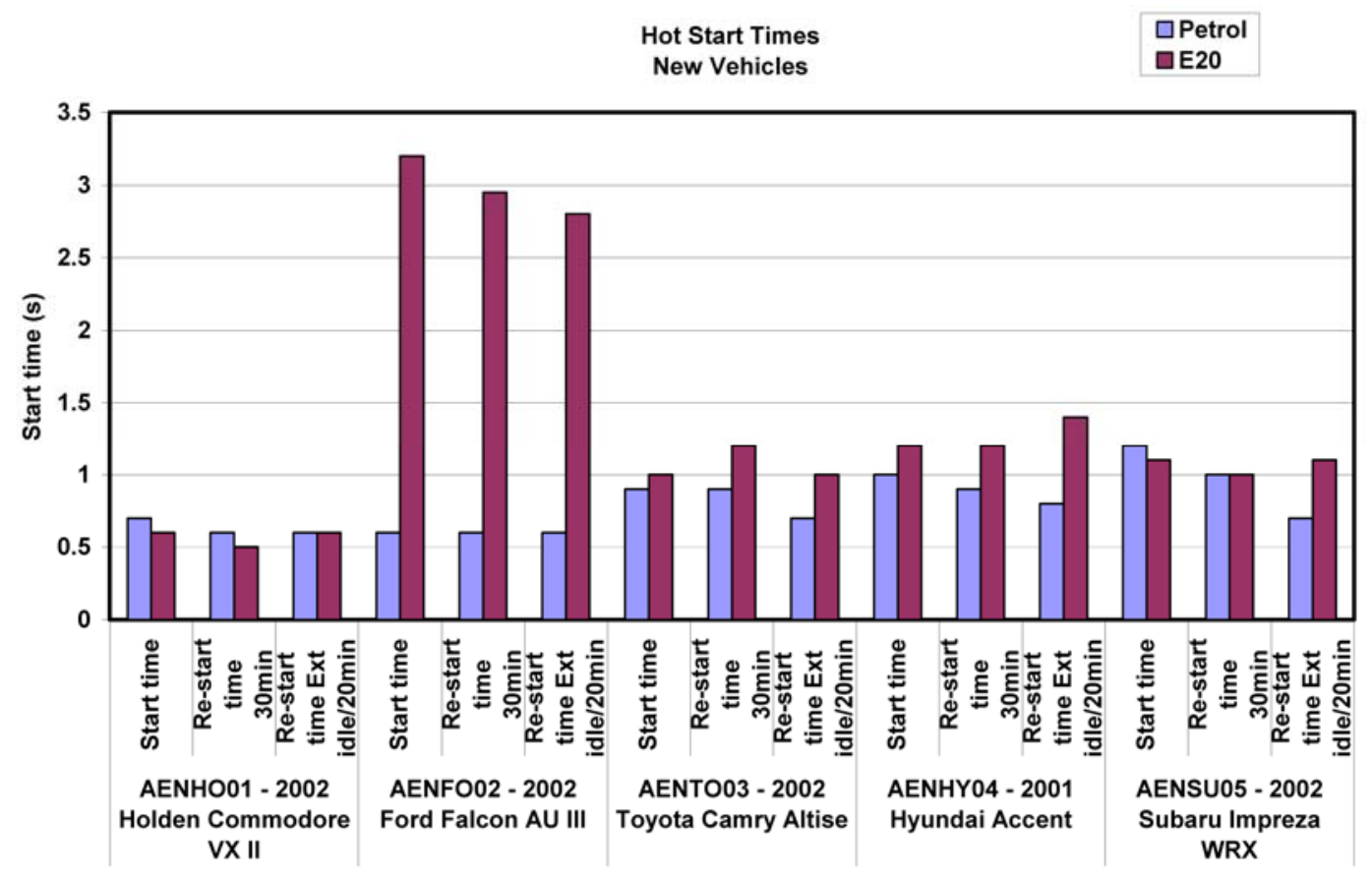

Fig. 4.3. Hot-start test results for five 2001 model vehicles using 20 vol \% ethanol. Source: Ref. 9, Orbital March 2003.

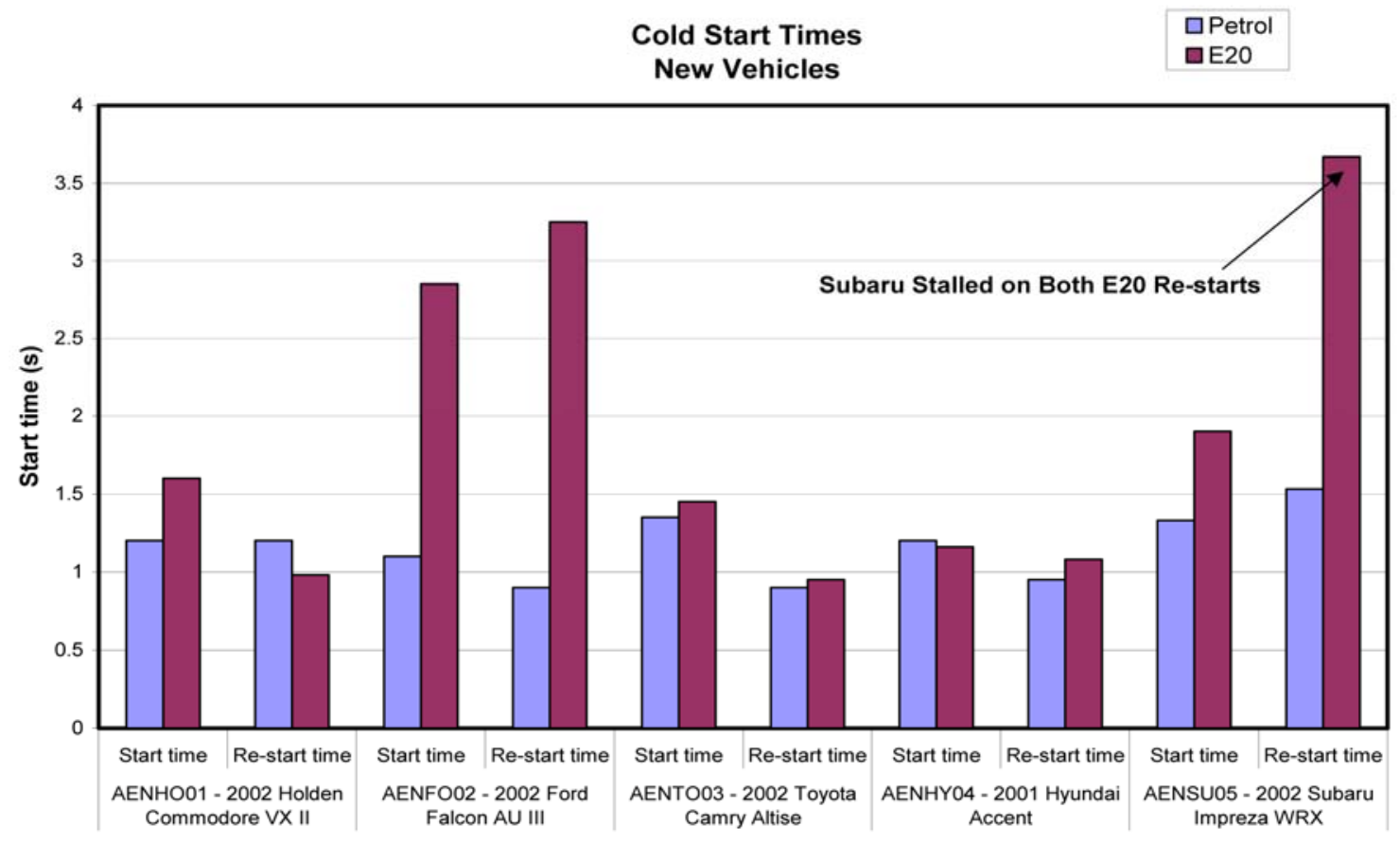

Fig. 4.4. Cold-start test results for five 2001 model vehicles using 20 vol \% ethanol. Source: Ref. 9, Orbital 2003. 
The model of Subaru Impreza used in the study is not recommended for ethanol blends ${ }^{4}$ and is required to use premium (high-octane) grade fuel. This may or may not have bearing on the cold-start problems encountered. Note that the majority of Australian vehicles are E10 compatible, but some are built to a European specification that includes only E5 compatibility. Furthermore, some Australian vehicles models come with recommendations not to use E5 or any alcohol fuels. ${ }^{12}$

Minnesota State University ${ }^{7}$ conducted one-year fleet test using a 30 vol \% ethanol blend in 15 vehicles ranging in MY from 1985 to 1997. It evaluated starting and driveability using driver reports. Over the duration of the test, there were no reported cold-start complaints or occurrences of long starting times.

\subsection{DRIVEABILITY}

Orbital also performed driveability testing at the ambient $\left(25^{\circ} \mathrm{C}\right)$, hot $\left(40^{\circ} \mathrm{C}\right)$, and cold $\left(-10^{\circ} \mathrm{C}\right)$ temperatures used for starting tests. The study found some slight differences between neat gasoline and a 20 vol \% ethanol blend but judged these differences to be within the normal range of operation and unlikely to be noticed by typical drivers.

Minnesota State University reported that there were no driveability complaints during its one-year test of a $30 \mathrm{vol} \%$ ethanol blend. ${ }^{7}$

The American Coalition for Ethanol recently conducted brief, 100-mile tests of three 2005 model vehicles using gasoline, E10, E20, and E30 (Ref. 13). It was not explained how the fuels were prepared, and it is assumed these were splash blends. The study reported no driveability problems in any of the vehicles using any of the fuels.

\subsection{ACCELERATION}

Orbital measured the acceleration of its five vehicles in terms of passing performance (40-60 mph) and quarter-mile elapsed time. The study found no significant difference among the vehicles in acceleration times. The Minnesota State University and American Coalition for Ethanol studies did not conduct comparative acceleration tests.

\subsection{SUMMARY AND CONCLUSIONS}

Based on these studies, it is apparent that a wide range of vehicles will operate satisfactorily on blends of ethanol of up to $30 \mathrm{vol} \%$. The Orbital work using E20 shows that a few vehicles will experience starting problems (e.g., long starting times and stalls after start) that drivers will notice and that may be severe enough to prompt them to take their vehicles in for service. However, none of the problems caused the vehicles to fail to operate. Although Orbital was able to measure some changes in driveability when using E20, these changes were judged to be within the typical range of vehicle operation and would likely not be noticed by the typical driver. Orbital also measured no significant difference among its vehicles in acceleration times despite the fact that the vehicles apparently did not fully compensate for the enleanment caused by ethanol addition. The untrained driver survey testing done by Minnesota State University resulted in no reports of any starting, driveability, or acceleration problems. The American Ethanol Coalition monitoring of the onboard vehicle computers showed that no (OBDII) error codes associated with driveability were set.

The U.S. vehicle fleet contains a very wide variety of vehicles powered by numerous engine families. Vehicle operation and performance response to ethanol blend fuels will no doubt vary not only by engine family but also within the engine family (the same engine may power vehicles of different weights, etc.). It seems unwise to attempt any predictions concerning these operation and performance responses without more data. 


\subsection{REFERENCES}

1. Robert Bosch, Automotive Handbook, 3rd ed., ISBN 1-56091-372-X, distributed by SAE, 1993.

2. R. L. Bechtold, Alternative Fuels Guidebook, Society of Automotive Engineers, Warrendale, PA, 1997.

3. L. E. Dodge et al., "Development of an Ethanol-Fueled Ultra-Low Emissions Vehicle," SAE Paper 981358, Society of Automotive Engineers, 1998.

4. Frank Cox, "The Physical Properties of Gasoline/Alcohol Automotive Fuels," in Proceedings of the Alcohol Fuels Technology Third International Symposium, May 28-31, 1979, Vol. II, U.S. Department of Energy, 1979.

5. "Alcohols and Ethers-A Technical Assessment of Their Application as Fuels and Fuel Components," API Publication 4261, 2nd ed., American Petroleum Institute, 1220 L Street, Northwest, Washington, DC 20005, July 1988.

6. Orbital Engine Company, A Literature Review Based Assessment on the Impacts of a 20\% Ethanol Gasoline Fuel Blend on the Australian Vehicle Fleet, report to Environment Australia, November 2002.

7. B. Jones et al., Use of Mid-Range Ethanol/Gasoline Blends in Unmodified Passenger Cars and Light Duty Trucks, report MnCAR/MSU 106, Minnesota Center for Automotive Research, Minnesota State University, 1999.

8. D. A. Guerrieri, P. J. Caffrey, V. Rao, Investigation into the Vehicle Exhaust Emissions of High Percentage Ethanol Blends, SAE Paper 950777, Society of Automotive Engineers, Warrendale, PA, 1995.

9. Orbital Engine Company, Market Barriers to the Uptake of Biofuels Study-A Testing Based Assessment to Determine Impacts of a 20\% Ethanol Gasoline Fuel Blend on the Australian Passenger Vehicle Fleet, report to Environment Australia, March 2003.

10. Orbital Engine Company, Market Barriers to the Uptake of Biofuels Study, Testing Gasoline Containing 20\% Ethanol (E20), Phase 2B Final Report to the Department of the Environment and Heritage, Australia, May 2004.

11. C. Hammel-Smith et al., Issues Associated with the Use of Higher Ethanol Blends, E17-E24, National Renewable Energy Laboratory, NREL/TP-510-32206, 2002.

12. Capability of Vehicles to Satisfactorily Operate on Ethanol Blend Petrol, Australia Federal Chamber of Automotive Industries Web site, http://www.fcai.com.au.

13. Fuel Economy Study_Comparing Performance and Cost of Various Ethanol Blends and Standard Unleaded Gasoline, American Coalition for Ethanol, 2500 S Minnesota Avenue, Suite 200, Sioux Falls, SD 57105, www.ethanol.org, 2005. 



\section{EMISSIONS IMPACT}

\subsection{EXHAUST EMISSIONS}

The exhaust emissions from SI engine vehicles are highly dependent on the mass ratio of air and fuel entering the engine cylinders. When ethanol is blended with gasoline, the air/fuel mass ratio is changed because ethanol contains oxygen and has a lower heating value per volume than gasoline. Without any adaptation, these changes cause the effective air/fuel ratio under which the engine operates to be leaner, with consequent changes in exhaust emissions. Even though current vehicles employ oxygen sensors to maintain the stoichiometric ratio between air and fuel during operation, ethanol blends cause a leaning effect (as explained in Sect. 6). While much work has been done measuring the emissions impact of $10 \mathrm{vol} \%$ ethanol blends, much less work has been done using $20 \mathrm{vol} \%$ and higher ethanol blends. In addition, the early work measuring emissions from $10 \mathrm{vol} \%$ blends was done using carbureted vehicles, which are no longer representative of the vehicles in use.

\subsubsection{Criteria Emissions}

The EPA tested six in-use passenger cars chosen to have fuel and emission systems representative of popular ones in use in 1995, using blends of ethanol in gasoline of up to $40 \mathrm{vol} \%$. $^{1}$ The vehicles were 1990 and 1992 models, all equipped with fuel injection and TWC feedback emission control systems. The gasoline used was representative of a summertime gasoline, and the ethanol was splashblended (i.e., the hydrocarbon portion was not tailored for ethanol blending). All the emissions tests were conducted on a chassis dynamometer using the Federal Test Procedure. The data presented are the linear regression lines developed by EPA from its data.

Figure 5.1 shows the impact of ethanol addition on the total hydrocarbon (THC) emissions of the vehicles tested by EPA. As can be seen, all the vehicles had lower THC emissions when using ethanol blends. On average, these vehicles had $16.1 \%$ lower THC emissions when using 20 vol \%\% ethanol

\section{THC Emissions}

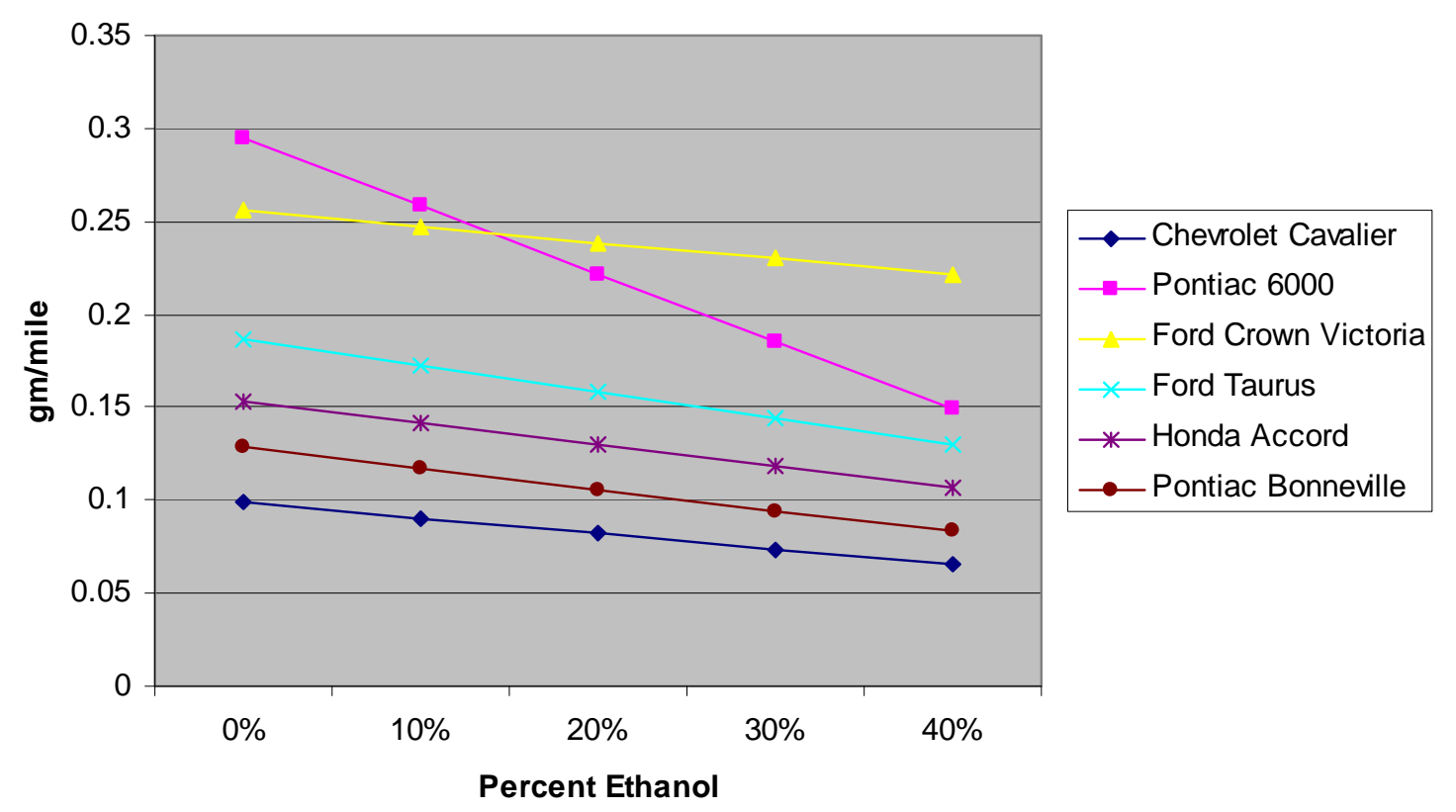

Fig. 5.1. Effect of ethanol addition on THC emissions. Source: Ref. 1. 
compared with using neat gasoline. Five of the six vehicles showed very similar changes in THC emissions with ethanol addition, with one showing much larger decreases.

Figure 5.2 shows the impact of ethanol addition on $\mathrm{CO}$ emissions of the vehicles tested by EPA. As with the results for THCs, all the vehicles had lower $\mathrm{CO}$ emissions when using ethanol blends. On average, these vehicles had $22.3 \%$ lower CO emissions when using 20 vol \% ethanol compared with using neat gasoline.

\section{CO Emissions}

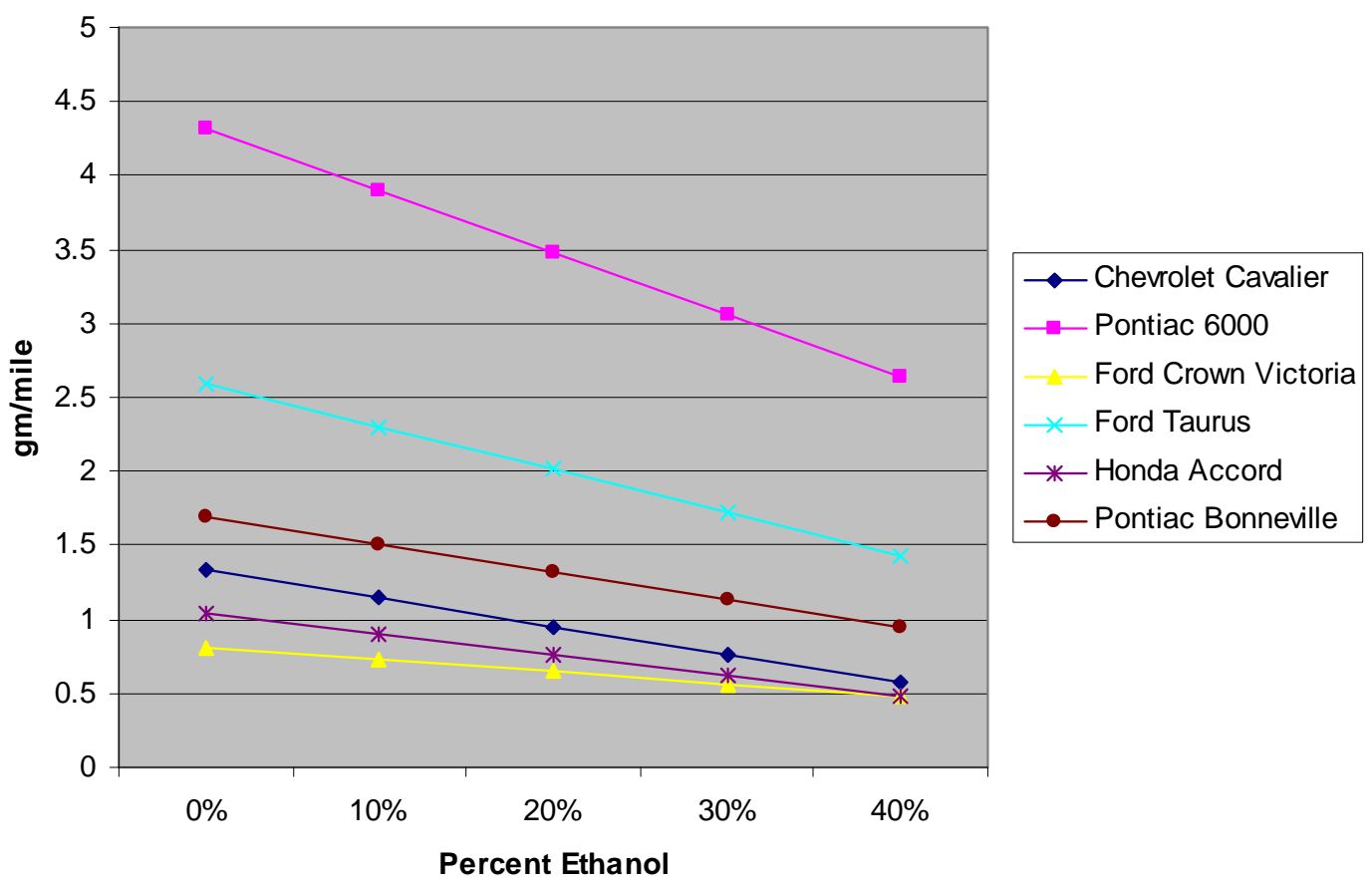

Fig. 5.2. Effect of ethanol addition on $\mathrm{CO}$ emissions. Source: Ref. 1.

Figure 5.3 shows the impact of ethanol addition on $\mathrm{NO}_{\mathrm{x}}$ emissions of the vehicles tested by EPA. All the vehicles had higher $\mathrm{NO}_{\mathrm{x}}$ emissions when using ethanol blends, with the two vehicles most affected showing a doubling at $20 \mathrm{vol} \%$ ethanol. On average, these vehicles had $31.9 \%$ higher $\mathrm{NO}_{\mathrm{x}}$ emissions when using $20 \mathrm{vol} \%$ ethanol compared with using neat gasoline.

These results are consistent with those from other tests and indicate a leaning of the air/fuel ratio, even though they all had fuel injection with TWCs and closed-loop control systems.

The most recent comprehensive test of late-model vehicles using 20 vol \% ethanol was conducted by Orbital Engine Company for Environment Australia. ${ }^{2}$ Orbital tested five MY 2001 vehicles, all of which had electronic fuel injection and TWC emission control systems (see Table 3.2). Five pairs of vehicles were tested, five using E20 and five using neat gasoline. Although these vehicles were chosen to be representative of the fleet in Australia, they have similar fuel and emission control systems to their U.S. counterparts but likely have different calibrations or catalyst formulations. The emissions of these vehicles were tested using the U.S. Federal Test Procedure, the same procedure EPA used in its test program. Orbital found that on average, THC emissions decreased by $30 \%$, CO emissions decreased by $29 \%$, and $\mathrm{NO}_{\mathrm{x}}$ increased by $48 \%$ when $20 \mathrm{vol} \%$ ethanol was used. These results are similar in direction to but larger than what EPA found (i.e., 16\% decrease in THC, $22 \%$ decrease in $\mathrm{CO}$, and $32 \%$ increase in $\mathrm{NO}_{\mathrm{x}}$ ). One difference between these two groups of vehicles is that the Orbital vehicles were purchased new and were operated 4,000 miles before emissions testing was conducted, whereas the vehicles tested by EPA were in-use vehicles (their individual mileage accumulations were not listed). 


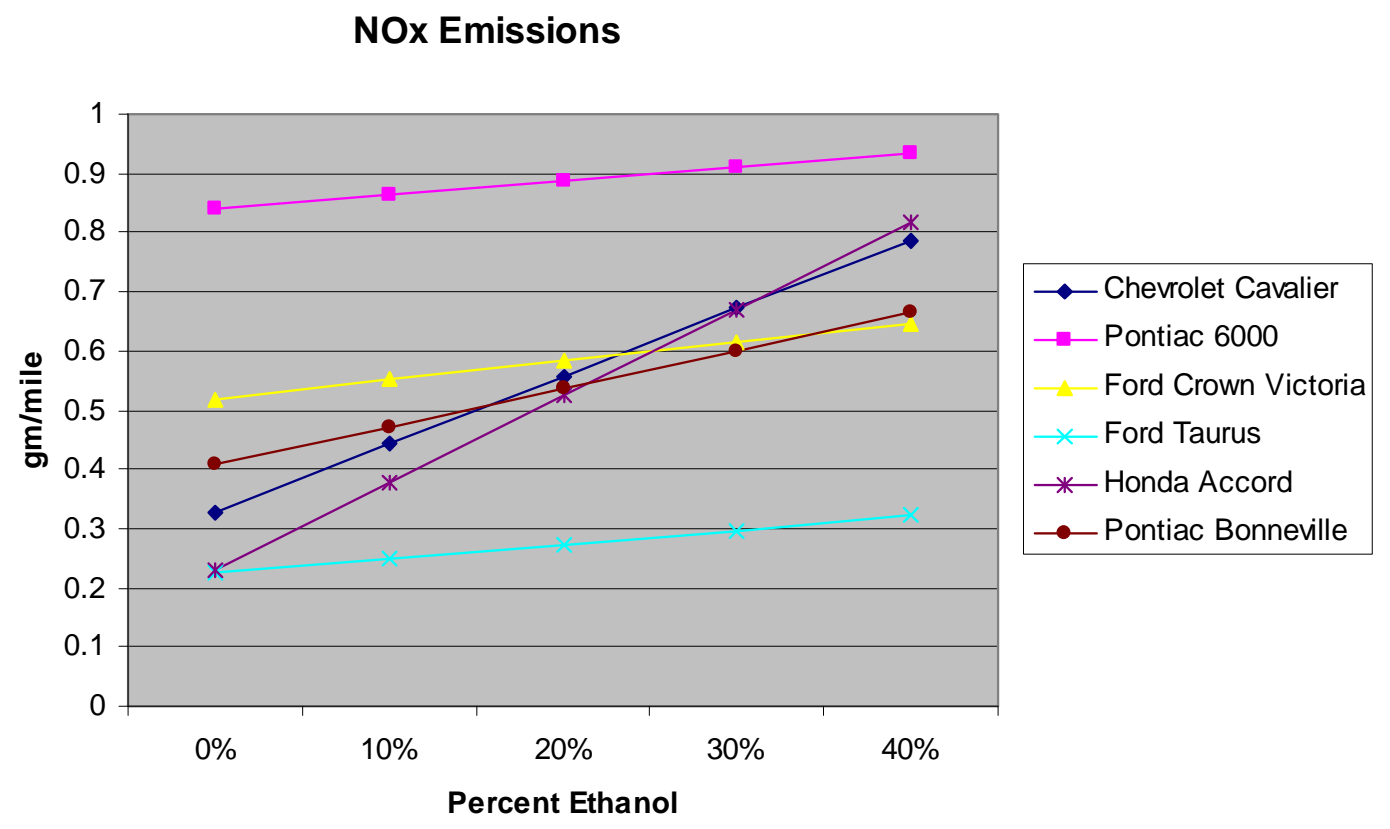

Fig. 5.3. Effect of ethanol addition on $\mathbf{N O}_{\mathbf{x}}$ emissions. Source: Ref. 1.

Both of these test programs captured the emissions changes that occur initially from using ethanol blends. These changes in emissions are indicative of the inability of the fuel systems to compensate completely under all circumstances for the lower heating value of ethanol. One potential long-term emissions impact associated with the inability of fuel systems to fully compensate is more rapid deterioration of the catalyst. Orbital measured catalyst temperatures that were higher in every vehicle during WOT using $20 \mathrm{vol} \%$ ethanol compared with neat gasoline because of the inability of the fuel system to maintain the desired stoichiometry. Elevated catalyst temperatures during WOT cause more rapid catalyst deterioration and increases in all emissions as the catalyst degrades (Norm Brinkman, General Motors, personal communication to Rich Bechtold, Alliance Technical Services, Oak Ridge National Laboratory, April 24, 2007). This is in fact what Orbital found after driving its vehicles for $80,000 \mathrm{~km}(50,000$ miles $)$ on a mileage accumulation dynamometer and retesting emissions. ${ }^{3}$

Figure 5.4 shows THC emissions for the vehicles Orbital tested on gasoline at 4,000 and 50,000 miles and on E20 at 50,000 miles. Only two of the five vehicles show decreased THC emissions at 50,000 miles compared with testing at 4,000 miles, at which point all the vehicles showed decreased THCs using E20. Figure 5.5 shows similar data for $\mathrm{CO}$ emissions. In Figure 5.5, two out of five vehicles show $\mathrm{CO}$ emission decreases at 50,000 miles vs four out of five at 4,000 miles. For $\mathrm{NO}_{\mathrm{x}}$ (Fig. 5.6), four out of five vehicles show an increase at 50,000 miles using E20, and four out of five also show an increase at 4,000 mile testing-except that a different vehicle showed a $\mathrm{NO}_{\mathrm{x}}$ decrease at 4,000 miles vesus 50,000 miles. The $\mathrm{NO}_{\mathrm{x}}$ emission results highlight the severe emissions problems of the Hyundai vehicle. Orbital investigated and found that the catalyst had a large decrease in conversion efficiency, with higher catalyst operating temperatures being the most likely reason. 


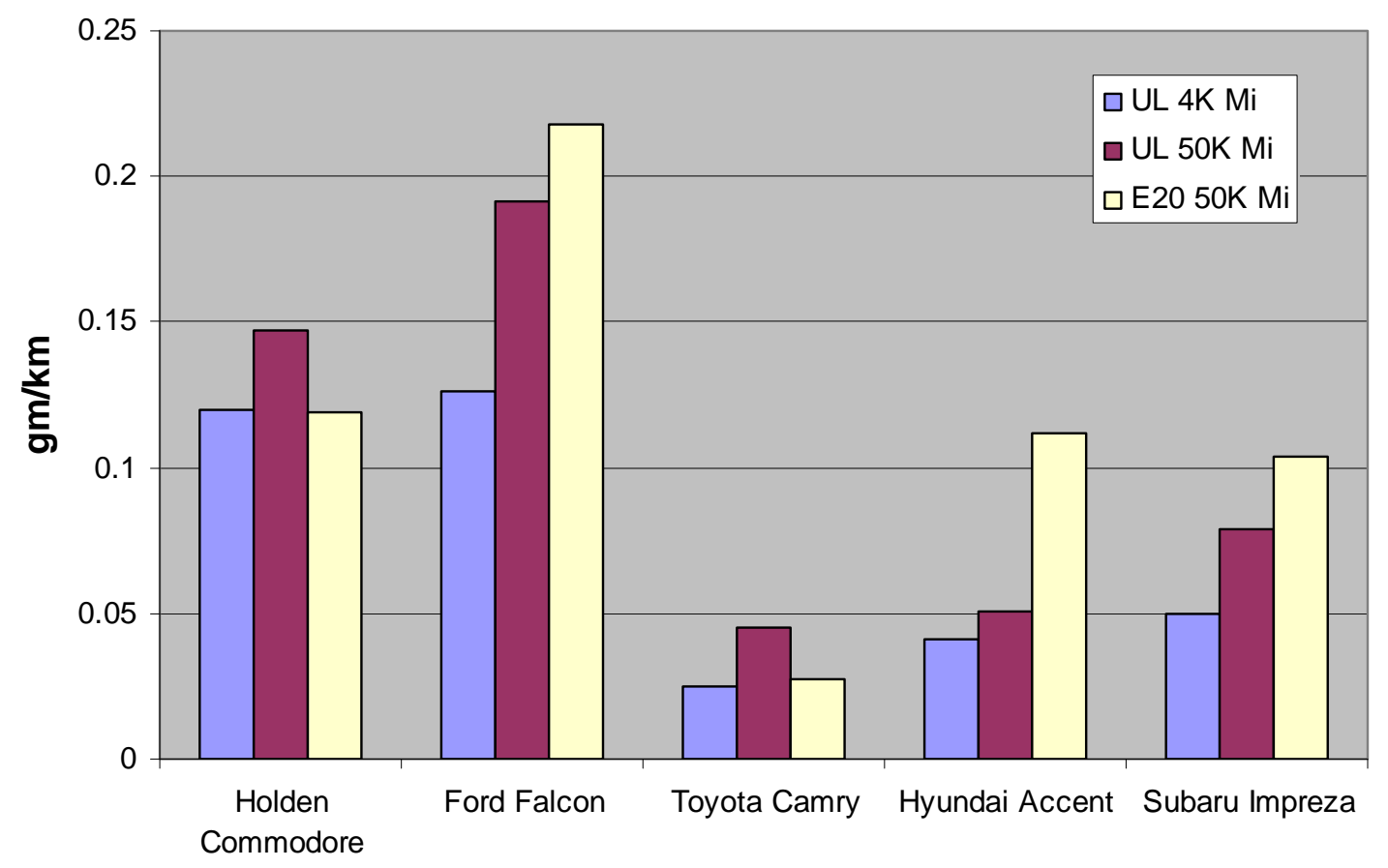

(Note: UL represents unleaded gasoline.)

Fig. 5.4. Change in THC emissions after 50,000 miles operation on E20. Source: Ref. 3.

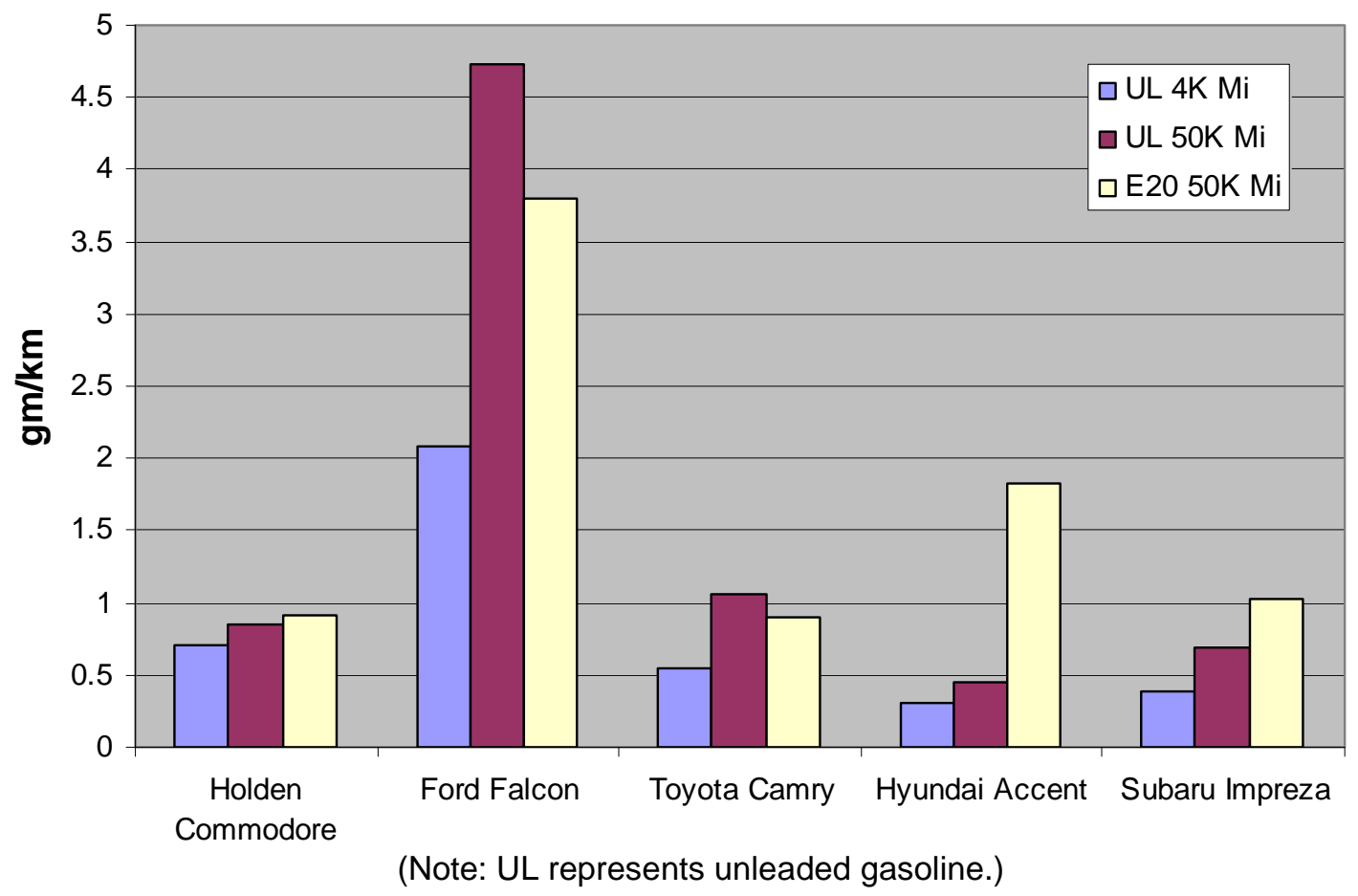

Fig. 5.5. Change in CO emissions after 50,000 miles operation on E20. Source: Ref. 3. 


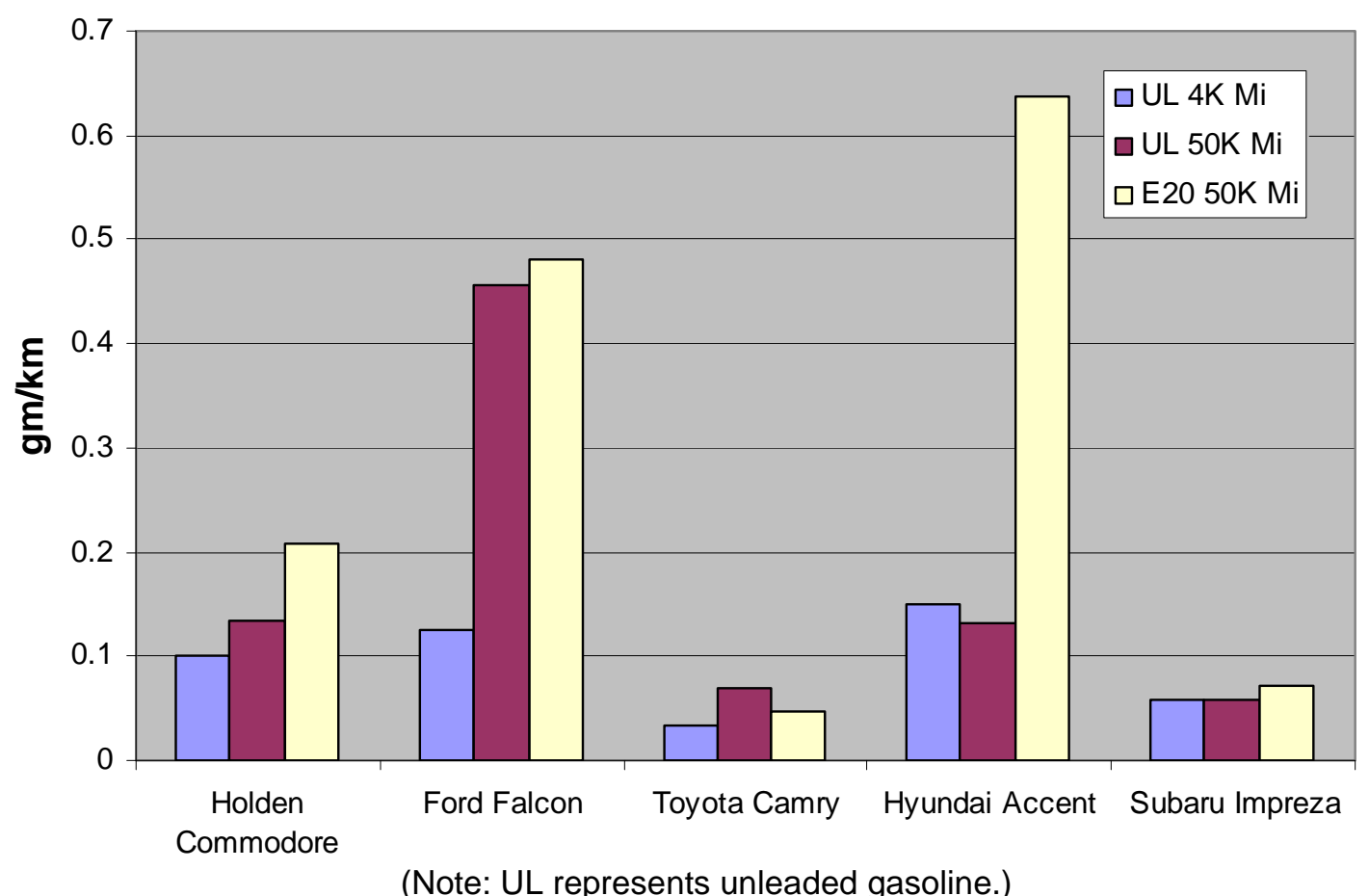

Fig. 5.6. Change in $\mathrm{NO}_{\mathrm{x}}$ emissions after 50,000 miles operation on E20. Source: Ref. 3 .

Figure 5.7 shows the average emissions increases of the five vehicles Orbital tested after 50,000 miles. These data suggest that all the vehicles experienced greater emissions deterioration using E20 than using gasoline. The Hyundai vehicle Orbital tested had a low power-to-weight ratio and therefore operated at high engine loads for a greater percentage of the time, which accelerated its catalyst deterioration because of higher exhaust temperatures. The effect on the other vehicles is similar, albeit less severe.

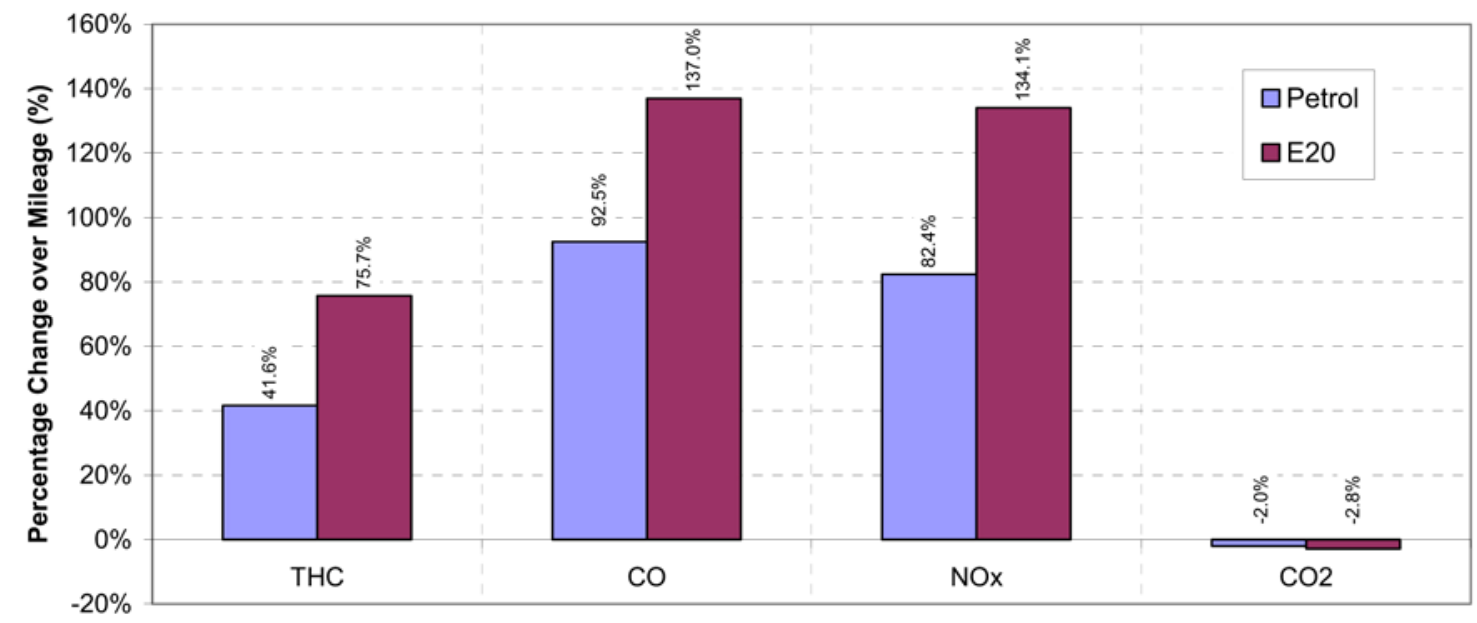

Fig. 5.7. Average change in emissions after 50,000 miles for operation on gasoline and E20. Source: Ref. 3. 


\subsection{2 $\mathrm{CO}_{2}$ Emissions}

Both EPA and Orbital found that $\mathrm{CO}_{2}$ emissions were reduced by $1 \%$ when using 20 vol \% ethanol blends (tailpipe emissions, not well-to-wheels). This result is twice as large a reduction as would be predicted by fuel chemistry alone. Given that all the vehicles tested showed signs of running leaner than designed when using $20 \mathrm{vol} \%$ ethanol, the remainder of the difference is no doubt due to leaner operation.

\subsubsection{Toxic Gas Emissions}

EPA tested for formaldehyde and acetaldehyde emissions from the vehicles in its test program, and Orbital tested for those emissions and for hydrocarbon toxics. Both EPA and Orbital found that formaldehyde emissions did not significantly change, but emissions of acetaldehyde increased significantly - all during cold-start operation. After the catalysts became active, acetaldehyde emissions were not increased relative to operation using neat gasoline. In the EPA testing, acetaldehyde emissions increased by $132 \%$ on average for the six vehicles tested (see Fig. 5.8) using the $20 \mathrm{vol} \%$ ethanol blend. Orbital did not calculate a percentage increase because some of its baseline values for acetaldehyde were so low as to be below measurement levels for its instruments, but clearly acetaldehyde emissions increased significantly in some of the vehicles (see Fig. 5.9). Orbital found that the $\mathrm{HC}$ toxics of benzene, hexane, and toluene decreased by similar amounts to the decrease in THC emissions (see Table 5.1). However, emissions of 1,3-butadiene and xylene, although very small, appeared to have increased slightly.

Testing conducted by EPA on a 10 vol \% ethanol blend in five MY 1983 through 1990 vehicles found quite similar results. ${ }^{4}$ Significant decreases in benzene and toluene were found in those vehicles in which THCs decreased when using the $10 \mathrm{vol} \%$ ethanol fuel, despite the higher aromatic content of the base gasoline, match blended to have an octane rating equal to the $10 \mathrm{vol} \%$ ethanol blend.

\section{Acetaldehyde Emissions}

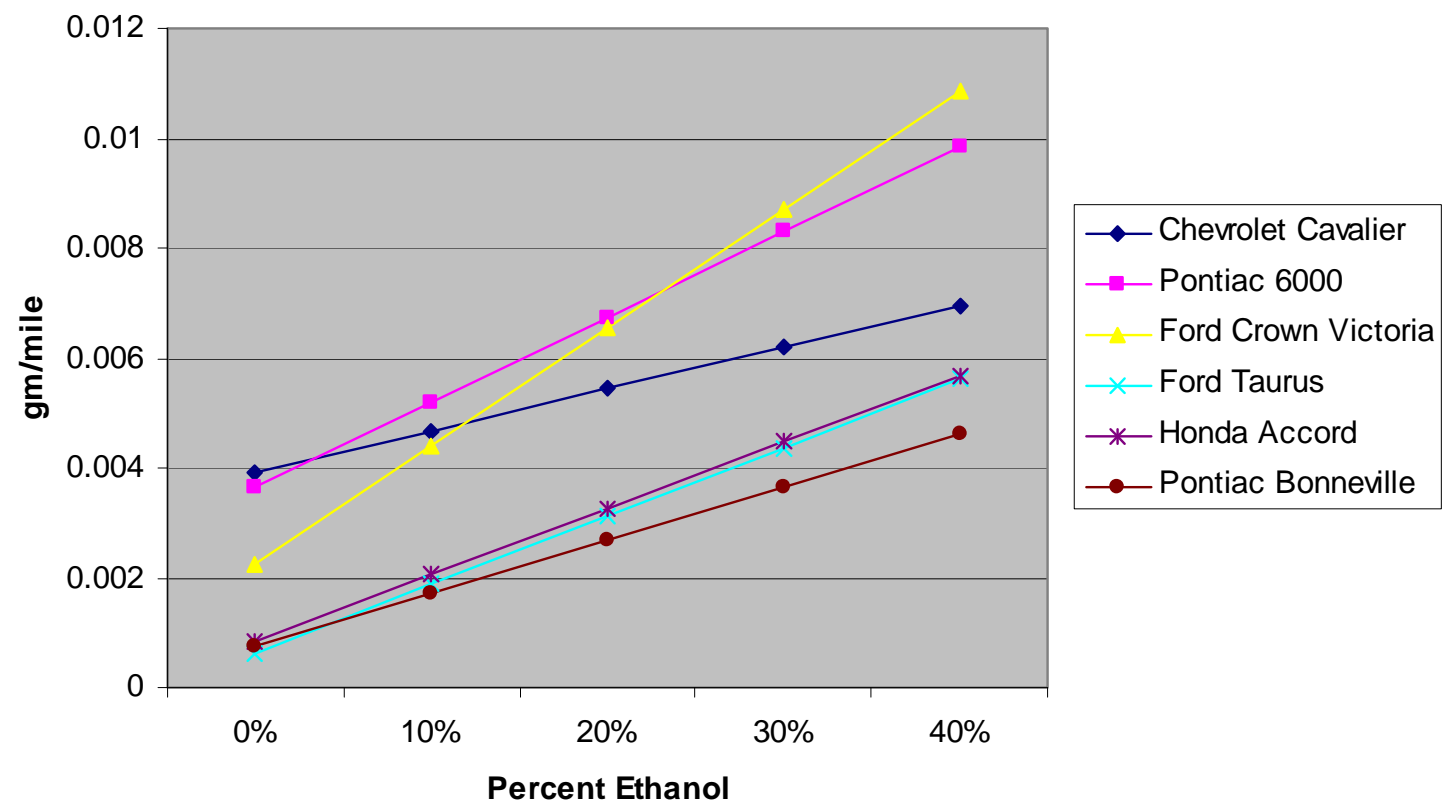

Fig. 5.8. Effect of ethanol addition on acetaldehyde emissions. Source: Ref. 1. 


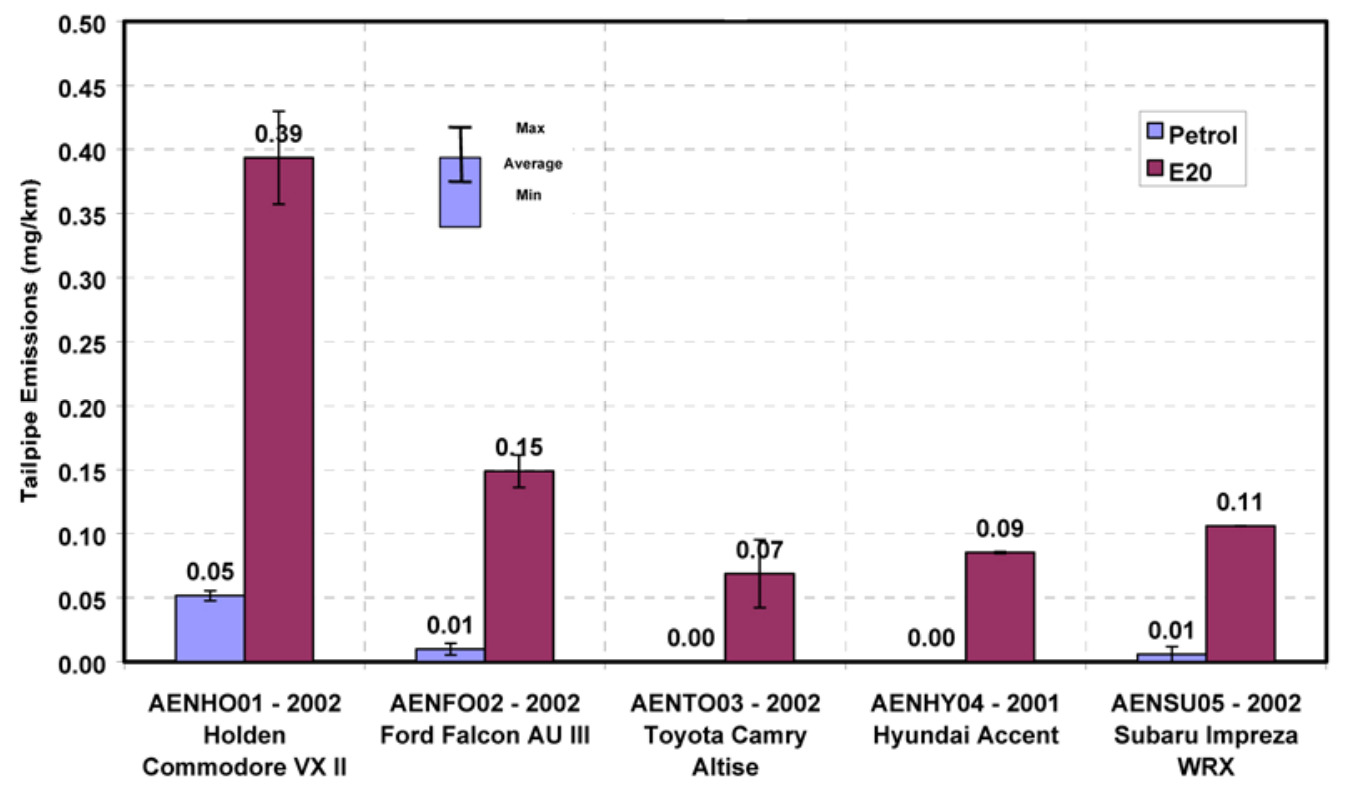

Fig. 5.9. Effect of ethanol addition on acetaldehyde emissions. Source: Ref. 2.

Table 5.1. Changes in hydrocarbon toxics when using 20 vol \% ethanol (Source: Ref. 2)

\begin{tabular}{lc}
\hline \multicolumn{1}{c}{ Toxic } & $\begin{array}{c}\text { Average \% change } \\
\text { from gasoline to E20 }\end{array}$ \\
\hline 1,3-butadiene & $+11 \%$ \\
Benzene & $-46 \%$ \\
Hexane & $-44 \%$ \\
Toluene & $-28 \%$ \\
Xylene & $+4 \%$ \\
\hline
\end{tabular}

EPA found no significant change in formaldehyde emissions but did cite statistically significant increases in acetaldehyde emissions in four of the five vehicles it tested.

\subsection{EVAPORATIVE EMISSIONS}

There are three sources of evaporative emissions from vehicles: leaks of vapor and liquid, vapor release from the evaporative canister, and permeation of fuel through nonmetallic fuel system lines and components. The chemical properties of ethanol can affect vehicle evaporative emissions even if RVP is controlled to within limits. The following section discusses these potential impacts for evaporative emissions other than leaks.

\subsubsection{Description of Evaporative System and Operation}

The evaporative fuel system and charcoal canister purge (see Fig. 5.10) are designed to prevent evaporated fuel from escaping to the atmosphere. The powertrain control module (PCM) monitors fuel tank pressure through a pressure sensor. Pressure in the fuel tank will increase when the fuel 


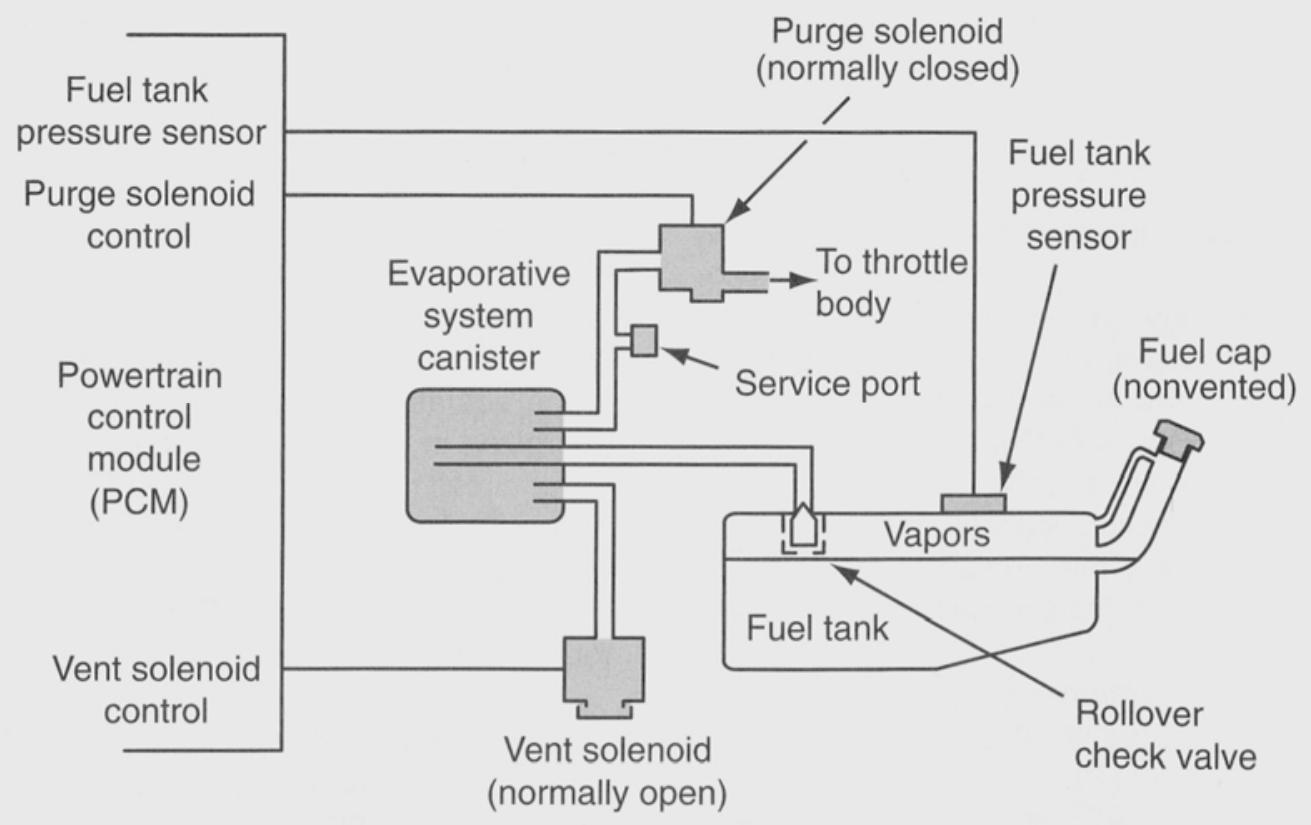

Fig. 5.10. Schematic diagram of a typical evaporative emission system. Source: Steve V. Hatch, Computerized Engine Controls, 7th ed., Thomson Delmar Learning, 2006.

heats up and vaporizes, either from the heat of the day or operation of the vehicle. When fuel tank pressure exceeds the manufacturer's predetermined value, the vent solenoid allows the fuel tank to vent fuel vapors to the charcoal canister, where they are adsorbed. When the charcoal canister is saturated with hydrocarbon vapors, subsequent vapors from the fuel tank will pass through without being adsorbed - this is the most common type of evaporative emission. When the engine is operating fully warm, air is pulled through the charcoal canister to release the stored vapors to the intake manifold to be used for combustion with the normal air/fuel mixture. These HC vapors are added only during closed-loop operation when the additional enrichment can be handled by the PCM, which receives feedback from the oxygen sensor. This operation is known as canister purge and typically happens at a certain engine condition such as hill 2 on the FTP.

Permeation is the evaporation of fuel through elastomeric materials used in the fuel system. Elastomers in the fuel system consist of seals, fuel hoses, and plastic fuel tanks located in the rear of the vehicle. Metals are believed to have zero or near-zero permeation. Plastic (high-density polyethylene) fuel tanks are another source for permeation. Treatments (fluorination and sulfonation) for these tanks were developed to reduce permeation losses. Later on, multilayer fuel tanks containing a continuous layer of a reduced permeation component in the middle were developed.

Carbureted vehicles have low-pressure fuel systems. Steel fuel lines typically run from the fuel tank to the engine with fuel pumps located low on the engine. Flexible fuel hoses are used where motion between components is necessary. Some carbureted vehicles employ fuel return lines, allowing a small amount of fuel to bleed back to the fuel tank to keep the fuel in the carburetor cool. This approach requires another chassis fuel line with an additional pair of connectors at both ends. The fuel fill typically has a flexible rubber tube that joins the fuel tank to the fill neck. Permeation can occur at the connections between the fuel tank and chassis fuel lines, the chassis fuel lines and the engine, and the fill neck connector. Less likely locations for permeation are at the sending unit seal and the fuel pump diaphragm.

Fuel-injected vehicles have fuel system setups similar to that of carbureted vehicles (see Fig. 5.11) with the same areas of vulnerability to permeation. The major difference is the fuel pump 


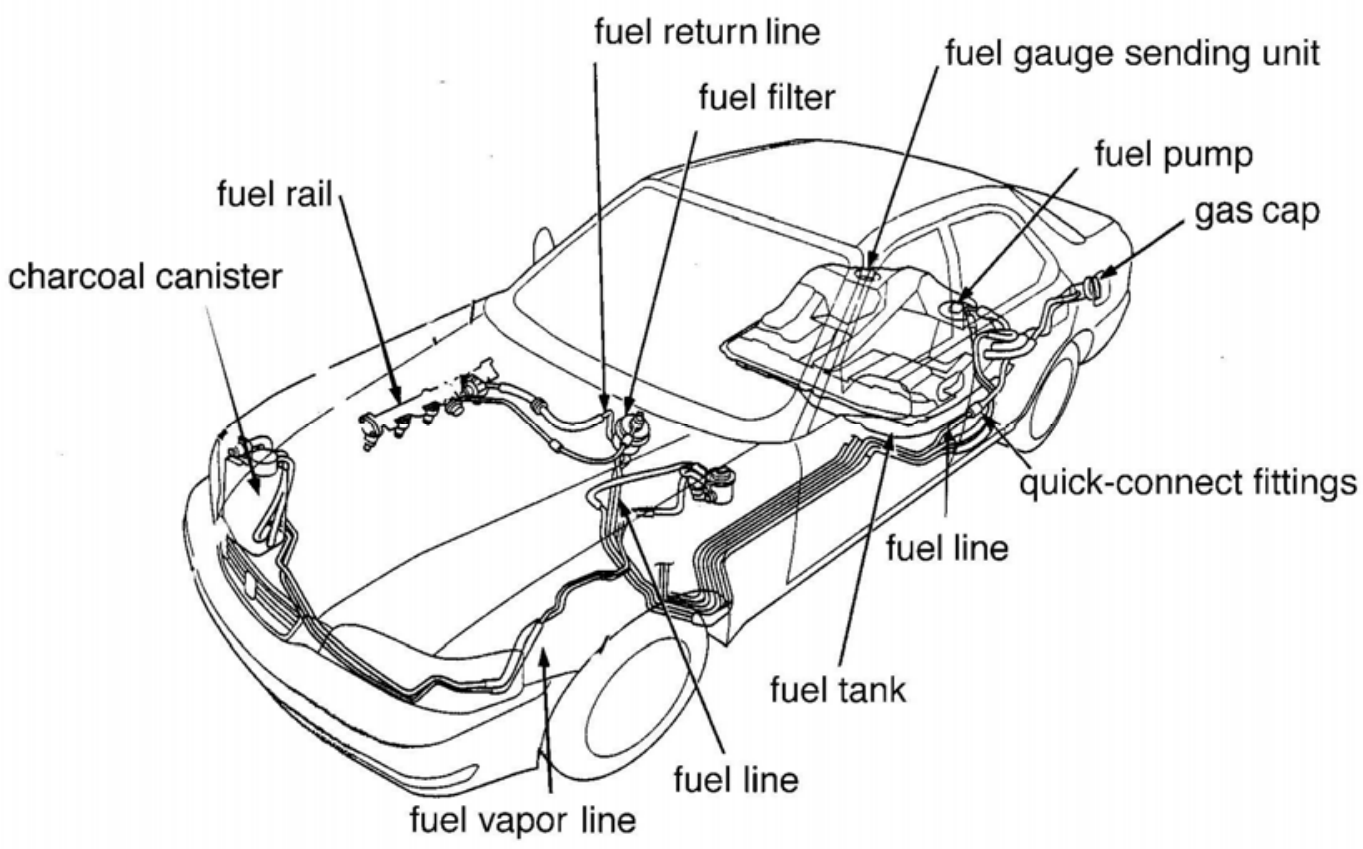

Fig. 5.11. Schematic diagram of typical fuel-injected fuel and evaporative emission control systems. Source: California Air Resources Board.

location; fuel-injected systems have fuel pumps mounted in the tank that supply higher pressures (required for fuel injectors) through the fuel line to the engine. The fuel lines for fuel-injected vehicles increasingly utilize plastic, greatly increasing the surface area from which permeation emissions can occur. Just less than 5\% of all light-duty vehicles on the road today are carbureted, and with virtually $100 \%$ of new vehicles being fuel-injected, the impact of carbureted vehicles will soon be insignificant.

\subsubsection{Ethanol Impacts on Permeation}

While some permeation losses occur with neat gasoline, ethanol use increases permeation losses. Gasoline vehicles are certified for evaporative emissions using neat gasoline, not ethanol blends. The increase in permeation emissions with ethanol blends may be beyond the allowable standard.

The Coordinating Research Council (CRC) was contracted by the California Air Resources Board (CARB) to evaluate the effect of ethanol addition to gasoline on permeation emissions. ${ }^{5}$ The CRC measured the permeation of neat gasoline and of blends of 6, 10, and $20 \mathrm{vol} \%$ ethanol in gasoline (and E85 in a FFV) in a variety of vehicles:

- Conventional gasoline vehicles meeting a $2.0 \mathrm{gm} / \mathrm{test}$ evaporative emission standard (both metal and plastic fuel tanks)

- A California LEVII vehicle meeting a $0.5 \mathrm{gm} /$ test evaporative emission standard

- A California PZEV vehicle meeting a $0.054 \mathrm{gm} / \mathrm{test}$ standard

- An E85 FFV

Figure 5.12 shows the average permeation emissions from all the test vehicles using the ethanol blends (E6Hi is 6 vol \% ethanol in a high aromatic base gasoline). These results show that ethanol increases permeation emissions from all vehicles; and $20 \mathrm{vol} \%$ ethanol appears to have higher permeation emissions than the lower-level ethanol blends, but this result was found to be not statistically significant. 


\section{Average Permeation Emissions}

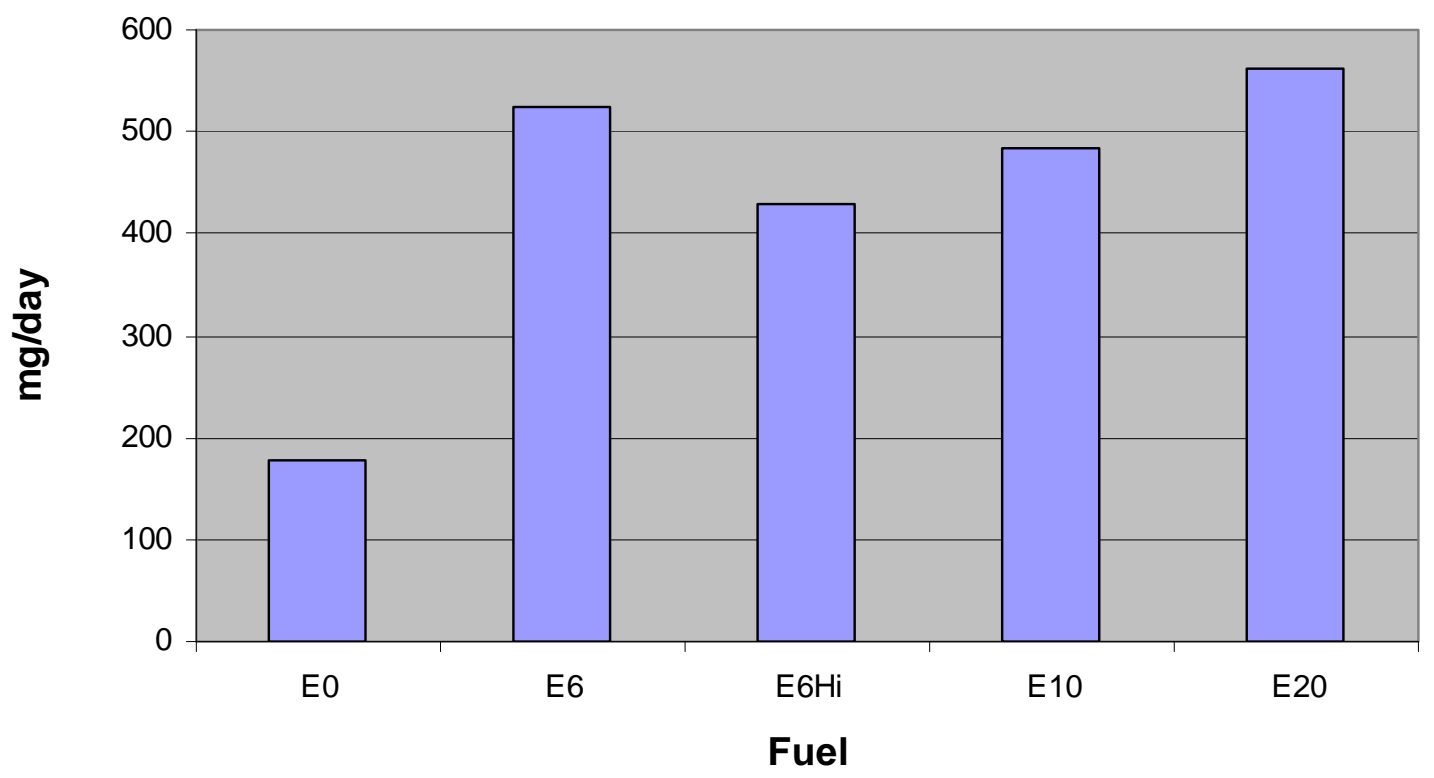

Fig. 5.12. Effect of ethanol addition on permeation emissions of all vehicles except the FFV using E85. Source: Ref. 5.

However, the average permeation emissions obscure significant differences among the vehicles tested. Figure 5.13 shows the permeation emissions of the two $2.0 \mathrm{gm} / \mathrm{test}$ vehicles with steel and plastic fuel tanks. The vehicles with the plastic fuel tank had the highest permeation emissions of all the vehicles tested.

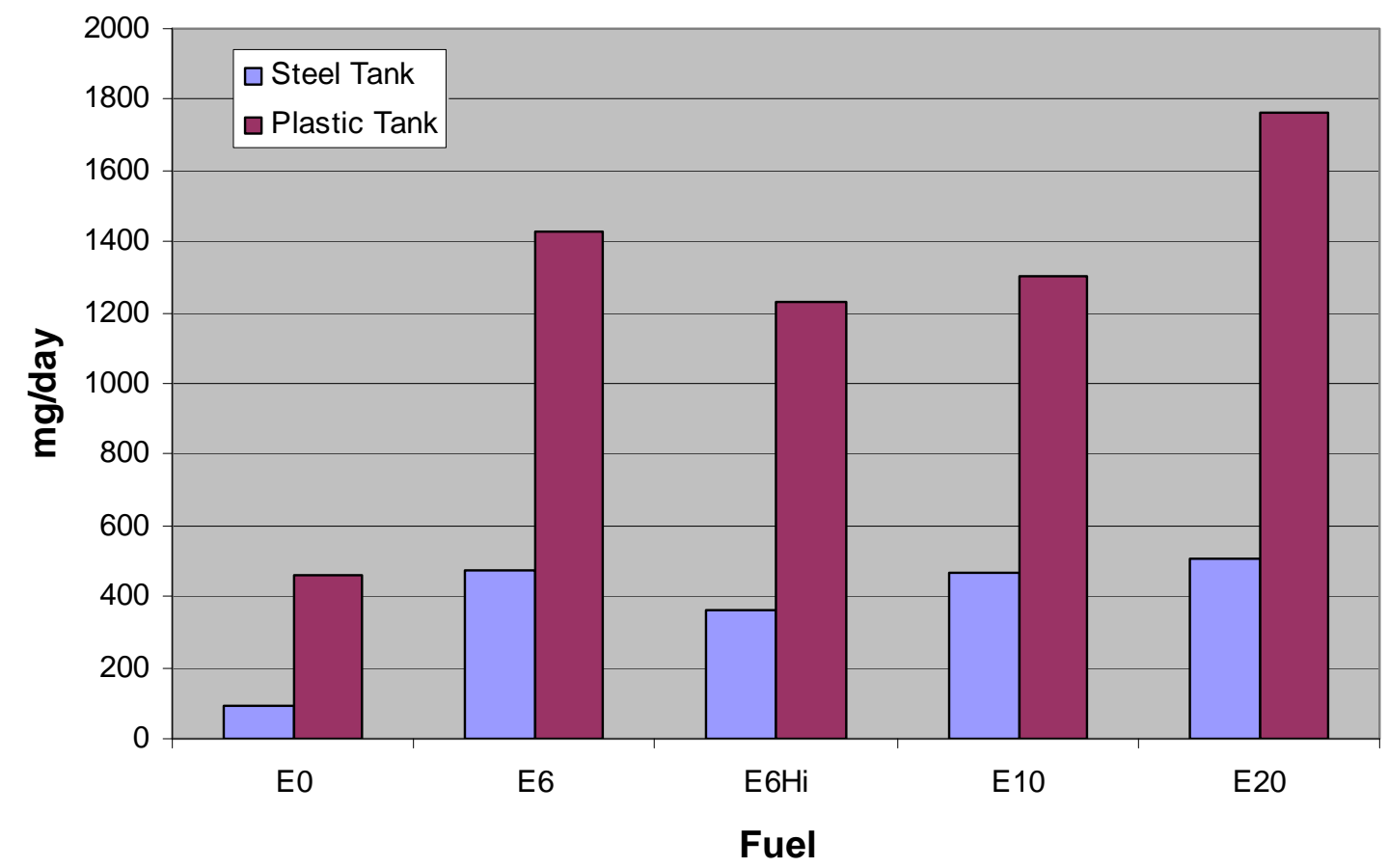

Fig. 5.13. Effect of ethanol addition on permeation emissions of two $2.0 \mathrm{gm} / \mathrm{test}$ vehicles with steel and plastic fuel tanks. Source: Ref. 5. 
Both the LEVII and PZEV vehicles (see Fig. 5.14) have much lower permeation losses, and they appear to be affected less by ethanol blends than the conventional gasoline vehicles (Fig. 5.13). Both of these vehicles have steel gasoline tanks, which no doubt helps them achieve low permeation emissions.

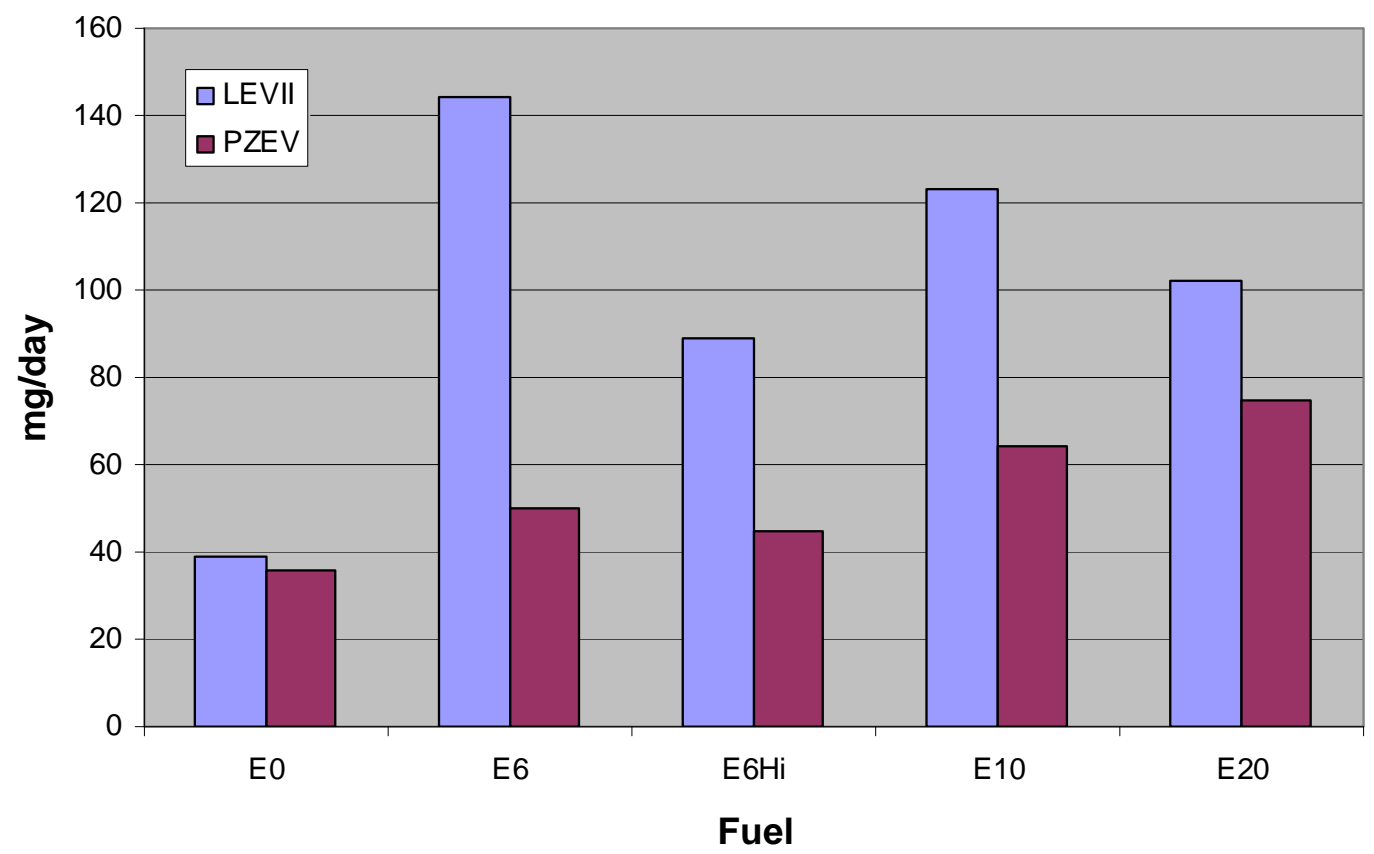

Fig. 5.14. Effect of ethanol addition on permeation emissions of LEVII and PZEV vehicles. Source: Ref. 5.

The FFV vehicle tested by CRC showed relatively good permeation emissions despite being a large vehicle with a 26-gallon plastic fuel tank (see Fig. 5.15). This vehicle has its lowest permeation emissions using E85 (the only vehicle tested using E85), with intermediate blends causing higher

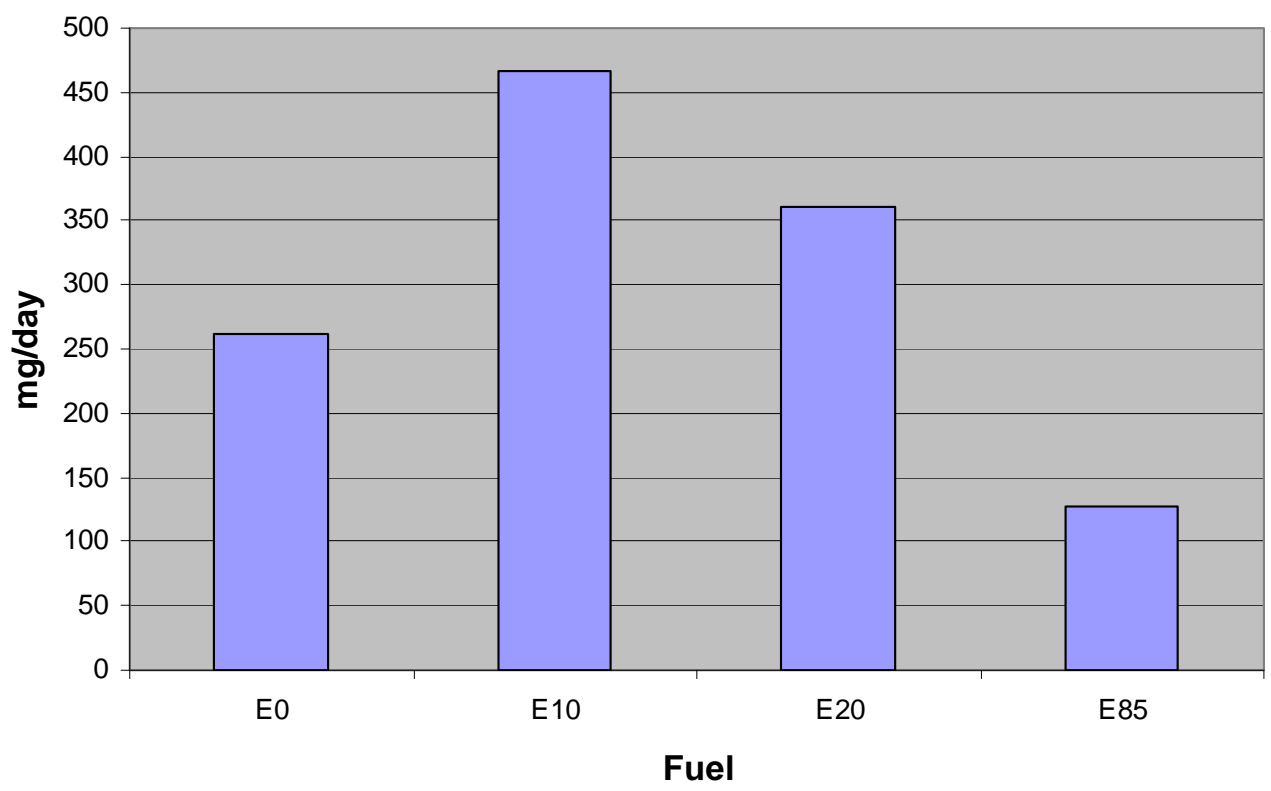

Fig. 5.15. Effect of ethanol addition on permeation emissions of a flexible fuel vehicle. Source: Ref. 5. 
emissions. This result suggests that proper material selection can mitigate the impact of ethanol on permeation emissions.

\subsubsection{Vehicle Test Results}

Much of the early work on alcohol-gasoline blends focused on methanol and its cosolvents, although some testing was done using ethanol blends. In 1979, EPA conducted testing of various gasohol blends in response to the original gasohol waiver request submitted by Gas Plus and the Illinois Department of Agriculture in June 1978. In this testing, EPA found that evaporative emissions increased by about 50\%, though the gasohol blend had an RVP 1 psi higher than that of the baseline gasoline. ${ }^{6}$ In 1982, the CRC completed testing of gasohol and a 10 vol \% ethanol blend adjusted to the same RVP as the base gasoline. ${ }^{7}$ In this testing, CRC found that evaporative emissions increased by about $65 \%$ for gasohol and by $22 \%$ for the RVP-matched 10 vol $\%$ blend. In the early 1980 s, the DOE conducted in-use testing of several alcohol-gasoline blends in nine separate fleets. ${ }^{8}$ Four of these fleets used $10 \mathrm{vol} \%$ ethanol blends. Evaporative emissions testing was conducted on one fleet using a 10 vol $\%$ blend that was adjusted to have the same front end volatility index (RVP $+0.13 \times \%$ evaporated @ $158^{\circ} \mathrm{F}$ ). This test resulted in the 10 vol \% blend having an 8.6 psi RVP versus the baseline gasoline with $9.1 \mathrm{psi}$ RVP. No difference in evaporative emissions was found between these two fuels.

While relatively little evaporative emissions testing was done with 10 vol \% ethanol blends, almost none was done using higher-level blends. The University of Santa Clara did measure evaporative emissions of a vehicle using several ethanol blends. ${ }^{9}$ The study measured the same evaporative emissions for this vehicle using both $10 \mathrm{vol} \%$ and $20 \mathrm{vol} \%$ ethanol blends. This is consistent with the physical property changes that predict slightly less vapor pressure increase for 20 vol \% blends versus 10 vol \% blends for the same base gasoline. More recently, Orbital measured the evaporative emissions from five 2001/2002 model year vehicles using a 20 vol \% ethanol blend. On average, there was an increase of $8 \%$ in evaporative emissions for the $20 \mathrm{vol} \%$ ethanol blend, though the per-vehicle results varied widely, with two vehicles actually showing decreases (see Fig. 5.16). Although Orbital did not say how its 20 vol \% blend was made, inspection of the fuel

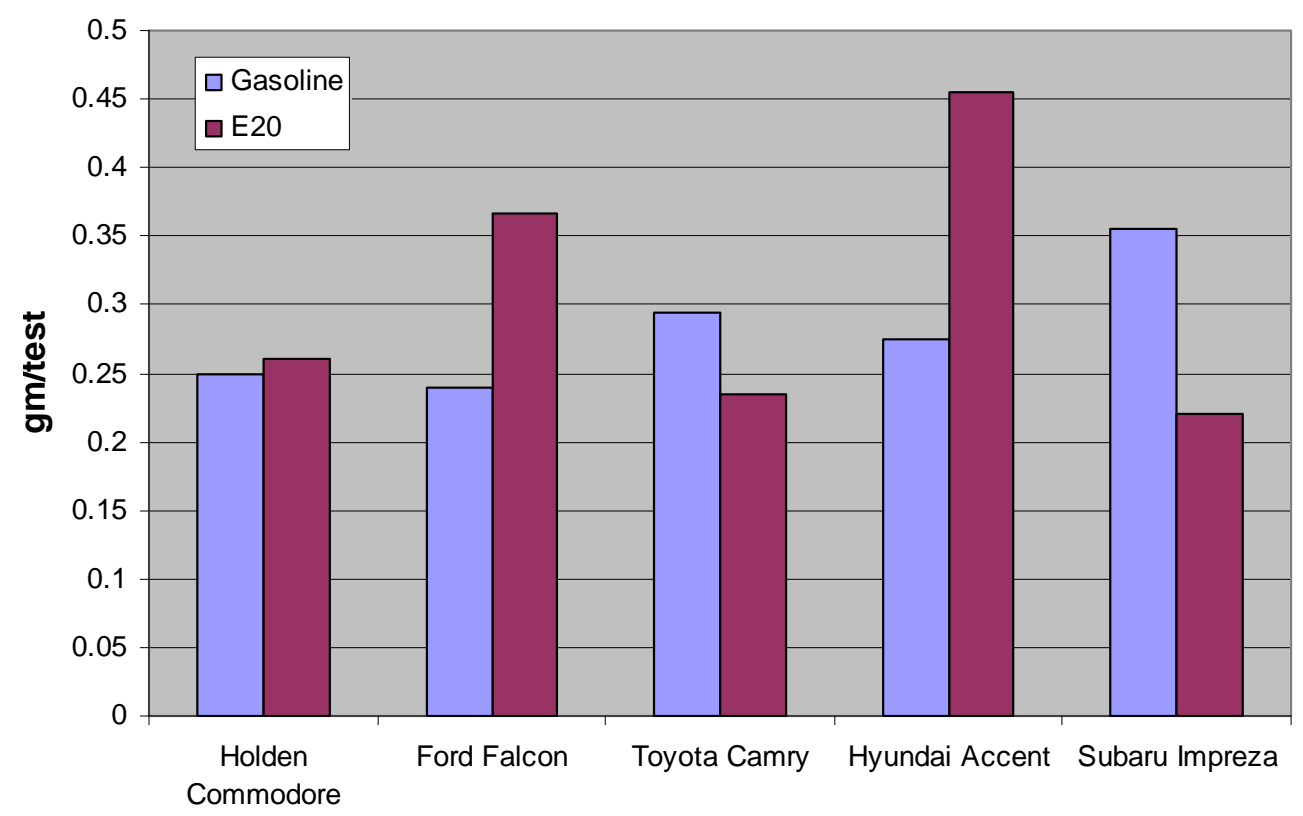

Fig. 5.16. Evaporative emissions from five 2001 model vehicles using gasoline and a 20 vol \% ethanol blend. Source: Ref. 2. 
properties indicate that the RVP of the 20 vol \% blend was 10.1 psi versus 10.25 psi for the gasoline used. Also, the distillation curves from initial boiling point through $20 \mathrm{wt} \%$ distilled are very similar for both fuels. The distillation curve data and RVP suggest that the E20 used by Orbital was tailored somewhat to mitigate the increase in fuel volatility from adding ethanol.

\subsection{EMISSION SUMMARY}

Conventional gasoline vehicles using ethanol blends on average will probably initially demonstrate decreases in THC and $\mathrm{CO}$ and increases in $\mathrm{NO}_{\mathrm{x}}$ emissions. The changes vary significantly in magnitude by vehicle and are mostly linear with ethanol addition despite feedback fuel systems that attempt to maintain stoichiometric operation. Long-term changes are more unpredictable. The increase in catalyst temperature that occurs from the inability of fuel systems to fully compensate for the leaning impact of ethanol has been shown to result in faster catalyst deterioration. Those vehicles with very limited capability to compensate may show rapid catalyst deterioration and, consequently, very high emissions of all constituents-catalyst deterioration overcoming the benefits of the enleanment caused by the addition of ethanol. These comments apply specifically to $20 \mathrm{vol} \%$ ethanol blends in conventional gasoline vehicles. Similar testing has not been done using $10 \mathrm{vol} \%$ ethanol or higher blends of ethanol in gasoline.

Toxic emissions tend to follow the change in THCs, with the exception of acetaldehyde, which is increased as a result of incomplete ethanol combustion during cold-starts. Although the increase in acetaldehyde emissions is high, it is one of the less potent toxic emissions.

If the ethanol blends are formulated to have the same or lower RVP and similar front end volatility, evaporative emissions should not appreciably increase relative to neat gasoline. No evidence exists suggesting that the carbon used in evaporative canisters degrades any quicker when exposed to ethanol vapors than to neat gasoline vapors. Ethanol does, however, increase permeation emissions from plastic fuel system components such as seals, fuel lines, and tanks. Testing done to date suggests that LEVII and PZEV vehicles are less affected than conventional gasoline vehicles presumably because of the greater focus on low evaporative emissions of these vehicle types. FFVs also appear to be less affected than conventional vehicles, illustrating the potential for emission containment if the proper materials are selected.

\subsection{REFERENCES}

1. D. A. Guerrieri, P. J. Caffrey, and V. Rao, Investigation into the Vehicle Exhaust Emissions of High Percentage Ethanol Blends, SAE Paper 950777, Society of Automotive Engineers, Warrendale, PA, 1995.

2. Orbital Engine Company, Market Barriers to the Uptake of Biofuels Study-A Testing Based Assessment to Determine Impacts of a 20\% Ethanol Gasoline Fuel Blend on the Australian Passenger Vehicle Fleet, report to Environment Australia, March 2003.

3. Orbital Engine Company, Market Barriers to the Uptake of Biofuels Study, Testing Gasoline Containing 20\% Ethanol (E20), Phase 2B Final Report to the Department of the Environment and Heritage, Australia, May 2004.

4. Mary A. Warner-Selph and Craig A. Harvey, "Assessment of Unregulated Emissions from Gasoline Oxygenated Blends," SAE Technical Paper No. 902131, Society of Automotive Engineers, Warrendale, PA, 1990.

5. Fuel Permeation From Automotive Systems: E0, E6, E10, E20, and E85-Final Report, Coordinating Research Council, 3650 Mansell Road, Suite 140, Alpharetta, GA 30022, December 2006.

6. Richard D. Lawrence, "Emissions from Gasohol Fueled Vehicles," Alcohol Fuels Technology Third International Symposium, Asilomar, California, May 28-31, 1979. 
7. R. R. Carlson, L. S. Bernstein, and E. E. Ecklund, "Performance Evaluation of EthanolGasoline Blends in 1980 Model Year U.S. Vehicles," presented at Fifth International Alcohol Fuel Technology Symposium, May 13-18, 1982.

8. John D. Tosh et al., Project for Reliability Fleet Testing of Alcohol/Gasoline Blends, DOE Report DOE/CS/50004-1, Southwest Research Institute, December 1985.

9. R. K. Pefley et al., Characterization and Research Investigation of Alcohol Fuels in Automobile Engines-Final Report, U.S. Department of Energy, December 1980. 


\section{REFINERY AND FUEL DISTRIBUTION IMPACTS}

\subsection{GASOLINE FORMULATIONS}

Refineries in the United States are configured to maximize gasoline production, which accounts for about $45 \%$ of all crude oil entering refineries. Gasoline is a product blended from streams derived from multiple refinery unit operations. The gasoline boiling-range cut distilled directly from crude oil, known as straight run naphtha, accounts for less than $10 \%$ of finished gasoline because it has a low octane number. The largest contributing blending streams are reformate from the catalytic reformer, alkylate from the alkylation unit, and naphtha from the fluidized catalytic cracking (FCC) unit, all of which require considerable processing. Each stream differs in chemistry and fuel properties; straight run naphtha is high in C5 short-chain paraffins, reformate contains high concentrations of aromatic compounds, alkylate is high in iso-paraffins, and FCC naphtha possesses the highest olefin concentration. Crude oil feedstock composition, refinery-specific equipment or operating techniques, desired output composition and quantity, seasonal fuel demand, and other factors affecting refinery operating parameters contribute to determining the exact composition of each of these streams. Example compositions for each of these streams, shown in Table 6.1, demonstrate that the compositions can vary considerably. Lesser contributing refinery streams not discussed here include isomerate, polymerization naphtha, hydrocracked naphtha, butane, and coker naphtha.

Table 6.1. Example composition of refinery streams from various sources

\begin{tabular}{|c|c|c|c|c|c|c|}
\hline & $\begin{array}{c}\text { Saturates } \\
(\%)\end{array}$ & $\begin{array}{c}\text { Olefins } \\
(\%)\end{array}$ & $\begin{array}{c}\text { Aromatics } \\
(\%)\end{array}$ & RON & MON & $\begin{array}{l}\text { RVP } \\
\text { (psi) }\end{array}$ \\
\hline \multicolumn{7}{|l|}{ Straight Run Naphtha } \\
\hline Gary and Handwerk ${ }^{1}$ & 88 & 2 & 10 & 66.4 & 61.6 & 11.1 \\
\hline CRC AVFL- $13^{2}$ & 78.9 & 1.2 & 19.9 & 44.8 & 42.4 & 0.6 \\
\hline \multicolumn{7}{|l|}{ Reformate } \\
\hline Gary and Handwerk ${ }^{1}$ & 36 & 1 & 63 & 98 & 86.5 & 2.2 \\
\hline CRC AVFL-13 ${ }^{2}$ & 42.5 & 2.5 & 55 & 94.2 & 86.7 & 5.8 \\
\hline Kalhatgi $^{3}$ & 27.74 & 0.62 & 71.64 & 102 & 90.5 & 4.7 \\
\hline \multicolumn{7}{|l|}{ FCC Naphtha } \\
\hline Gary and Handwerk $^{1}$ & 41 & 29 & 30 & 92.1 & 77.1 & 1.4 \\
\hline CRC AVFL-13 ${ }^{2}$ & 53.2 & 27.3 & 19.5 & 91.2 & 79.5 & 6.2 \\
\hline Kalhatgi $^{3}$ & 46.75 & 46.6 & 6.65 & 95.6 & 85.7 & 15.2 \\
\hline \multicolumn{7}{|l|}{ Alkylate } \\
\hline Gary and Handwerk ${ }^{1}$ & 99.1 & 0.5 & 0.4 & 94.5 & 93 & 5 \\
\hline CRC AVFL- $13^{2}$ & 100 & 0 & 0 & 91.7 & 91.1 & 4.3 \\
\hline Kalhatgi $^{3}$ & 98.7 & 0 & 1.3 & 94 & 91.8 & 7.4 \\
\hline
\end{tabular}

$\mathrm{RON}=$ road octane number; $\mathrm{MON}=$ motor octane number.

Refinery streams are blended together to meet targeted gasoline specifications. The road octane requirement is the average of the research octane number (RON) and motor octane number (MON), often denoted as $(\mathrm{R}+\mathrm{M}) / 2$ There are restrictions on the upper limits of aromatics for air quality purposes, and restrictions on the upper limits of olefins exist for fuel stability purposes. In addition, fuel RVP is also regulated. An RVP that is too low is a safety concern and can lead to driveability problems. High RVP leads to high evaporative emissions and can cause vapor lock in fuel systems. Summer and winter gasolines have different RVP limits because of the differences in ambient temperature each is expected to experience. Refineries can increase the RVP of a gasoline to meet the required specifications by adding butane to the fuel. 
While conventional gasoline makes up approximately $75 \%$ of the national gasoline pool, some regions mandate different gasoline specifications to reduce emissions, usually in the form of a lower RVP. Currently in the United States, there are 6 federal zones of gasoline regulation and a minimum of 12 additional zones on the state level. Each of these different zones has seasonal fuel requirements. An EPA Task Force has concluded that these unique fuel blends, often referred to as boutique fuels, are effective at improving air quality, and that the fuel infrastructure can support this number of gasoline formulations. To prevent local gasoline shortages in the event of supply disruptions, authorities can waive local gasoline requirements until supply of the boutique fuel is restored. ${ }^{4}$

The finished gasoline products from refineries are complex mixtures that have been blended from numerous refinery streams to meet a narrow band of specifications. Although changing the formulation of the gasoline can be done, refineries operate best when they do not have to frequently change the formulations of the finished products. The reason is that refineries are complex, interconnected systems, and changes to products and processes cannot be made in isolation from the other products and processes in the refinery. For instance, changes in gasoline composition may result in composition or volume changes to the diesel fuel, jet fuel, heating oil, etc.

\subsection{BLENDING AND TRANSPORTATION OF ETHANOL AND GASOLINE}

There are two ways ethanol can be added to gasoline: splash blending and match blending. In splash blending, ethanol is added to a finished gasoline product meeting applicable specifications. As discussed in Sect. 3, azeotropes that are formed when gasoline is mixed with ethanol result in an RVP that is higher than either of the individual components, so splash blending ethanol into a gasoline meeting RVP specifications results in an increased RVP for the ethanol mixture. To enable the use of ethanol in gasoline, Sect. 211(h)(4) of the Clean Air Act Amendments permits the RVP of E10 to be 1 psi above the applicable RVP specification. ${ }^{5}$ The 1 psi RVP waiver is sufficient for $75 \%$ of gasoline consumed in the United States that does not require a lower RVP for air quality purposes, making splash blending the preferred method for ethanol. However, for lower-RVP gasoline required in areas of poor air quality, the increase in RVP with ethanol addition is greater than $1 \mathrm{psi}$. This point is illustrated in Table 6.2.

Table 6.2. Effect of 10 vol \% ethanol addition on gasolines of different RVP ${ }^{6,7}$

\begin{tabular}{ccc}
\hline $\begin{array}{c}\text { Finished gasoline RVP } \\
\text { requirement }\end{array}$ & $\begin{array}{c}\text { Approximate RVP } \\
\text { increase when ethanol } \\
\text { added to make 10 vol \% } \\
\text { blend }\end{array}$ & $\begin{array}{c}\text { Base gasoline RVP } \\
\text { adjustment needed if 1 psi } \\
\text { waiver not allowed }\end{array}$ \\
\hline 9.0 & 1.0 & $(1.1)$ \\
7.8 & 1.2 & $(1.3)$ \\
7.0 & 1.3 & $(1.4)$ \\
\hline
\end{tabular}

For the fuels that cannot achieve the required RVP with the 1 psi waiver, splash blending is not sufficient and the fuels must be match blended. In match blending, a gasoline blend stock is formulated to meet applicable specifications after ethanol has been added. The most notable example of match blending is the reformulated blend stock for oxygenate blending (RBOB). The EPA envisions that all ethanol will be match blended in the coming years. ${ }^{8}$ Depending on the scale of ethanol penetration in the market, and the number of different ethanol blends being sold, additional gasoline formulations for ethanol match blending may require refiners to make a larger number of smaller batches of fuel, which are more difficult to manage from the standpoint of a refinery system. In addition, it is not clear how much flexibility refiners have to produce large quantities of a blend stock with a sufficiently low RVP for match blending with ethanol. 
It should be noted that the RVP waiver in Sect. 211(h)(4) of the Clean Air Act Amendments applies only to $10 \mathrm{vol} \%$ denatured ethanol in gasoline. The RVP waiver does not apply to higher concentrations of ethanol in gasoline. Without a change in legislation, higher ethanol concentrations will require that the blend stock for match blending be sufficiently low to actually meet the RVP specifications without the 1 psi waiver.

Logistically, blending ethanol into gasoline at the refineries would be the simplest way to ensure that the finished product met all required specification. However, pipelines are used to transport most gasoline away from refineries to distribution centers, where trucks and rail can transport the fuel to end-users. Ethanol blending at the refinery can be done only for the small percentage of fuel that does not leave the refinery through the pipeline. Finished ethanol-containing gasoline cannot be distributed via pipeline because ethanol is hydrophilic, and in all pipeline systems the fuel is inevitably exposed to water. Therefore, the majority of ethanol is blended into gasoline at distribution centers or ethanol production centers. As with refiners, it is more difficult for pipeline operators to manage larger numbers of fuel formulations with each containing smaller quantities of fuel.

\subsection{IMPACTS ON GASOLINE FORMULATION FOR MATCH BLENDING}

Ultimately, the blend stock that is produced for match blending with ethanol will depend on what is most economical for refineries. Ethanol does have some desirable fuel properties that could potentially be attractive to refiners, though. First, the EPA regulates the concentration of aromatic compounds allowed in gasoline because of air quality standards. Ethanol is an aromatic-free blending component (assuming the denaturant is free of aromatics), so the content of aromatics in the blending stock can be increased. Increasing the aromatic content in the blending stock would likely be done by increasing the reformate in the blend stock for match blending, which is desirable from a refining standpoint because reforming produces hydrogen, a valuable product that is consumed in other parts of the refinery. As shown in Table 6.1, reformate is also a low RVP blending stream.

Another desirable fuel property of ethanol is its high octane value, as previously shown in Table 4.1. The higher octane of ethanol would allow the refiners to upgrade a lower octane, and potentially lower-cost, blending stock. The extent to which lower-quality streams can be upgraded is uncertain, though, because of blending nonlinearities. Octane blending is nonlinear for all fuels, and ethanol in particular is highly nonlinear. An additional consideration is the octane sensitivity, which is defined as the difference between RON and MON. The blending streams with high concentrations of saturates, alkylate and straight run naphtha, have low octane sensitivities, whereas reformate, FCC naphtha, and ethanol all have higher octane sensitivities. There are currently no regulations on the octane sensitivity of gasoline, but the relatively low MON, in comparison to RON, may limit the ability of ethanol to upgrade the octane number of a fuel blend. The likelihood that this issue will be an actual limitation increases as the octane sensitivity of the gasoline blendstock increases.

\subsection{SUMMARY OF REFINERY IMPACTS}

Gasoline is carefully formulated from numerous blending streams in the refinery to meet a narrow band of fuel specifications. Most ethanol that is consumed as fuel in the United States is splash blended into gasoline, meaning that the refineries do not have to alter the formulation of gasoline for ethanol blending. This method increases the RVP of the fuel, but it is acceptable because of Sect. 211(h)(4) or the Clean Air Act Amendments, which allow E10 blends to have an RVP 1 psi higher than that of gasoline. For low RVP fuels, such as reformulated gasoline, the RVP increase with ethanol addition is greater than $1 \mathrm{psi}$, so a special gasoline blend stock is required for match blending, such as RBOB. The legislation allowing a higher RVP for ethanol applies only to $10 \mathrm{vol} \%$ denatured ethanol blends. Therefore, under the current legislation, higher blend levels of ethanol are not granted a 1 psi waiver for RVP. 
Depending on the penetration of ethanol into the consumer market, and the number of different ethanol blend levels being sold, it may be necessary for refineries to produce a larger number of smaller-quantity gasoline blends, which is more difficult to manage. In addition to blend stock production being more difficult to manage, transportation becomes more difficult to manage. Gasoline blendstocks cannot be preblended with ethanol before they are transported because the hydrophilic nature of ethanol is incompatible with pipelines, making the logistics of blend stock transportation more difficult. Ethanol does have some favorable fuel properties, though. First, ethanol is an aromatic-free blending stream, allowing refiners to increase the aromatic content of the ethanol blend stock. Also, ethanol has a high octane rating, so it could be used to upgrade lower-octane, and potentially less expensive, gasoline streams in the refinery.

\subsection{DISTRIBUTION OF ETHANOL BLENDS}

Ethanol has been used mainly in gasoline in the Midwest, close to where the ethanol is produced. Finished ethanol-containing gasoline is not distributed via pipeline because ethanol is hydrophilic, and in all pipeline systems the fuel is inevitably exposed to water. There is high risk of water absorption into the fuel, violating the ASTU fuel quality standard, and also a high risk of phase separation in which a water-ethanol mixture separates from the fuel. Therefore, the majority of ethanol is blended into gasoline at distribution centers or ethanol production centers.

Requirements for oxygenates in gasoline and reduced use of MTBE have caused a growing market for ethanol as an additive in other regions. This means ethanol is trucked farther from the production source, increasing costs and energy use to bring it to market. If ethanol-blend fuels begin to dominate the gasoline market, it is more likely some pipeline distribution will take place. Water is present in existing pipelines because of its very low solubility in the fuels being transported, and water collects at "low points" in the pipes. Pipelines that were dedicated mainly to E10 or higher ethanol blends would likely stay "dry" because of the continual absorption of small amounts of water into the fuel.

The end point of gasoline distribution is the fuel station. A large number of fuel stations are already experienced with ethanol blends, but many are not. When a fuel station changes over from non-ethanol fuel to an ethanol blend such as E10, an essential practice is to check for and remove any water (and sludge) from the underground storage tank. The use of E10-compatible fuel filters is necessary, and material compatibility issues with elastomers also need to be examined. It is not known what further materials compatibility problems could be caused by changing from E10 to a higher blend such as E15 or E20, but aluminum and brass seem to pose at least a small risk (and are not used for E85), and wetted polymeric materials need to be scrutinized. This consideration should apply to the fuel trucks, the gas-station tanks, any piping involved, and dispenser systems.

\subsection{REFERENCES}

1. J. H. Gary and G. E. Handwerk, Petroleum Refining, 4th ed., New York, Marcel Decker, p. 441, 2001.

2. Fuel Chemistry Impacts in Gasoline HCCI, Coordinating Research Council Report AVFL-13, Coordinating Research Council, Alpharetta, GA, 2007.

3. G. T. Kalghatgi, "Fuel Anti-Knock Quality_Part I. Engine Studies," Technical Paper 200101-3584, Society of Automotive Engineers, Warrendale, PA, 2001.

4. Report to the President: Task Force on Boutique Fuels, U.S. Environmental Protection Agency, Washington, D.C., 2006, available at www.epa.gov/oms/boutique/resources/bftf62306finalreport.pdf.

5. 1990 Clean Air Act Amendments, Section 211(h)(4), available at www.epa.gov/air/caa/.

6. W. J. Piel, "Oxygenate Flexibility for Future Fuels," presented at API National Conference on Reformulated Gasoline and Clean Air Act Implementation, 1991. 
7. "Potential Supply Impacts of Removal of 1-Pound RVP Waiver," United States Energy Information Administration, available at www.eia.doe.gov/oiaf/servicerpt/fuel/rvp.html. Posted October 5, 2004, accessed on June 1, 2007.

8. J. Herzog, "Federal Clean Fuel Standards," presented at the API Annual Pipeline Conference, April, 2007. Available at http://www.api.org/meetings/proceedings/upload/Federal_Clean_Fuel_ Standards_Jeff_Herzog.pdf. 



\section{NON-AUTOMOTIVE APPLICATIONS}

If an E15 or E20 fuel is to become broadly used, then the issue of how it affects non-automotive engines must also be considered. When E10 was introduced in the late 1970s, it was essentially a specialty fuel. E0 was plentiful and available for non-automotive engines, and E0 or low-ethanol fuels are still plentiful in most of the United States. Because E10 was becoming common, the nonautomotive engine market responded and began to introduce technology changes to allow robust performance with blends containing 0 to 10 vol \% ethanol. Particularly, material incompatibility problems were addressed, although many non-road engine manufacturers recommend not storing oxygenated fuels in the tank for long periods.

Orbital published a five-report series on the topic of E0, E10, and E20 fuel use in non-automotive engines. ${ }^{1-5}$ Experimental work was carried out focusing only on a small marine engine model and a very small consumer product engine - both of which were two-stroke engines common in Australia. Obviously the U.S. non-automotive market is very broad, but very little is documented concerning use of higher ethanol blends. The amount of information available from the Orbital work is quite limited, but it is very likely applicable to the U.S. market. The Orbital non-automotive work is discussed in Sect. 7.2.

\subsection{CATEGORIES OF NON-AUTOMOTIVE GASOLINE ENGINES}

There may be many ways to group or categorize non-automotive gasoline engines, and there is quite a large variety of such engine applications. Some common categories are listed here with a few specific examples of each. This list is certainly not exhaustive.

- Lawn and garden: mowers, tillers, pressure washers, etc.

- Lawn and garden with two-stroke engines: blowers, trimmers, chainsaws, cultivators

- Industrial applications: generator sets, mixers, loaders, pump units

- Industrial mobile equipment: backhoes, forklifts, farm vehicles

- Off-road vehicles: motorbikes, go-carts, all-terrain vehicles, snowmobiles

- Marine: inboard and outboard engines

- Aviation: gasoline aircraft engines (special E0 aviation fuel is used in most cases)

- Heavy-duty trucks

With a few notable exceptions, SI engine aircraft use special aviation grades of gasoline that are different from automotive fuel. Separate fuel streams are maintained for aircraft. These aviation SI fuels contain no ethanol, and the few aircraft that can use automotive fuel use E0 exclusively.

Although most new engines are now of a four-stroke design, there remains a population of twostroke engine applications. Recent and proposed environmental regulations are likely to diminish the application of two-stroke engines, which are still marketed for very lightweight applications (e.g., blowers, trimmers, chainsaws, and marine applications). Past applications of two-stroke engines were for a much broader market, and a significant population of these engines exists.

\subsection{RECENT ENGINE TESTS}

Orbital published a literature review in December 2002 concerning E10 and E20 blend applications to the Australian non-automotive engine market. ${ }^{1}$ It considered aircraft, consumer devices, off-road land vehicles, marine, generators and other stationary engines. Much of this market encompasses engine sizes similar to or smaller than those used in passenger vehicles (large engines are almost always diesel). No literature applicable to $20 \mathrm{vol} \%$ ethanol blends was uncovered. Orbital found that generally manufacturers allow use of up to $10 \mathrm{vol} \%$ ethanol (and no higher), with an 
exception being aircraft applications that do not allow ethanol blends. The issues for non-automotive engines were seen to be the same as those for automotive application, except for the virtual universal dependence on open-loop fuel control. This type of operation results in enleanment that is proportional to the ethanol blend content and applies to all engine operating points. Higher exhaust temperatures and component temperatures are a concern.

Orbital carried out performance, durability, and material compatibility testing on two different two-stroke engine models: an outboard marine (Mercury) $15 \mathrm{hp}$ engine and a line trimmer engine (Stihl) with E10 and E20 fuels. ${ }^{3-5}$ The results for E10 were found to be acceptable (E10 is used in Australia). Material compatibility problems were found for E20 with both engine types, and evidence of possible long-term durability concerns was found for the marine outboard engines. A study using 2000-hour E20 immersion tests ${ }^{5}$ on materials found in these two engine models revealed concerns, and the effects on some polymeric materials were seemingly unacceptable. These studies also show E20 tarnishing and corroding brass and aluminum parts, and both these metals are avoided for E85 applications. ${ }^{6}$ Higher exhaust gas temperatures for E20 were observed and are considered a potential source of long-term durability problems.

Performance testing of 10 of these same $15 \mathrm{hp}$ marine outboard engines ${ }^{3}$ showed minor but measurable performance degradation for E20 operation. Specifically observed were increased misfire, engine stall, and difficulty maintaining a constant engine speed. Engines were always easily restarted after stalling however. It is curious that a four-stroke engine model was not considered, but perhaps two-stroke engines are more plentiful in Australia.

\subsection{REFERENCES}

1. Orbital Engine Company, A Literature Review Based Assessment on the Impacts of a $10 \%$ and $20 \%$ Ethanol Gasoline Fuel Blend on Non-Automotive Engines, report to Environment Australia, December 2002.

2. Orbital Engine Company, A Technical Assessment of E10 and E2O Petrol Ethanol Blends Applied to Non-Automotive Engines: Failure Mode and Effects Analysis of Engine Function and Component Design for Mercury Marine 15 hp Outboard and Stihl FS45 Line-Trimmer Engines, report to Environment Australia, November 2002.

3. Orbital Engine Company, Market Barriers to the Uptake of Biofuels Study: Marine Outboard Driveability Assessment to Determine Impacts of a $10 \%$ and $20 \%$ Ethanol Gasoline Fuel Blend on a Small Batch of Engines, report to Environment Australia, February 2003.

4. Orbital Engine Company, Market Barriers to the Uptake of Biofuels Study-A Testing Based Assessment to Determine Impacts of a $10 \%$ and $20 \%$ Ethanol Gasoline Fuel Blend on NonAutomotive Engines, report to Environment Australia, January 2003.

5. Orbital Engine Company, Market Barriers to the Uptake of Biofuels Study: A Testing Based Assessment to Determine Impacts of a 10\% and 20\% Ethanol Gasoline Fuel Blend on NonAutomotive Engines-2000 hrs Material Compatibility Testing, report to Environment Australia, May 2003.

6. http://www.eere.energy.gov/afdc/e85toolkit/specs.html. 


\section{RECOMMENDATIONS}

This report attempts to provide a fairly complete picture of the information that is available regarding the use of intermediate ethanol blends in the U.S. legacy fleet (i.e., non-FFVs).

Some valid testing has been conducted and is applicable to the current investigation; however, some notable differences exist between the Australian studies conducted by Orbital and the situation in the United States. The U.S. emissions regulations are significantly more stringent than those in Australia, a situation that tends to drive engine/vehicle technology. Therefore, new vehicles in the United States are more advanced than those tested in the Orbital study. Nonetheless, the Orbital reports can provide indications of what to expect for various technologies used in many vehicles in the U.S. fleet, but some of the conclusions drawn by Orbital may not necessarily be valid for the current U.S. fleet.

Significant gaps exist in the body of information that would be necessary to resolve in order to make informed decisions about the impact of intermediate blends in legacy vehicles in the United States. Notably, almost no information exists on the impact of E15. Some data are available for E20, but gasoline/ethanol blending is known to alter properties in a nonlinear fashion, so simple interpolations are not necessarily valid. Based on the information available, most U.S. vehicles can probably be expected to operate satisfactorily on E15 or even E20 without significant difficulty. However, a certain number of vehicles can also be expected to experience issues with ethanol blends as low as E10. The number and severity of the issues will tend to increase with increased ethanol content. What is not known at this time are the quantity and the relative difficulty of these issues or the optimum steps for resolving them. Additionally, one cannot adequately predict whether the issues would be one-time events (such as plugged fuel filters), continual in nature (poor driveability), or longer-term problems such as shortened full useful life (either emissions equipment or general service).

A thorough test program is recommended to better quantify the impacts of intermediate blends on the U.S. legacy vehicle fleet. The investigation will need to consider the impact on the materials of construction in vehicle fuel systems, the emissions impacts, and impacts on consumer acceptance of intermediate ethanol blends (e.g., driveability and annoyance issues). A statistically significant population of vehicles will need to be evaluated. 